\title{
REMR Management Systems-Navigation Structures, Condition Rating Procedures for Tainter Dam and Lock Gates
}

by Lowell Greimann, James Stecker, and Mike Nop Engineering Research Institute

Approved For Public Release; Distribution Is Unlimited.

Prepared for Headquarters, US Army Corps of Engineers 


\section{REMR Management Systems- \\ Navigation Structures \\ Condition Rating Procedures \\ for Tainter Dam and Lock Gates}

by Lowell Greimann, James Stecker, and Mike Nop

Engineering Research Institute

lowa State University

Ames, lowa 50011

Approved for public release; distribution is unlimited.

Prepared for US Army Corps of Engineers

Washington, DC 20314-1000

Under $\quad$ Civil Works Research Work Unit 32672

Monitored by Maintenance Management and Preservation Division US Army Construction Engineering Research Laboratories

PO Box 9005, Champaign, IL 61826-9005 


\section{Contents}

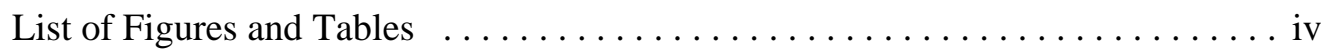

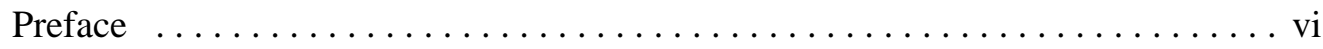

Conversion Factors, Non-SI to SI Units of Measurement $\ldots \ldots \ldots \ldots \ldots \ldots$ vii

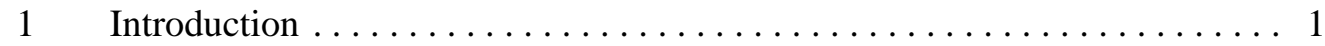

Background $\ldots \ldots \ldots \ldots \ldots \ldots \ldots \ldots \ldots \ldots \ldots \ldots \ldots \ldots \ldots \ldots \ldots \ldots \ldots$

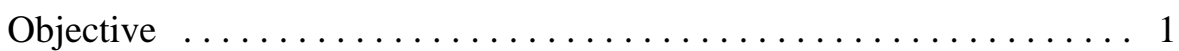

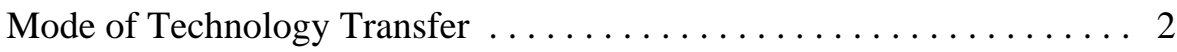

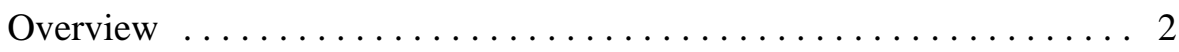

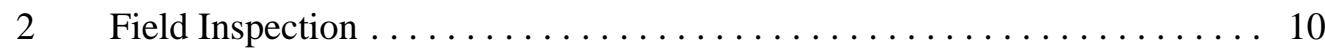

Inspection Procedure Development $\ldots \ldots \ldots \ldots \ldots \ldots \ldots \ldots$

Overview of Inspection Procedure $\ldots \ldots \ldots \ldots \ldots \ldots \ldots \ldots \ldots \ldots$

Overview of Inspection Form $\ldots \ldots \ldots \ldots \ldots \ldots \ldots \ldots \ldots$

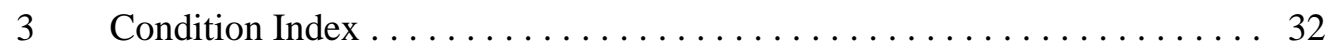

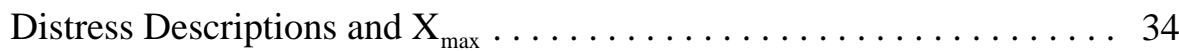

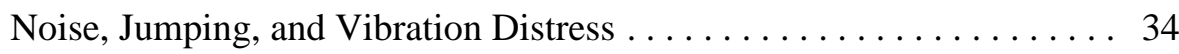

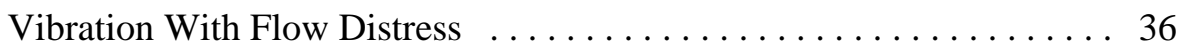

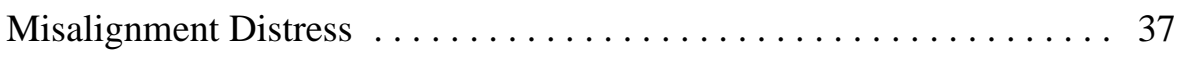

Anchorage Assembly Deterioration Distress .............. 38

Trunnion Assembly Wear Distress $\ldots \ldots \ldots \ldots \ldots \ldots \ldots \ldots 4$

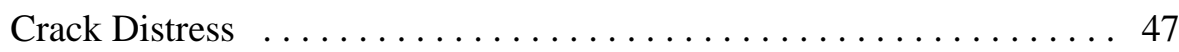

Dents Distress ........................... 49

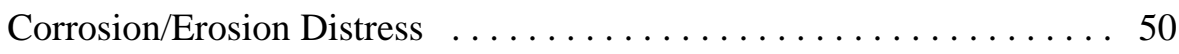

Cable/Chain Plate Wear Distress . . . . . . . . . . . . . . . . . . 53

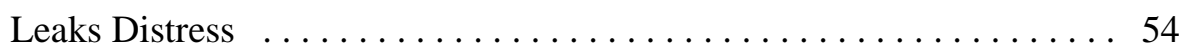

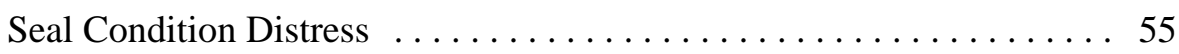

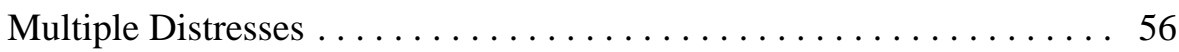

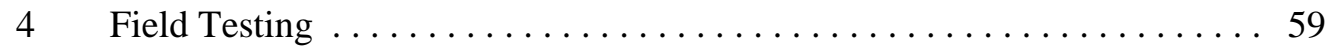

Noise, Jumping, and Vibration $\ldots \ldots \ldots \ldots \ldots \ldots \ldots \ldots \ldots \ldots \ldots \ldots$

Vibration With Flow $\ldots \ldots \ldots \ldots \ldots \ldots \ldots \ldots \ldots \ldots \ldots \ldots \ldots$ 


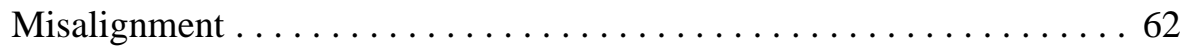

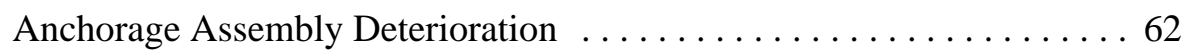

Trunnion Assembly Wear . . . . . . . . . . . . . . . . . 63

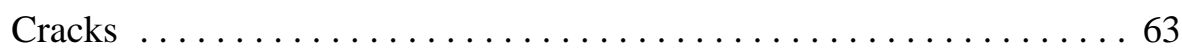

Dents .................................65

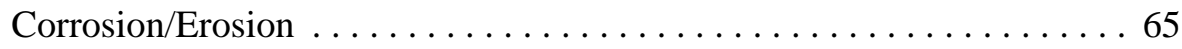

Cable/Chain Plate Wear $\ldots \ldots \ldots \ldots \ldots \ldots \ldots \ldots \ldots . \ldots . \ldots 6$

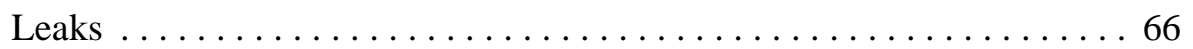

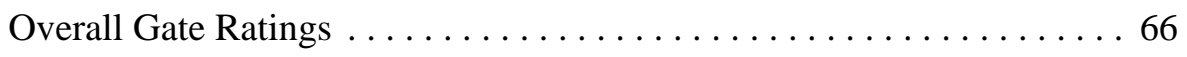

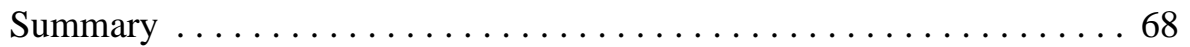

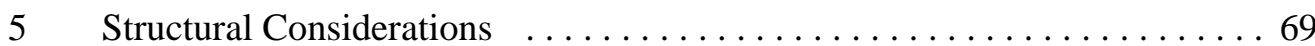

6 Summary and Recommendations $\ldots \ldots \ldots \ldots \ldots \ldots \ldots \ldots \ldots$

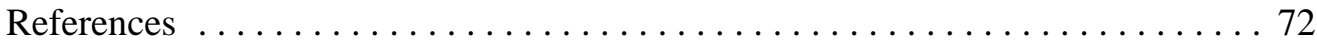




\section{Figures}

Figure 1. Inspection and rating procedure $\ldots \ldots \ldots \ldots \ldots \ldots \ldots \ldots$

Figure 2. Tainter lock and dam schematic $\ldots \ldots \ldots \ldots \ldots \ldots \ldots \ldots \ldots$

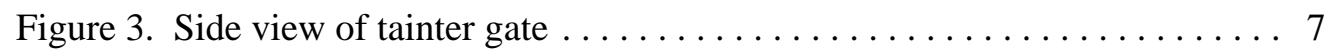

Figure 4. Elevation view of tainter gate $\ldots \ldots \ldots \ldots \ldots \ldots \ldots \ldots \ldots \ldots \ldots \ldots \ldots$

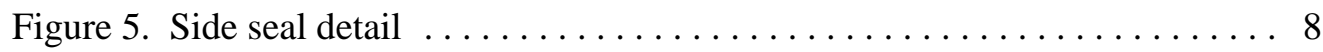

Figure 6. Example trunnion assembly detail (individual projects differ

considerably) ....................... 8

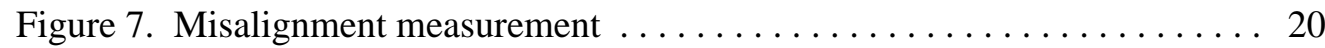

Figure 8. Anchorage measurement $\ldots \ldots \ldots \ldots \ldots \ldots \ldots \ldots \ldots \ldots \ldots \ldots \ldots$

Figure 9. Trunnion assembly wear measurement: dial gauges $\ldots \ldots \ldots \ldots 26$

Figure 10. Trunnion assembly wear measurement: feeler gauges $\ldots \ldots \ldots \ldots 26$

Figure 11. Trunnion assembly wear measurement: trammels . . . . . . . . 27

Figure 12. Trunnion assembly wear: lateral movement . . . . . . . . . . 27

Figure 13. Condition index related to $\mathrm{X} / \mathrm{X}_{\max } \ldots \ldots \ldots \ldots \ldots \ldots \ldots \ldots$

Figure 14. Percent head with tailwater $\ldots \ldots \ldots \ldots \ldots \ldots \ldots \ldots \ldots \ldots \ldots \ldots \ldots$

Figure 15. Percent head without tailwater $\ldots \ldots \ldots \ldots \ldots \ldots \ldots \ldots \ldots \ldots$

Figure 16. Weight adjustment factor for condition index $\ldots \ldots \ldots \ldots \ldots \ldots 8$

Figure 17. Flexible anchorage at lower St. Anthony Falls . . . . . . . . . 60

Figure 18. Noise, jumping, and vibration $\ldots \ldots \ldots \ldots \ldots \ldots \ldots \ldots \ldots$

Figure 19. Vibration with flow summary $\ldots \ldots \ldots \ldots \ldots \ldots \ldots \ldots \ldots \ldots \ldots$

Figure 20. Anchorage assembly deterioration $\ldots \ldots \ldots \ldots \ldots \ldots \ldots \ldots \ldots$

Figure 21. Trunnion assembly wear $\ldots \ldots \ldots \ldots \ldots \ldots \ldots \ldots \ldots \ldots \ldots \ldots \ldots$

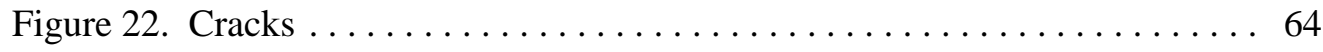

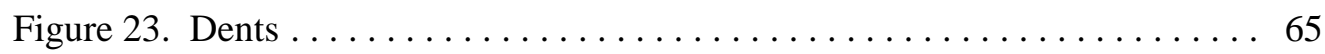

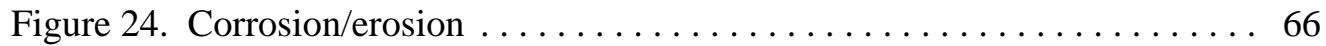

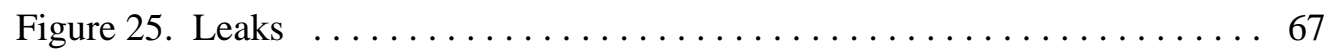

Figure 26. Overall ratings for the gates $\ldots \ldots \ldots \ldots \ldots \ldots \ldots \ldots \ldots \ldots \ldots$ 


\section{Tables}

Table 1. Condition index scale and zones $\ldots \ldots \ldots \ldots \ldots \ldots \ldots$

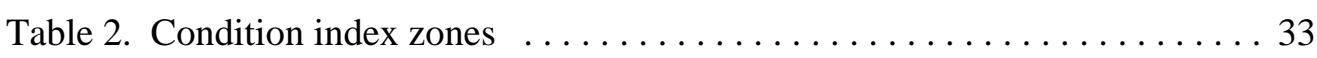

Table 3. Tainter dam and lock gate distresses $\ldots \ldots \ldots \ldots \ldots \ldots \ldots \ldots \ldots$

Table 4. Unadjusted weighting factors for tainter gate distresses $\ldots \ldots \ldots \ldots 56$

Table 5. Tainter gate structural distresses $\ldots \ldots \ldots \ldots \ldots \ldots \ldots \ldots$ 


\section{Preface}

The study reported herein was authorized by Headquarters, U.S. Army Corps of Engineers (HQUSACE), as part of the Operations Management problem area of the Repair, Evaluation, Maintenance, and Rehabilitation (REMR) Research Program. The work was performed under Civil Works Research Work Unit 32672, "Development of Uniform Evaluation for Procedures/Condition Index for Deteriorated Structures and Equipment," for which Stuart D. Foltz is the Principal Investigator. Mr. James E. Crews (CECW-O) is the REMR Technical Monitor for this work.

Mr. David B. Mathis (CERD-C) is the REMR Coordinator at the Directorate of Research and Development, HQUSACE; Mr. James Crews and Dr. Tony C. Liu (CEEC-ED) serve as the REMR Overview Committee; Mr. William F. McCleese, U.S. Army Engineer Waterways Experiment Station, is the REMR Program Manager; Dr. Anthony M. Kao was the Problem Area Leader for the Operations Management problem area during this study. Mr. David T. McKay is the current Problem Area Leader for the Operations Management problem area.

This study was performed by the Department of Civil and Construction Engineering, Iowa State University, under contract to the U.S. Army Construction Engineering Research Laboratories (USACERL). Principal Investigators for Iowa State University were Lowell Greimann, James Stecker, and Michael Nop. The study was conducted under the general supervision of Dr. Paul A. Howdyshell, Chief of the Engineering and Materials Division (FM), Infrastructure Laboratory (FL), USACERL. The USACERL technical editor was Linda L. Wheatley, Technical Resources Center.

COL James T. Scott is Commander and Acting Director, USACERL, and Dr. Michael J. O'Connor is Technical Director. 


\section{Conversion Factors, Non-SI to SI Units of Measurement}

Non-SI units of measurement used in this report can be converted to SI (metric) units as follows:

\begin{tabular}{lll} 
Multiply & \multicolumn{1}{c}{ By } & To Obtain \\
\cline { 2 - 3 } feet & 0.3048 & meters \\
inches & 0.0254 & meters \\
square ft & .0929 & square meters
\end{tabular}




\section{Introduction}

\section{Background}

Over the past 100 years the U.S. Army Corps of Engineers has designed and constructed numerous civil works structures such as locks and dams on the navigable inland waterways and coastal systems and dams for power generation. Recently, however, the potential for such undertakings has become limited, and the need for maintenance of the present facilities has become more significant. The Corps has responded by initiating and developing a Repair, Evaluation, Maintenance, and Rehabilitation (REMR) program.

A research effort concentrating on the inspection and rating of tainter dam and lock gates has been developed by the project team at Iowa State University (ISU). As part of the REMR program, the research has established a consistent means of identifying potential problems for tainter dam and lock gates through the use of an inspection procedure. With this tool the engineers have the capability to analyze and evaluate the inspection information before problems become severe.

Being able to rely on the functionality and structural integrity of tainter dam and lock gates as operating components of a navigation lock and dam, or a power dam facility, or a reservoir is essential. If a tainter lock gate does not work properly, navigation along the entire river may be held up, incurring large user costs. Tainter dam gates are critical for maintaining the upper pool and for use in flood control at lock and power dam facilities. If a dam gate fails, causing the loss of pool, navigation along an entire stretch of river may be at a standstill until the pool is restored. A power dam project faces decreased power generation capacity if head is lost.

\section{Objective}

The objective of this project was to develop an inspection and rating procedure that describes the current condition of tainter dam and lock gates in a uniform manner. 


\section{Mode of Technology Transfer}

It is recommended that the inspection procedures developed in this study for tainter dam and lock gates be incorporated into Engineering Regulation (ER) 11102-100, Periodic Inspection and Continuing Evaluation of Completed Civil Works Structures.

\section{Overview}

The concepts in this report for the inspection and rating of tainter dam and lock gates stem from work in similar projects for steel sheet pile structures (Greimann and Stecker 1989, 1990), miter lock gates Greimann, Stecker, and Rens 1990), sector gates (Greimann, Stecker, and Rens 1991), and tainter and butterfly valves (Greimann, Stecker, and Veenstra, 1993). Basic ideas such as condition indexes, safety and serviceability, quantification of distresses by field measurements, limiting values of distresses, and others have been refined as the investigation of new structures has broadened. Several enhancements and new ideas have been developed and applied to tainter dam and lock gates.

The investigation by the ISU project team consisted of meetings, site visits, and field investigations with Corps of Engineers personnel at several lock and power dam facilities. At these meetings and site visits, Corps experts expressed their opinions on the critical components and problems associated with the operation and repair of tainter dam and lock gates. They suggested means of quantifying these components and problems by relating them to the overall condition of the gates. Using the experts' comments, the project team formulated an inspection procedure and a tentative set of rating rules.

\section{Field Test}

A field test consists of performing the inspection procedure at several lock and dam facilities. The field test serves two purposes: First, to determine the plausibility of the inspection procedure, and second, to compare and calibrate the rating rule results with the experts' opinions to ensure that the current condition of a gate would be reflected. A field test was conducted at several lock and dam facilities in the St. Paul District. The ISU project team and Corps experts performed the inspections. The problems encountered in the inspection procedure and the discrepancies between the experts' opinions and the results attained from the rating rules were addressed. 


\section{Field Inspection}

Figure 1 illustrates the inspection and rating procedure. The field inspection is the means of gathering consistent data for any particular tainter dam or lock gate. The first two pages of the inspection form are used to record descriptive data, such as the type and location of the gate, general component information, and maintenance history. Additional pages provide space for field measurement data, such as anchorage assembly deterioration, corrosion, and cracks. The field measurement data is representative of the current state of the structure. All the information collected on the inspection form is entered into a data file on a microcomputer that performs all the calculations necessary to rate the gate.

\section{Condition Index}

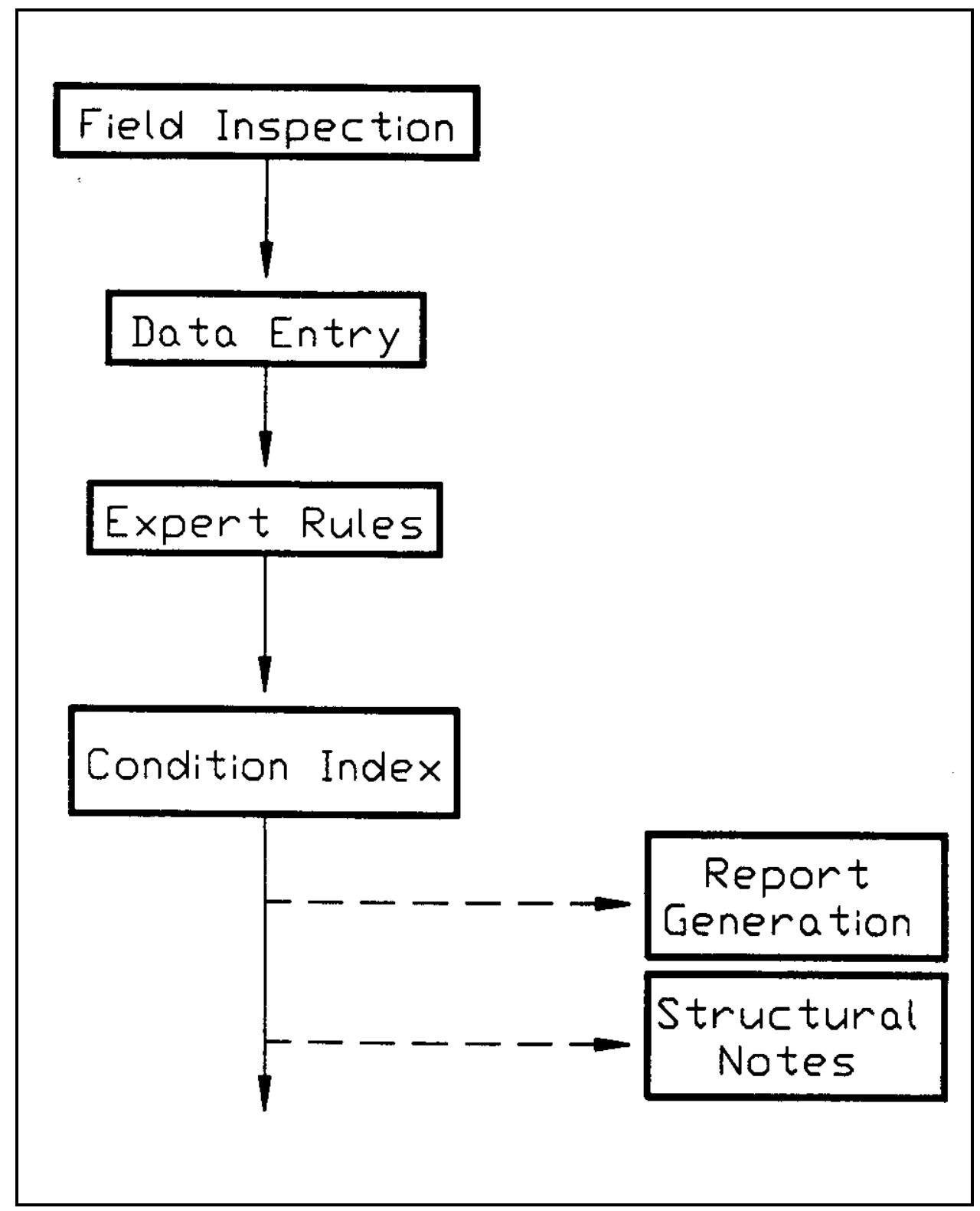

Figure 1. Inspection and rating procedure. 
A condition index $(\mathrm{CI})$ is the numerical measure used to rate the current state of a gate. The CI has two purposes: First, the CI values serve as a planning tool meant to focus management attention on those tainter dam and lock gates most likely to warrant immediate repair or further evaluation. Second, the CI values can be used to monitor change in general condition over time and can serve as an approximate comparison of the condition of different structures. One of the goals of this project was to define a CI that uniformly and consistently ranks the condition of structures.

The REMR CI is a numerical scale, ranging from a low of 0 to a high of 100 . The numbers indicate the relative need to perform REMR work because of deteriorating characteristics of the structure. For management purposes, the CI scale is also calibrated to group structures into three basic categories or zones (Table 1).

\section{Tainter Gate Description}

Tainter dam gates are used at the top of a dam to control the upper pool elevation, and tainter lock gates operate as upper gates in a lock chamber (Figure 2). Although the function of tainter dam gates and lock gates are somewhat different, their structural components are comparable. Their basic purpose is to hold back and to pass water. Tainter lock gates are submersible; i.e., they are lowered below the sill to allow vessels to pass over them during locking. Some dam gates are partially submersible; i.e., they do not rest on a sill when closed and can be lowered to allow

Table 1. Condition index scale and zones.

\begin{tabular}{|c|c|c|c|}
\hline Zone & Condition Index & Condition Description & Recommended Action \\
\hline \multirow{2}{*}{1} & 85 to 100 & $\begin{array}{l}\text { Excellent: No noticeable defects. Some } \\
\text { aging or wear may be visible. }\end{array}$ & \multirow{2}{*}{ Immediate action is not required. } \\
\hline & 70 to 84 & $\begin{array}{l}\text { Good: Only minor deterioration or } \\
\text { defects are evident. }\end{array}$ & \\
\hline \multirow{2}{*}{2} & 55 to 69 & $\begin{array}{l}\text { Fair: Some deterioration or defects are } \\
\text { evident, but function is not significantly } \\
\text { affected. }\end{array}$ & \multirow{2}{*}{$\begin{array}{l}\text { Economic analysis of repair } \\
\text { alternatives is recommended to } \\
\text { determine appropriate action. }\end{array}$} \\
\hline & 40 to 54 & $\begin{array}{l}\text { Marginal: Moderate deterioration. } \\
\text { Function is still adequate. }\end{array}$ & \\
\hline \multirow{3}{*}{3} & 25 to 39 & $\begin{array}{l}\text { Poor: Serious deterioration in at least } \\
\text { some portions of the structure. Function } \\
\text { is inadequate. }\end{array}$ & \multirow{3}{*}{$\begin{array}{l}\text { Detailed evaluation is required to } \\
\text { determine the need for repair, } \\
\text { rehabilitation or reconstruction. } \\
\text { Safety evaluation recommended. }\end{array}$} \\
\hline & 10 to 24 & $\begin{array}{l}\text { Very Poor: Extensive deterioration. } \\
\text { Barely functional. }\end{array}$ & \\
\hline & 0 to 9 & $\begin{array}{l}\text { Failed: No longer functions. General } \\
\text { failure or complete failure of a major } \\
\text { structural component. }\end{array}$ & \\
\hline
\end{tabular}




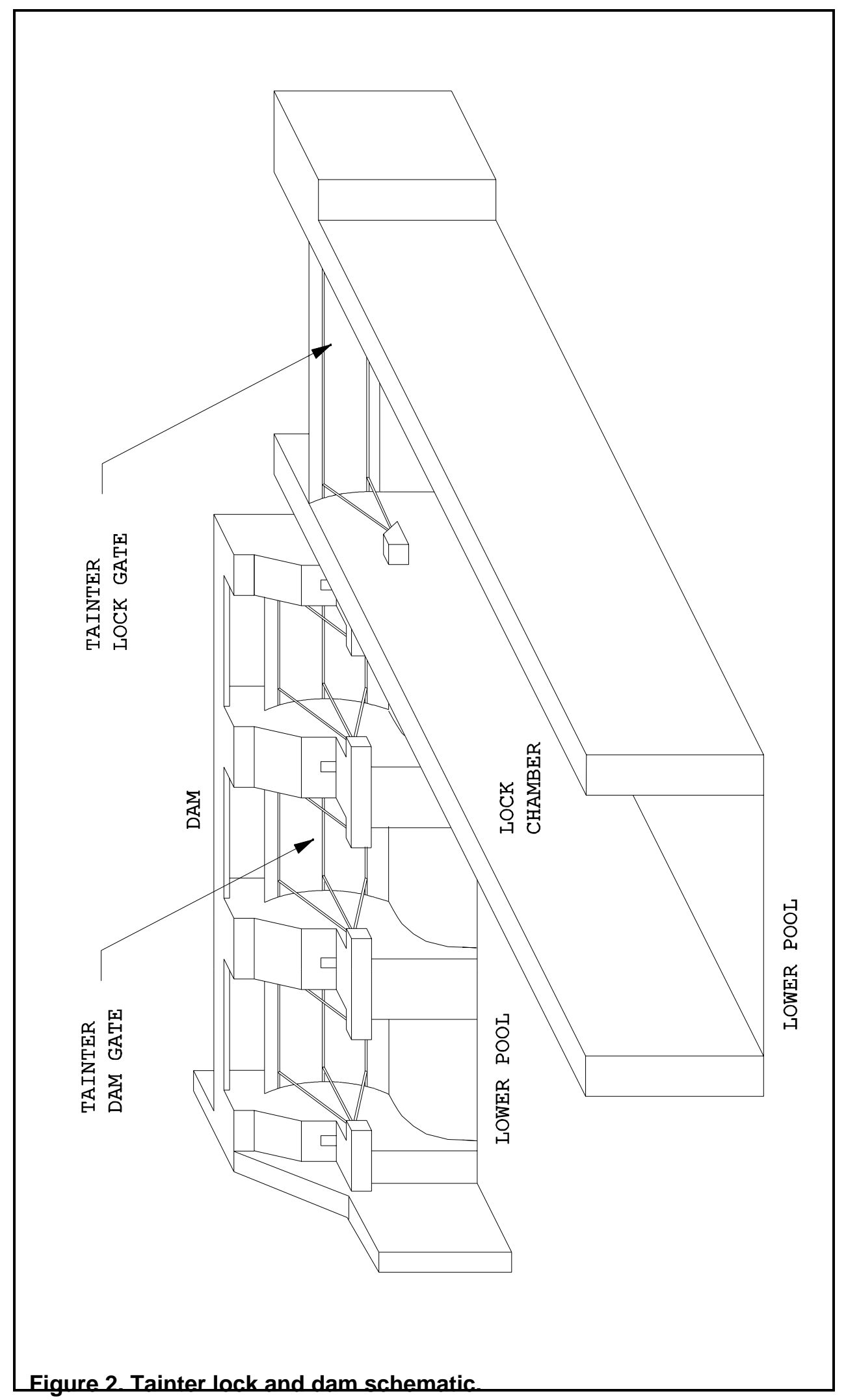

Figure 2. Tainter lock and dam schematic. 
water to pass over them. Partially submersible dam gates can also be raised to allow water to pass underneath.

\section{Tainter Gate Component Identification}

To inspect and rate tainter dam and lock gates requires familiarity with the configurations and components of such structures. Definitions and sketches of these components are presented in the following paragraphs:

Skin plate: An upstream skin plate is welded or riveted to the ribs to provide stiffness to the structure (Figures 3, 4, and 5). It dams the water and transfers load to the ribs. A downstream skin plate also may be present.

Ribs: The ribs, usually tees, are welded or riveted to the main girders. The ribs transfer load from the skin plate to the main girders (Figures 3, 4, and 5).

Main girders: The main girders can be either horizontally or vertically positioned. They span the width or height of the gate and transfer load from the skin plate and ribs to the strut arms (Figures 3, 4, and 5).

Strut arms: Strut arms are the steel girders that transfer load from the main girders to the trunnion assembly (Figures 3, 4, and 6). Some strut arms are parallel to the pier face and some slope toward the center of the gate from the trunnion, as shown in the figures.

Trunnion assembly: The trunnion assembly consists of a trunnion hub with bronze bushing and heavy flanges, a trunnion yoke, and a trunnion pin (Figure 6). The trunnion assembly transfers load from the strut arms to the trunnion girder.

Trunnion hub: The trunnion hub consists of a cylindrical plate and bushing which encompass the hinge pin and transmit load from the strut arms to the trunnion yoke (Figure 6). The flanges align the strut.

Trunnion yoke: The trunnion yoke is bolted to the concrete or steel trunnion girder (Figure 6). It transfers load from the trunnion hub to the trunnion girder.

Trunnion pin: The trunnion pin acts as the pivot point of the gate.

Trunnion girder: The concrete or steel trunnion girder is anchored into the pier or lockwall (Figures 3 and 6). It transfers load from the trunnion yoke to the pier or lockwall. 


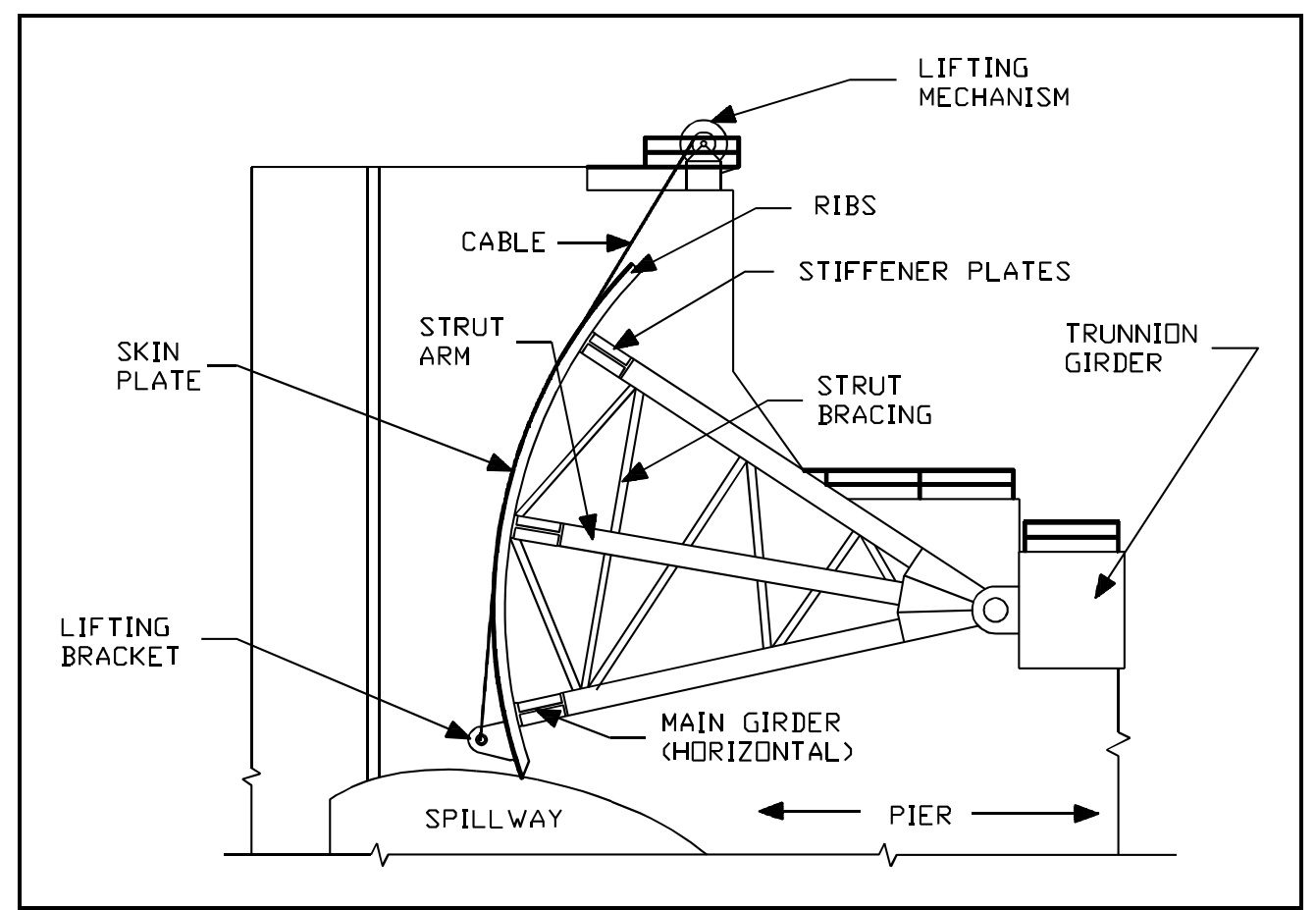

Figure 3. Side view of tainter gate.

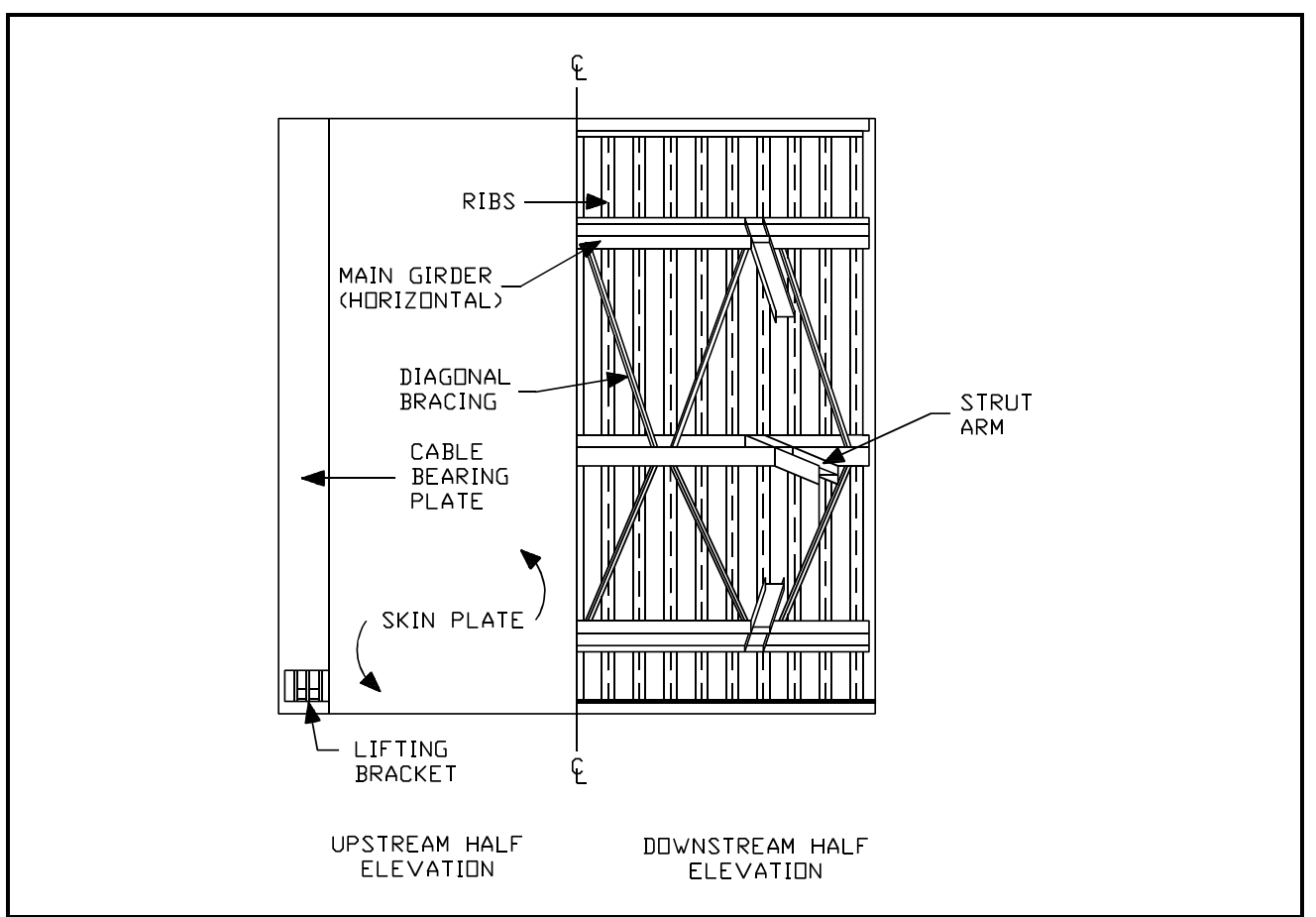

Figure 4. Elevation view of tainter gate. 


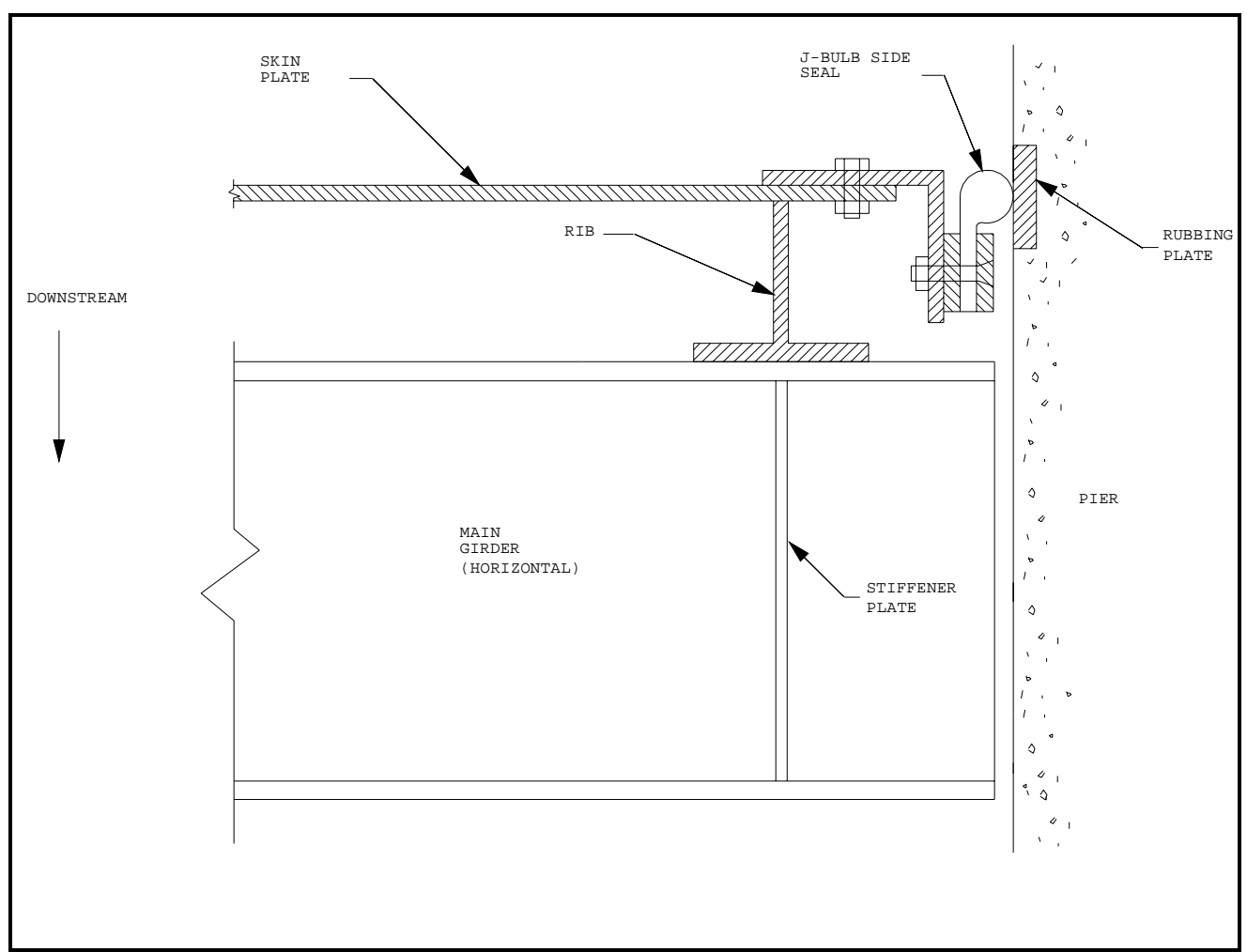

Figure 5. Side seal detail.

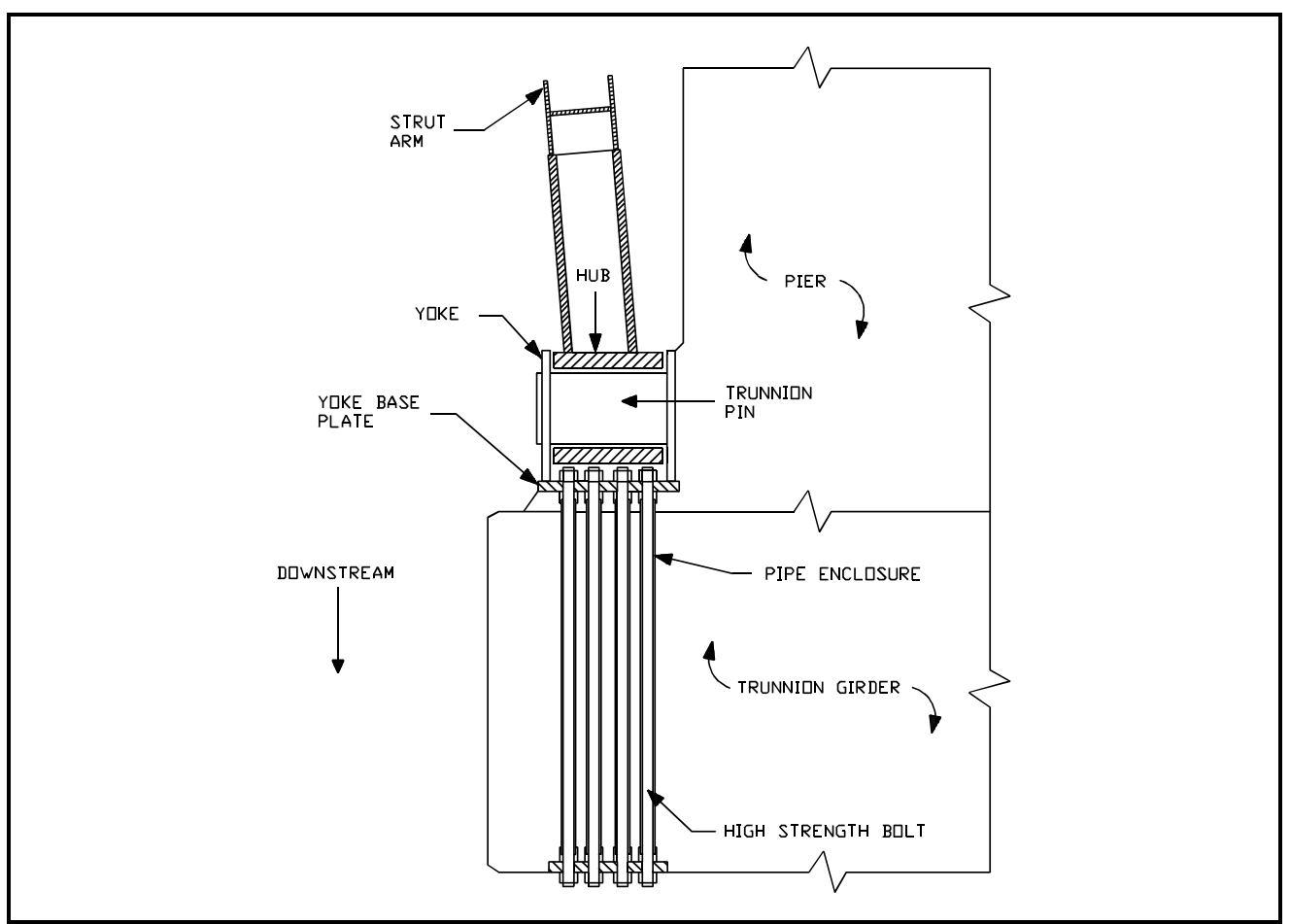

Figure 6. Example trunnion assembly detail (individual projects differ considerably). 
Prestressed anchors: In many cases, prestressed anchors are used to attach the trunnion girder to the pier.

Lifting chain or cable: The lifting chain or cable connects the operating machinery with the gate (Figure 3). It moves the gate between its open and closed positions.

Lifting bracket: The lifting brackets are located near the bottom of the gate on either the upstream or downstream side of the skin plate. They connect the chain or cable to the gate structure (Figures 3 and 4).

Cable or chain bearing plate: A bearing plate is a thickened or doubled strip of the skin plate or back-to-back channels located on the upstream side (Figure 4). It reduces the wear on the skin plate caused by the sliding contact of the cable or chain as the gate is moved.

Seals: Rubber seals are used on each side and sometimes on the bottom of a gate to prevent leakage around the gate perimeter (Figure 5).

Rubbing plates: Steel side-seal rubbing plates are placed in the pier or lockwall to maintain a smooth contact surface for the side seals as the gate is moved (Figure 5).

Diagonal bracing: Diagonal bracing is commonly used across the downstream flanges of the main girders (Figure 4). It aids in the field erection of the gate and adds to its rigidity.

Strut bracing: The strut bracing acts as an internal truss framework (Figure 3). The specific arrangement of the members varies from gate to gate. 


\section{Field Inspection}

\section{Inspection Procedure Development}

Simplicity and adaptability are the two ideas that form the basis of the inspection procedure. Applying the concept of simplicity to tainter dam and lock gates means that the inspection program must be simple to learn and easy to execute in the field. The inspection program must also be adaptable to both structures and the conditions under which they function.

Previous work done by the ISU project team suggests that field inspection be based upon easily obtainable data. Data that can be obtained from the pier, lockwall, or on the gate itself is considered to be easily obtainable. The safety aspect of gathering data while on the gate was also an important consideration in the development of the field inspection program. Each district takes special precautions to ensure the safety of its workers. Some districts allow their personnel to walk around on the gate if a safety harness is worn and some do not allow walking on the gate, but will lower personnel down to a gate by means of a basket or platform. Data is also considered easily obtainable if no underwater diving and ultrasonic or other sophisticated devices are implemented. All data would be gathered using a tape measure, a ruler, a trammel, dial gauges and the like. An interview with the chief lock or dam operator will assist the collection of data. The intent of this inspection procedure is that no specific engineering training or experience is needed to perform an inspection, although the interpretation of the inspection results often requires engineering expertise.

Gate configurations, function, project type, and operating conditions also affect inspection procedures. Single-skin and double-skin gates are inspected differently. The function of a tainter gate depends on whether it is a lock or dam gate. Power plant and non-power plant projects have different applications that require different rating rules. Operating conditions relate to the amount of head, if any, on the gate. Each aspect affects the inspection procedure and rating rules to some degree. For example, a gate that can be loaded first with full head and then have the head totally removed gives the best indication of anchorage wear. However, this situation seldom occurs, and the procedure for measuring wear is limited by the amount of head on the gate at the time of inspection. Often the total amount of head cannot be removed by placing bulkheads upstream to hold back the water, because it may be impractical. Or, if bulkheads are used to isolate lock gates, navigation along a river could be delayed if no auxiliary lock exists at the site. Addressing these types of 
problems has resulted in the inspection procedure for tainter gates described in the remainder of this chapter.

\section{Overview of Inspection Procedure}

Many Corps districts follow an annual schedule to inspect gates. Annual inspections are usually performed under normal operating conditions. Normal operating conditions refers to the usual status of the gate structure at the time of inspection. For example, the gate may be operating under load conditions or it may be dry. The amount of time and degree of detail spent on such inspections vary considerably among different districts. Some districts will place bulkheads every five years in order to conduct a thorough inspection and to perform any necessary maintenance. Some inspect only representative gates. Working within this established schedule, the ISU project team has developed an inspection procedure to handle the conditions under which the inspections will be performed. Generally speaking, an inspection performed under bulkheaded conditions gives a more accurate assessment of gate condition than inspections done during normal operating conditions; however, bulkheaded inspections are costly and require more time. Because of this, an inspection performed under normal operating conditions is the initial procedure in the evaluation process. The information gathered from this type of an inspection is used to calculate an initial CI. Generally, inspections performed under normal operating conditions will continue until a gate is bulkheaded for maintenance reasons or the initial CI value becomes low enough to warrant further investigation. To get a more accurate assessment of a gate's condition, an inspection should be performed under bulkheaded conditions in order to update the CI. This updated CI can be used to evaluate the approximate condition of other gates operating under similar conditions.

\section{Overview of Inspection Form}

The inspection form for tainter dam and lock gates has been designed to provide flexibility in documenting a variety of field conditions within one standard form. The first two pages of the form address historical information and should be completed before the field inspection. The remaining four pages are completed in the field. The following paragraphs briefly outline the inspection form.

\section{Historical Information}

Historical information related to the tainter gate structure is recorded on pages 1 and 2 of the inspection form. Project reference data is recorded to identify and locate the specific structure. Information that categorizes the structure into a 
particular type and function is requested. Some information is used to sort through the expert rules in the evaluation process, such as gate dimensions. Entries for historical descriptions of maintenance, modifications, and inspections are also provided on page 2 for reference only.

\section{Field Measurements}

Pages 3 through 6 of the inspection form are used to record field measurements. Some of the measurements requested include anchorage assembly deterioration, trunnion assembly wear, cracks, dents, corrosion, cable/chain plate wear, misalignment, noises, and vibrations. The expert rules described in Chapter 3 utilize these field measurements to determine the CI for tainter gates.

\section{General Notes}

The actual inspection form for tainter gates is shown on the following pages. Illustrations have also been provided to indicate how some of the measurements are taken. Specific explanations for entries on the inspection form are provided on the opposing page. 
This Page Intentionally Left Blank 
NAME OF CIVIL WORKS PROJECT:

LOCATION OF CIVIL WORKS PROJECT: (1.Body of water, 2.Nearest town)

1.

2.

INSPECTION DATE:

INSPECTED BY:

INSPECTION CONDITIONS:

1. NORMAL OPERATING

2. BULKHEADED

(no.)

FUNCTION AND LOCATION OF GATE:

1. DAM

2. LOCK

(no.)

TYPE OF PROJECT:

1. POWERPLANT

2. NON-POWERPLANT

(no.)

TYPE OF GATE:

1. SUBMERSIBLE

2. NON-SUBMERSIBLE

(no.)

TYPE OF FRAMING:

1. HORIZONTAL

2. VERTICAL

(no.)

TYPE OF SKIN PLATE:

1. SINGLE

2. DOUBLE

(no.)

TYPE OF LIFTING SYSTEM:

1. CHAIN

2. CABLE

(no.)

GATE WIDTH: (ft)

GATE RADIUS: (ft)

GATE HEIGHT: (ft)

UPPER POOL: (ft)

LOWER POOL: (ft)

ELEVATION OF SILL: (ft)

DO YOU ROUTINELY BULKHEAD THE GATE? (Y/N) IF YES, WHAT YEAR WAS THE GATE LAST BULKHEADED? INTERVAL PRD.? CONSTRUCTION DATE: 
Page 1 Comments: Historical or Recordkeeping Data

Completed before the site inspection and verified or changed during the site inspection.

Data blanks on page 1 prefaced by (no.) must be recorded as numbers.

Enter in the NAME of the Corps of Engineers Project Title.

Indicate the BODY OF WATER and NEAREST TOWN.

Indicate the CONDITIONS under which the inspection will be performed. A NORMAL OPERATING condition refers to the usual status of the gate structure. For example, the gate may be operating under load conditions or be in a dry condition. BULKHEADED conditions imply that bulkheads will be placed to remove head or load from the gate. After readings are recorded, the bulkhead is removed and full head is applied. The inspection conditions will affect how anchorage and trunnion assembly wear measurements will be taken. An inspection performed under normal operating conditions may also prevent some information such as cable/chain plate wear from being taken because it may not be visible.

Indicate FUNCTION AND LOCATION OF GATE, TYPE OF PROJECT, and GATE.

Indicate TYPE OF FRAMING, SKIN PLATE, and LIFTING SYSTEM by entering the appropriate number in the blank following each question. A double skin plate has an upstream skin plate and a downstream skin plate; a single skin plate can also be called an upstream skin plate.

Enter the WIDTH, HEIGHT, and RADIUS of the tainter gate.

Enter the UPPER and LOWER POOL WATER LEVELS and the ELEVATION OF SILL referenced to mean sea level. This is important for establishing the head on the gate at the time of inspection. Bulkheading periods and construction information may be important for reference. 
IS THE ORIGINAL GATE CURRENTLY IN PLACE? (Y/N) IF SO, WHAT YEAR WAS IT PUT INTO OPERATION? IF NOT, IDENTIFY CURRENT GATE HISTORY:

ARE DRAWINGS AVAILABLE FOR THE GATE IN PLACE? (Y/N)

ARE THE DRAWINGS INCLUDED WITH THIS FILE? (Y/N)

$\underline{\text { PAST } 10 \text { YEAR HISTORY }}$

MAJOR MAINTENANCE, REPAIRS, OR OTHER MODIFICATIONS

DATE DESCRIPTION

(1):

(2):

(3):

(4):

PREVIOUS INSPECTIONS OR STRUCTURAL REVIEWS (attach avail. copies)

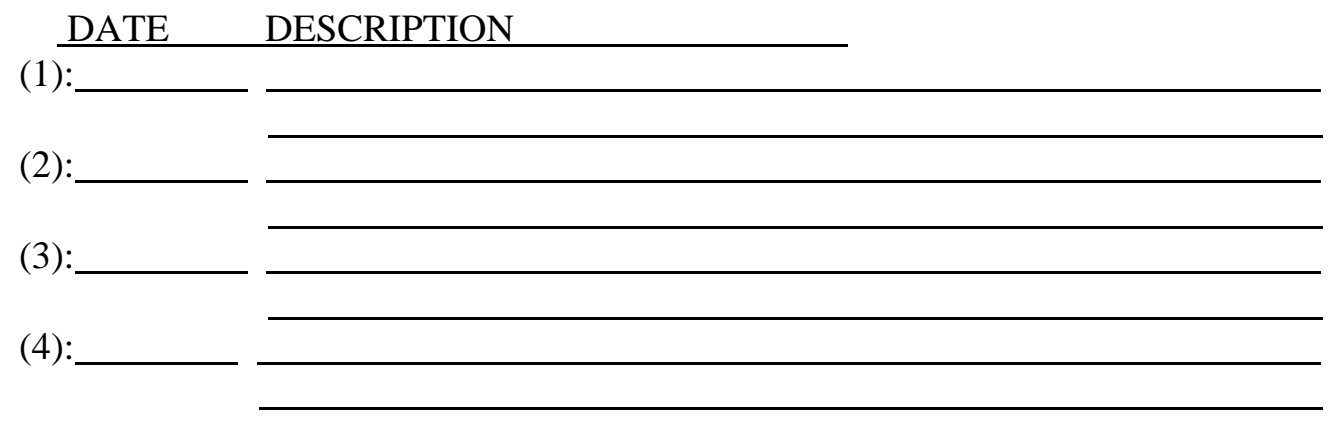

CONDITION OF LIFTING EQUIPMENT:

CONDITION OF GREASING SYSTEM:

OTHER COMMENTS: 
Page 2 Comments: Historical or General Data

Completed prior to the site inspection and verified or changed during the site inspection.

Gates are sometimes replaced or removed during rehabilitation. It is important for later reference to record the history of the gate which is currently in place.

Enter major MAINTENANCE, REPAIRS, OR OTHER MODIFICATIONS

performed on the gate within the last 10 years. A major repair is any repair which takes the gate out of service.

Enter PREVIOUS INSPECTION information for reference purposes.

Record the CONDITION OF LIFTING EQUIPMENT and the overall CONDITION OF GREASING SYSTEM. 
OPENING AND CLOSING OF THE GATE

NOISE?

JUMPING?

VIBRATION?

$\begin{array}{ll}\mathrm{Y} & \mathrm{N} \\ \mathrm{Y} & \mathrm{N} \\ \mathrm{Y} & \mathrm{N}\end{array}$

IS IT NORMAL?

$\mathrm{Y} \quad \mathrm{N}$

$\mathrm{Y} \quad \mathrm{N}$

$\mathrm{Y} \quad \mathrm{N}$

VIBRATION WITH FLOW

GATE VIBRATION (LEVEL 0, 1, 2, 3, or 4):

CAN VIBRATION BE ELIMINATED BY GATE OPENING ADJUSTMENT? Y N MISALIGNMENT

HOW WILL MEASUREMENTS BE TAKEN? (no.) 1. TAPE MEASURES

2. ELECTRONIC LEVEL

COMPLETE IF TAPE MEASURES ARE USED

CLOSED 2' OPEN CLOSED

LEFT EDGE (in.)

RIGHT EDGE (in.)

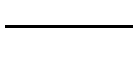

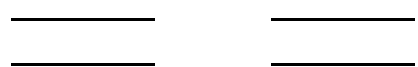

COMPLETE IF ELECTRONIC LEVEL IS USED

CLOSED 2' OPEN

CLOSED

ANGLE (degrees)

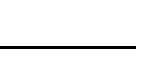

$\underline{\text { ANCHORAGE ASSEMBLY DETERIORATION }}$

CONCRETE CRACKED OR SPALLED?

BOLTS/NUTS:

CORRODED?

LOOSE?

MISSING?

\begin{tabular}{cccc}
\multicolumn{2}{c}{ LEFT SIDE } & \multicolumn{2}{c}{ RIGHT SIDE } \\
Y & $\mathrm{N}$ & $\mathrm{Y}$ & $\mathrm{N}$ \\
$\mathrm{Y}$ & $\mathrm{N}$ & $\mathrm{Y}$ & $\mathrm{N}$ \\
$\mathrm{Y}$ & $\mathrm{N}$ & $\mathrm{Y}$ & $\mathrm{N}$ \\
$\mathrm{Y}$ & $\mathrm{N}$ & $\mathrm{Y}$ & $\mathrm{N}$
\end{tabular}

IS THE EMBEDDED ANCHORAGE FLEXIBLE OR RIGID? $\quad \mathrm{F} \quad \mathrm{R}$ IF FLEXIBLE, LENGTH OF EMBEDMENT (in.):

ANCHORAGE MEASUREMENT (Measurements are taken in the downstream direction.)

COMPLETE IF NORMAL OPERATING CONDITIONS

LEFT SIDE (in.)

RIGHT SIDE (in.)

CLOSED 2' OPEN CLOSED CLOSED 2' OPEN CLOSED

Dials

Trammels

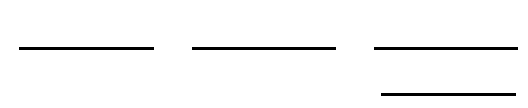

COMPLETE IF BULKHEADED CONDITIONS

LEFT SIDE (in.)

RIGHT SIDE (in.)

NO HEAD FULL HEAD NO HEAD FULL HEAD

Dials

Trammels 
Completed at site inspection.

OPENING AND CLOSING OF THE GATE: Observation of the gate during operation is a good indicator of problems. Open the gate $2 \mathrm{ft}$. and record the occurrence of any noise, jumping, or vibration of the gate. Observe the gate during closing also. If any of the three exist indicate whether or not it is normal.

VIBRATION WITH FLOW: During opening of the gate to $2 \mathrm{ft}$., indicate the level of gate vibration observed using the scale below.

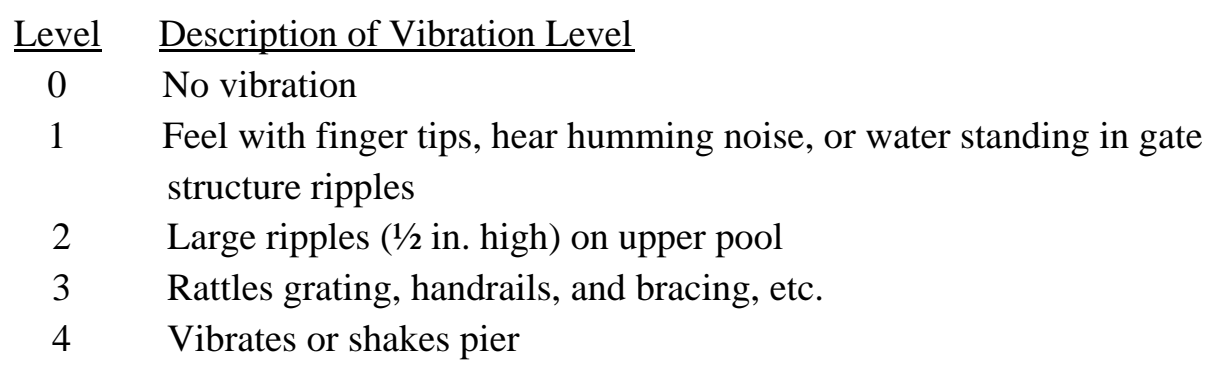

If vibration exists determine whether or not it can be eliminated by adjusting the height of the gate.

MISALIGNMENT: Measurements are recorded with the gate in the closed and $2 \mathrm{ft}$. open positions and then again in the closed position. Measurements can be made by attaching a tape measure to the skin plate on each side of the gate and recording the distance from a fixed reference point above the gate to the top of the gate (Figure 7). An alternative method of measurement consists of placing an electronic level horizontally along the skin plate and recording the angles (in degrees) at each gate position. (Levels should measure angles to the nearest 0.001 degrees.)

ANCHORAGE ASSEMBLY DETERIORATION: Indicate the presence of excessive cracked or spalled concrete at the interface around the anchorage connections. Excessive concrete spalling may indicate a displacement occurred at this location at some time and may or may not show up in the current inspection. Small hairline cracks, probably caused by thermal expansion or contraction of the concrete, should be ignored in this analysis. Indicate whether the anchor or casting bolts and nuts are significantly corroded. Significant corrosion refers to an approximate $10 \%$ volume reduction. Indicate whether or not the anchor and casting nuts are tightened properly. This is done with a torque wrench or by visual inspection for signs of movement between the bolted components during operation. Indicate if there are any broken or missing anchor or casting bolts and nuts. Some embedded anchorages are designed to permit small movements. These types of anchorage configurations are called flexible anchorage systems. Indicate if the embedded anchorage is rigid or flexible and if flexible give the length of embedment in inches. 


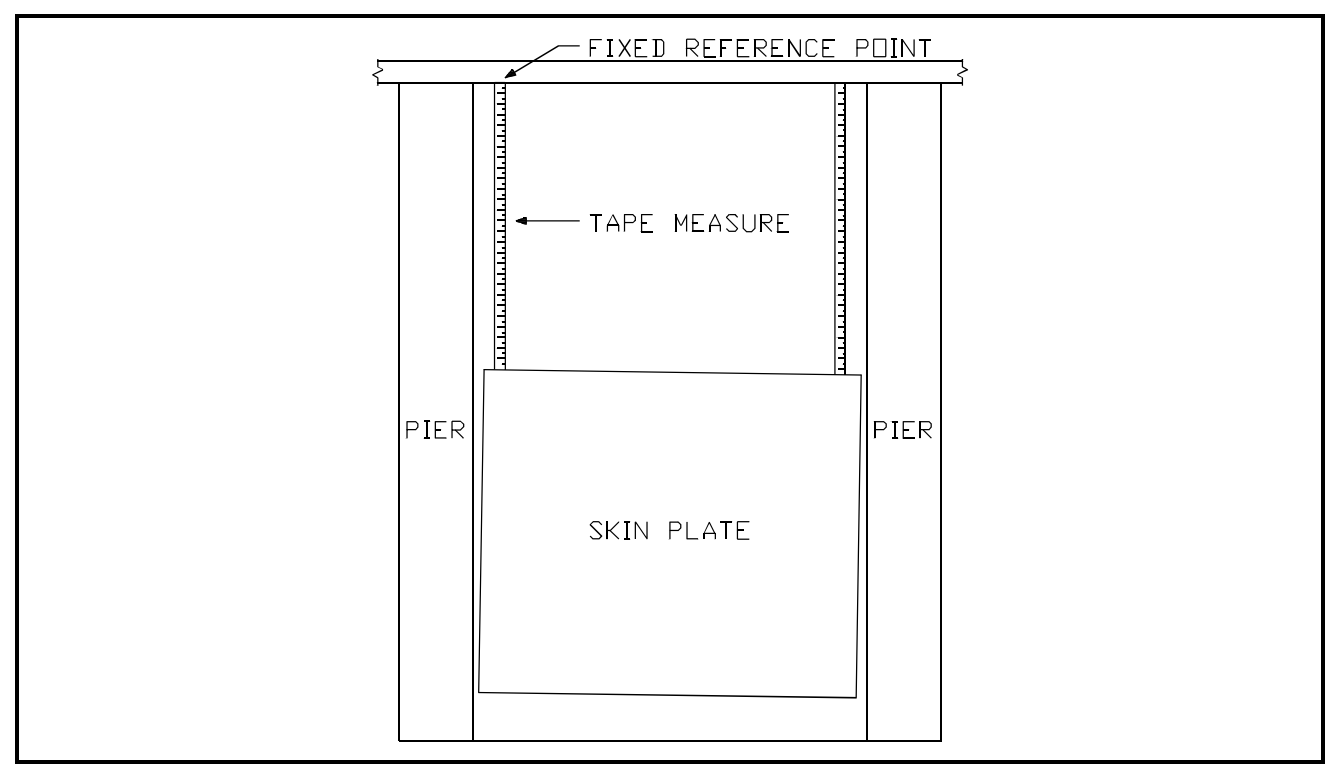

Figure 7. Misalignment measurement. 
This Page Intentionally Left Blank 
OPENING AND CLOSING OF THE GATE

NOISE?

JUMPING?

VIBRATION?

$\begin{array}{ll}\mathrm{Y} & \mathrm{N} \\ \mathrm{Y} & \mathrm{N} \\ \mathrm{Y} & \mathrm{N}\end{array}$

IS IT NORMAL?

$\begin{array}{ll}\mathrm{Y} & \mathrm{N} \\ \mathrm{Y} & \mathrm{N} \\ \mathrm{Y} & \mathrm{N}\end{array}$

$\underline{\text { VIBRATION WITH FLOW }}$

GATE VIBRATION (LEVEL 0, 1, 2, 3, or 4):

CAN VIBRATION BE ELIMINATED BY GATE OPENING ADJUSTMENT? Y N MISALIGNMENT

HOW WILL MEASUREMENTS BE TAKEN? (no.) 1. TAPE MEASURES
2. ELECTRONIC LEVEL COMPLETE IF TAPE MEASURES ARE USED

CLOSED 2' OPEN CLOSED

LEFT EDGE (in.)

RIGHT EDGE (in.)

COMPLETE IF ELECTRONIC LEVEL IS USED

CLOSED 2' OPEN

CLOSED

ANGLE (degrees)

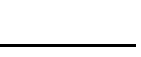

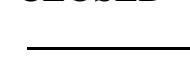

ANCHORAGE ASSEMBLY DETERIORATION

CONCRETE CRACKED OR SPALLED?

BOLTS/NUTS:

CORRODED?

LOOSE?

MISSING?

\begin{tabular}{cccc}
\multicolumn{2}{c}{ LEFT SIDE } & \multicolumn{2}{c}{ RIGHT SIDE } \\
Y & $\mathrm{N}$ & $\mathrm{Y}$ & $\mathrm{N}$ \\
$\mathrm{Y}$ & $\mathrm{N}$ & $\mathrm{Y}$ & $\mathrm{N}$ \\
$\mathrm{Y}$ & $\mathrm{N}$ & $\mathrm{Y}$ & $\mathrm{N}$ \\
$\mathrm{Y}$ & $\mathrm{N}$ & $\mathrm{Y}$ & $\mathrm{N}$
\end{tabular}

IS THE EMBEDDED ANCHORAGE FLEXIBLE OR RIGID? $\quad F \quad \mathrm{~F}$ IF FLEXIBLE, LENGTH OF EMBEDMENT (in.):

ANCHORAGE MEASUREMENT (Measurements are taken in the downstream direction.)

COMPLETE IF NORMAL OPERATING CONDITIONS

LEFT SIDE (in.) RIGHT SIDE (in.)

CLOSED 2' OPEN CLOSED CLOSED 2' OPEN CLOSED

Dials

Trammels

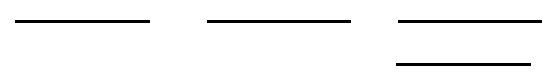

COMPLETE IF BULKHEADED CONDITIONS

LEFT SIDE (in.)

RIGHT SIDE (in.)

NO HEAD FULL HEAD NO HEAD FULL HEAD

Dials

Trammels 
ANCHORAGE MEASUREMENT: Measurements of relative movement between the concrete pier and trunnion yoke or girder are taken in the downstream direction (Figure 8). If the inspection is performed under NORMAL OPERATING

CONDITIONS, dial gauges are used to measure this movement and measurements are taken with the gate in the closed and $2 \mathrm{ft}$. open positions and then again in the closed position. For tracking relative movement over time, permanent reference points or benchmarks are established on the trunnion girder and on the pier adjacent to the girder. The distance between these points are recorded with the gate in the closed position after the gate has been lifted and reset. A convenient means of doing this is by using a trammel with permanently fixed trammel points for benchmarks. If BULKHEADED CONDITIONS exist, dial gauge measurements are taken in the closed position with no head on the gate and with full head on the gate. The term, no head, implies that the water on the upstream face of the gate will be removed by opening the gate. If a tailwater is present on the gate, the upper pool will be equal to the level of the lower pool with no net head. To apply full head or load, lift the bulkhead and flood the gate. Dial gauge measurements should be recorded to 0.001 inch. Trammel measurements between the permanent reference points are taken in the no head condition. Trammel measurements should be recorded as accurately as possible (about 0.0313 in. or $1 / 32$ in.).

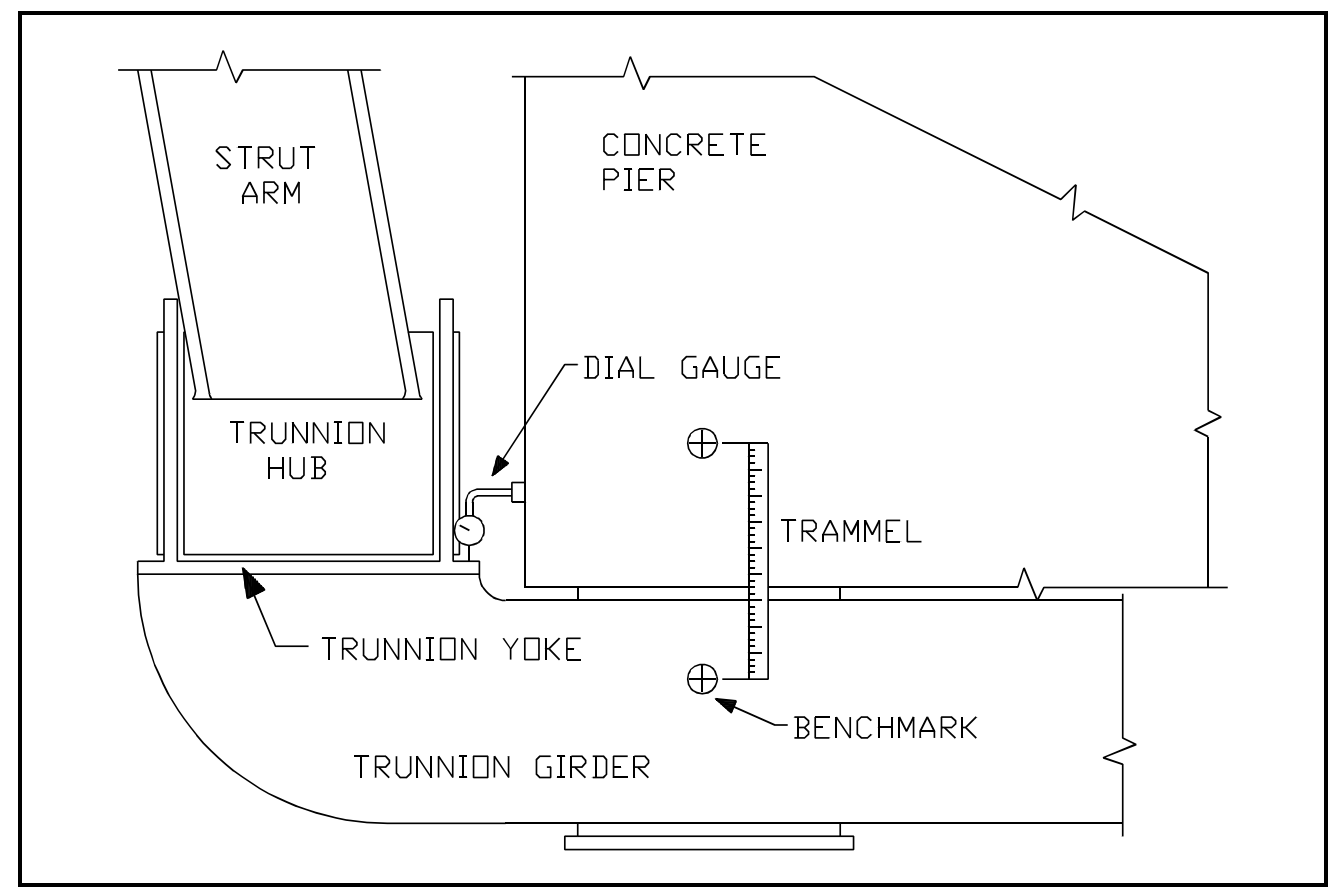

Figure 8. Anchorage measurement. 
TRUNNION ASSEMBLY WEAR

LEFT SIDE RIGHT SIDE ANY PROBLEMS WITH THE LUBRICATION SYSTEM? Y N NA Y N NA INDICATE HOW VERTICAL AND HORIZONTAL MEASUREMENTS WILL BE TAKEN: (no.) 1. FEELER GAUGES \& TRAMMELS 2. DIAL GAUGES \& TRAMMELS

COMPLETE IF NORMAL OPERATING CONDITIONS

LEFT SIDE (in.) RIGHT SIDE (in.) CLOSED 2' OPEN CLOSED CLOSED 2' OPEN

CLOSED HORIZONTAL:

Dials

Feeler US

Trammel

VERTICAL:

Dials

Feeler TOP BOT
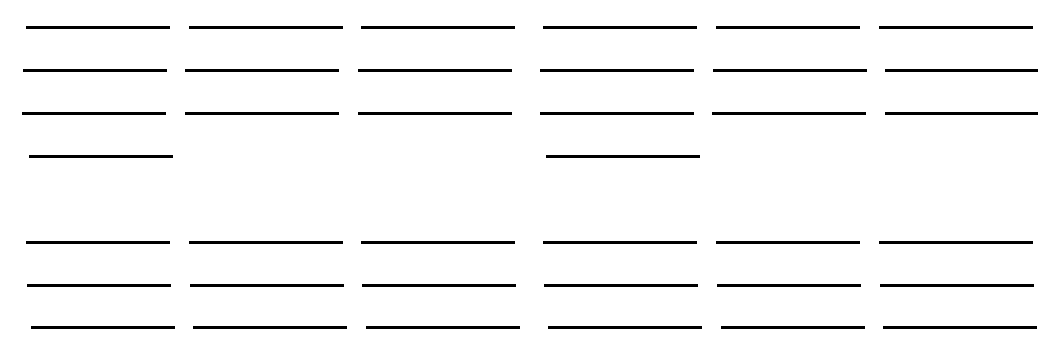

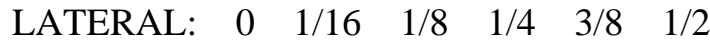
IS ANY GOUGING NOTICEABLE? Y N

$\begin{array}{llllll}0 & 1 / 16 & 1 / 8 & 1 / 4 & 3 / 8 & 1 / 2 \\ \mathrm{Y} ~ \mathrm{~N} & \end{array}$

COMPLETE IF BULKHEADED CONDITIONS

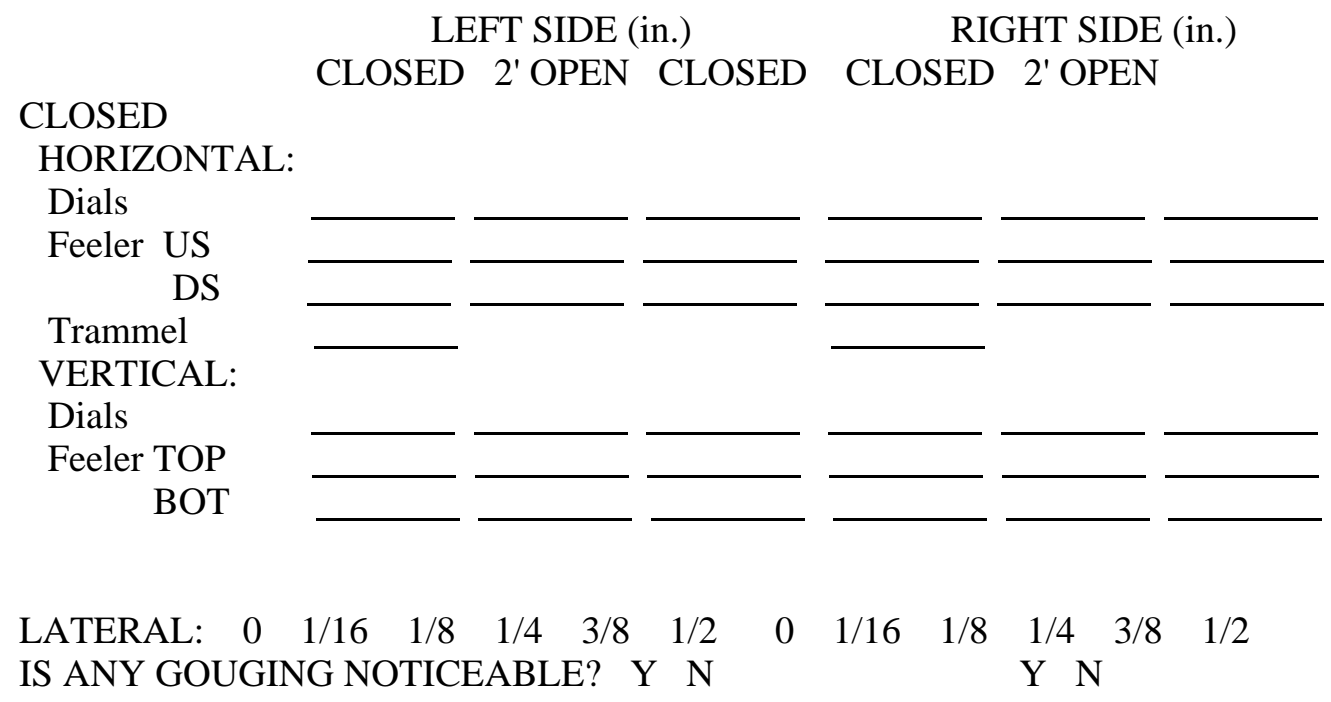


Completed at site inspection.

TRUNNION ASSEMBLY WEAR: Indicate whether the lubrication system is functional. If a unique situation exists, such as a nonlubricated trunnion, NA can be circled. The horizontal and vertical measurements are used to detect motion between the trunnion pin and the bushing. Indicate whether feeler or dial gauges will be used to take the horizontal and vertical measurements. For some gate designs the trunnion pin is exposed and, therefore, it may be possible and simpler to take the horizontal and vertical gap measurements using feeler gauges. Trammel measurements are required.

For an inspection performed under NORMAL OPERATING CONDITIONS the horizontal and vertical measurements are made with the gate in the closed and $2 \mathrm{ft}$. open positions and then again in the closed position. If dial gauges are used to measure the horizontal and vertical movement, it is important that the bearing surface for the dial gauge stem be smooth, with no unevenness, since the trunnion hub rotates. If feeler gauges are used, gap measurements are taken between the pin and bushing in four locations: upstream, downstream, top, and bottom. Horizontal trammel measurements are taken between permanent reference points or benchmarks which have been established in convenient positions on the trunnion hub and yoke. Trammel measurements are recorded in the closed position after the gate has been lifted and reset. Estimate lateral movements and circle correct answer.

Gouging occurs when the trunnion hub bears on the trunnion yoke.

Under BULKHEADED CONDITIONS the measurements will be recorded with the gate in the closed position when no head or load is present on the gate and when full head exists. If feeler gauges are used, gap measurements shall be taken between the pin and bushing in the same locations as under NORMAL OPERATING

CONDITIONS. If dial gauges are used, no special precautions are required to ensure a smooth bearing surface for the stem because the trunnion hub will not rotate. Horizontal trammel measurements are also taken between the permanent reference points for the no head condition. 


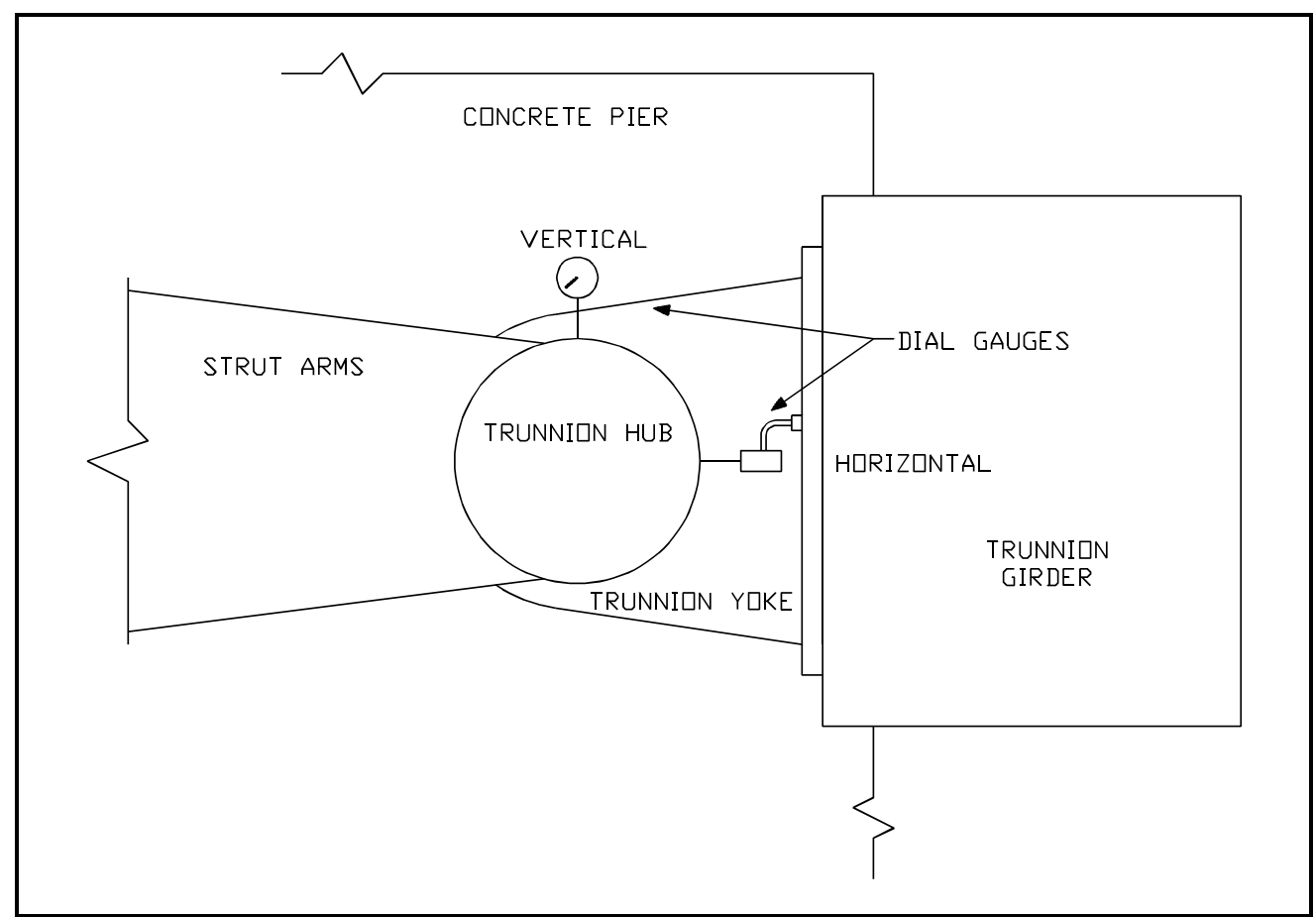

Figure 9. Trunnion assembly wear measurement: dial gauges.

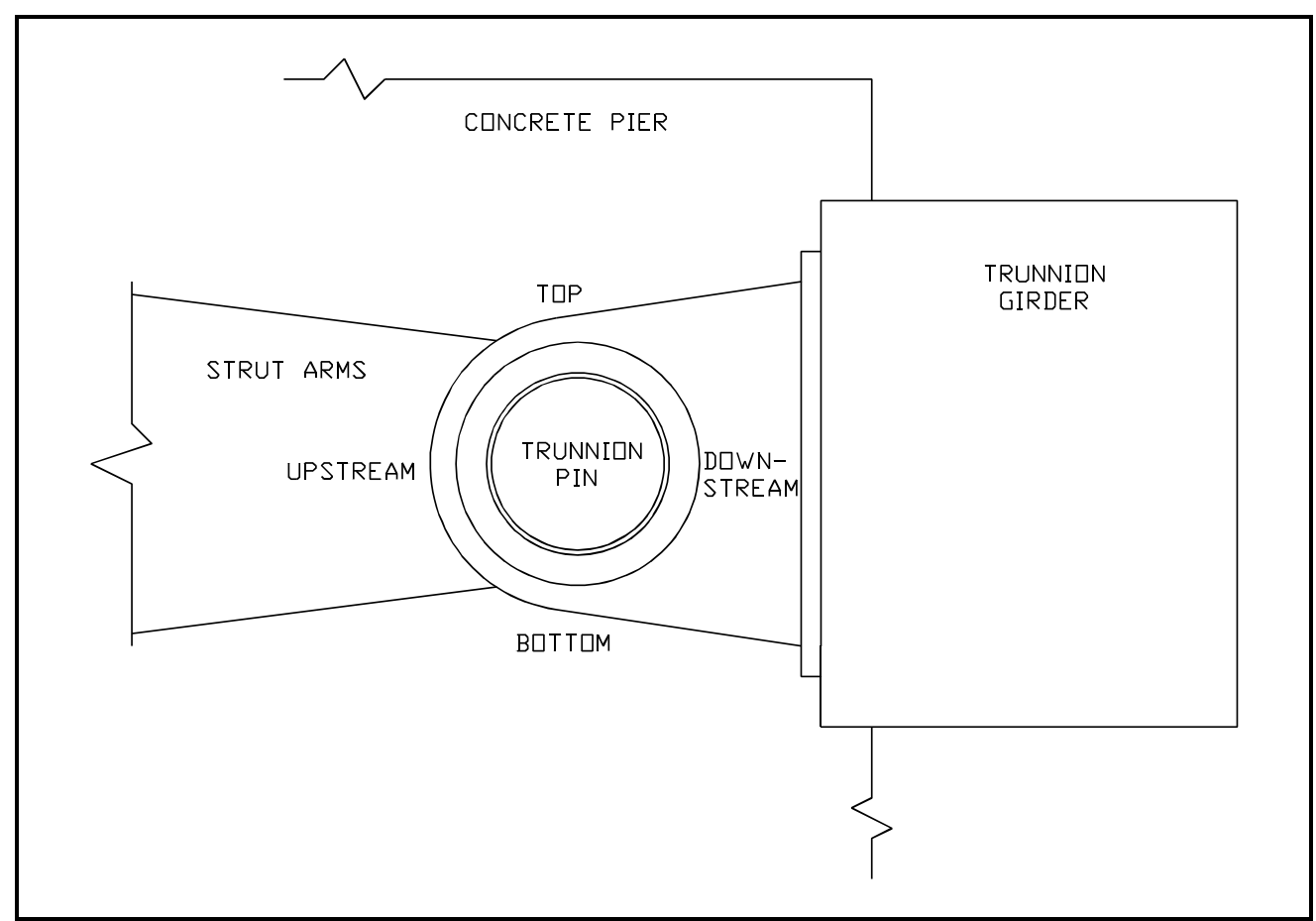

Figure 10. Trunnion assembly wear measurement: feeler gauges. 


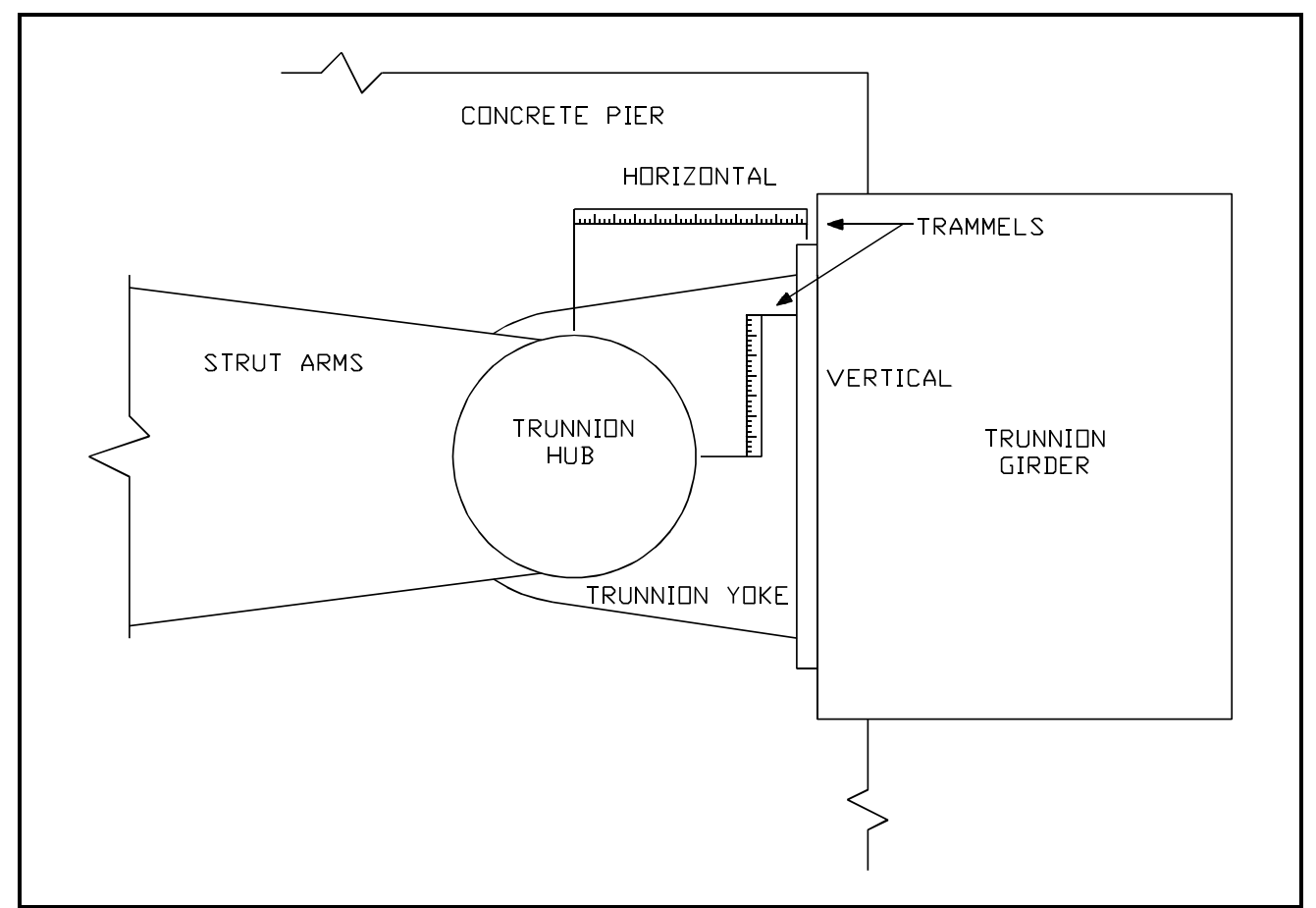

Figure 11. Trunnion assembly wear measurement: trammels.

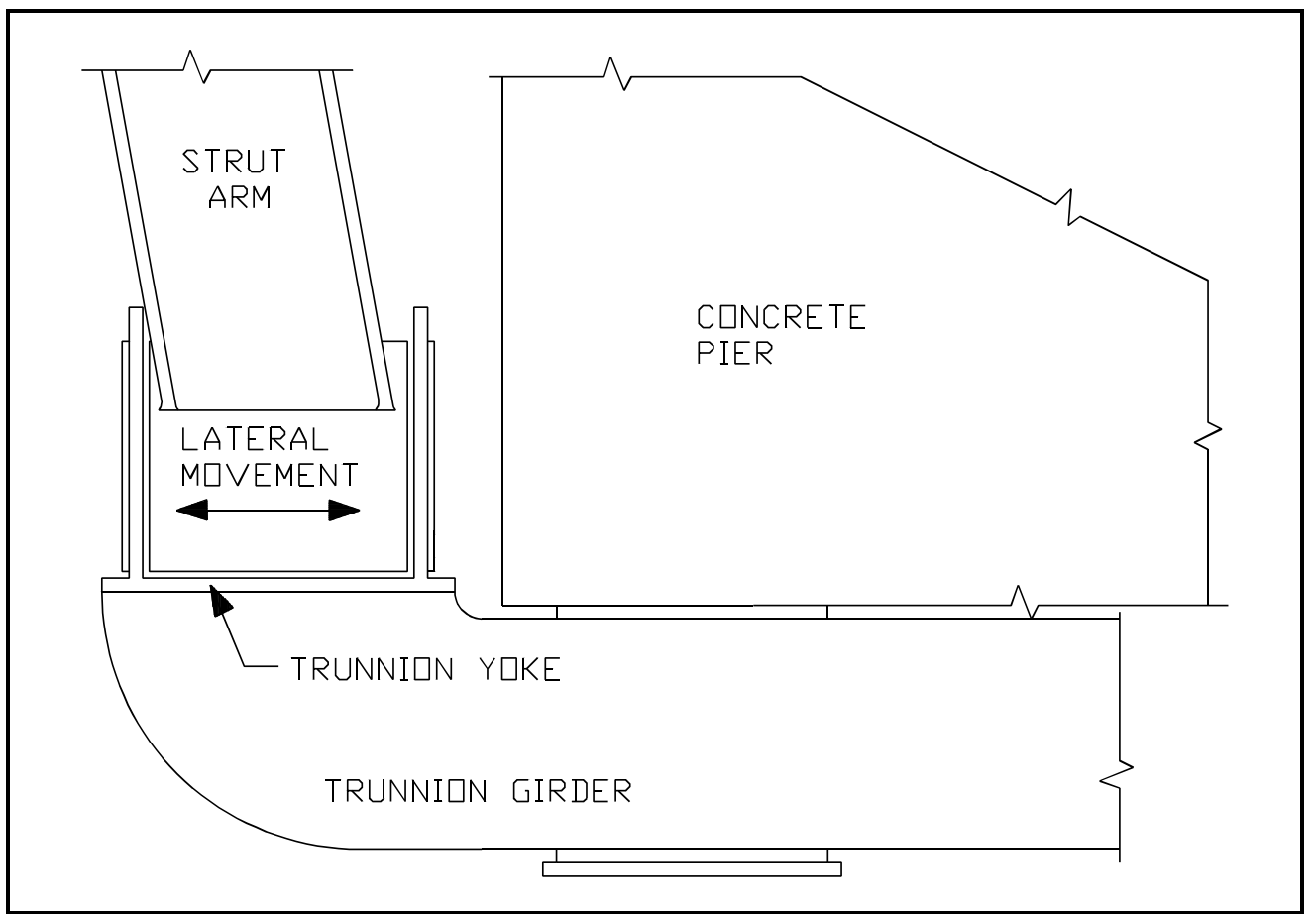

Figure 12. Trunnion assembly wear: lateral movement. 


\section{CORROSION (C) or EROSION (E)}

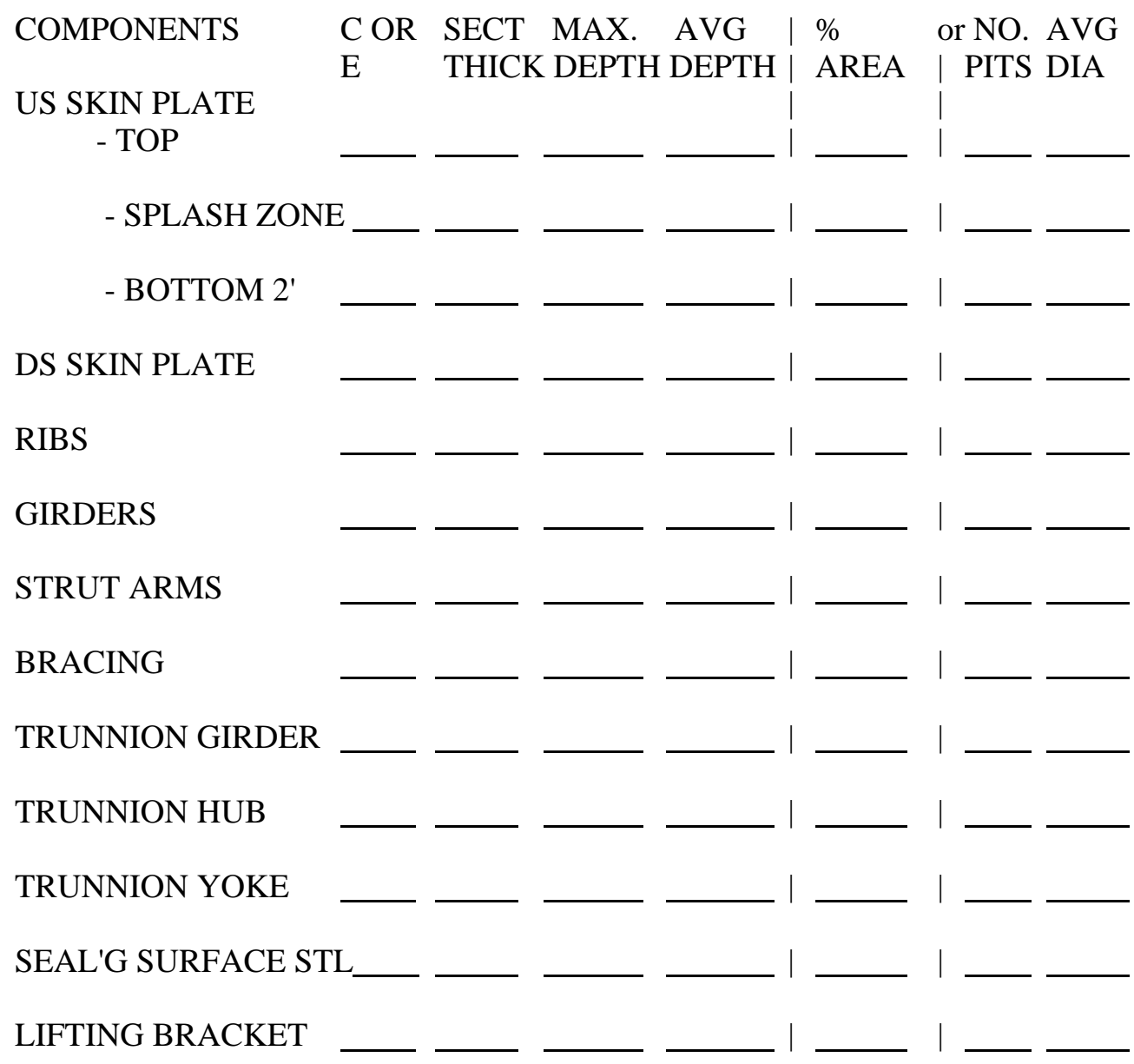

\section{CABLE/CHAIN PLATE WEAR}

IS THERE A BEARING PLATE ATTACHED TO THE SKIN PLATE? Y N IF YES, WHAT IS THE ORIGINAL BEARING PLATE THICKNESS:

OTHERWISE WHAT IS THE ORIGINAL SKIN PLATE THICKNESS:

IS THE WEAR VISIBLE? Y N IF YES, CIRCLE THE MAX. DEPTH OF WEAR:

$\begin{array}{llllllll}\text { LEFT SIDE (in.) } & 0 & 1 / 32 & 1 / 16 & 1 / 8 & 1 / 4 & 3 / 8 & 1 / 2 \\ \text { RIGHT SIDE (in.) } & 0 & 1 / 32 & 1 / 16 & 1 / 8 & 1 / 4 & 3 / 8 & 1 / 2\end{array}$


Completed at site inspection.

CORROSION: An area of one square foot of corrosion or erosion is selected on each component. This area should characterize the maximum density of average depth corrosion or erosion. For each component, indicate if corrosion (C) or erosion (E) caused the material loss. Estimate or check drawings for the original section thickness (SECT THICK) of each component. The maximum pitting depth (MAX. DEPTH) is recorded in column 3. For the one square foot, the average pitting depth (AVG DEPTH) is also recorded. Deterioration can be measured in one of two ways. For the selected area record either the percentage of the area (\% AREA) which is pitted or count the actual number of representative pits (NO. PITS). If the data was entered by counting the number of pits, record the average diameter (AVG DIA) of the representative pits in the last column. In some cases, when the percentage area method is used and the deterioration is uniform, the percentage of area affected could be $100 \%$ and the average pitting depth is the average thickness reduction.

CABLE/CHAIN PLATE WEAR: Indicate if there is a bearing plate attached to the skin plate for the cable or chain to bear upon. Estimate or check drawings for the original section thickness of the bearing plate, if one exists, or the skin plate. Circle the proper answer to indicate if wear is visible. If visible, estimate the maximum depth of wear and circle the correct depth. 
CRACKS RECORD COMPONENT, LENGTH, AND LOCATION

COMPONENT: US SKIN PLATE (U), DS SKIN PLATE (D), RIBS (R), MAIN GIRDERS (M), BRACING (B), STRUT ARMS (S), TRUNNION HUB (H), TRUNNION YOKE (Y), TRUNNION GIRDER (G)

(1):

(2):

(3):

(4):

COMPONENT LENGTH (in)

LOCATION

(5):

DENTS RECORD COMPONENT, HEIGHT, WIDTH, DEPTH, AND LOCATION COMPONENT: US SKIN PLATE (U), DS SKIN PLATE (D)

COMPONENT HEIGHT(ft.) WIDTH(ft.) DEPTH(in.) LOCATION

(1):

(2):

(3):

(4):

$(5)$ :
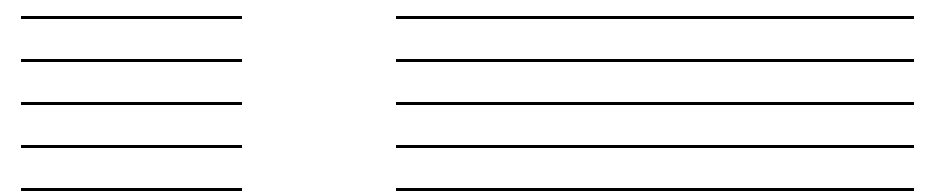

RECORD COMPONENT, LENGTH OF DENT, OUT OF PLANE DISTANCE, AND LOCATION. COMPONENT: RIBS (R), MAIN GIRDERS (M), BRACING (B), STRUT ARMS (S)

COMPONENT

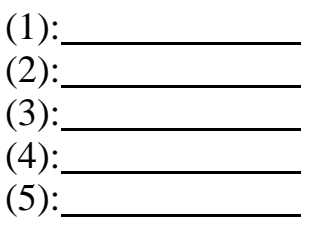

LENGTH OF DENT (in.)
OUT OF PLANE DISTANCE(in.)

LEAKS RECORD TYPE, LENGTH, AND LOCATION

TYPE: BOTTOM (B), LEFT (L), RIGHT (R)

(1):
LOC'N(B,L,R)
LENGTH (in)
DISTANCE FROM TOP/LEFT(ft.)

(2):

(3):

(4):

(5):

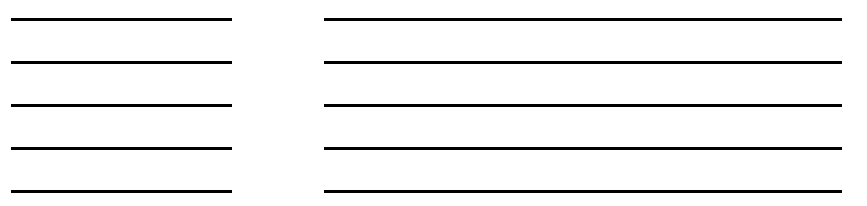

SEAL CONDITION

HOW MANY (IF ANY) SEAL BOLTS ARE MISSING? _ RECORD LENGTH AND LOCATION OF DAMAGED(D) AND MISSING(M) SECTIONS.

LOCATION: BOTTOM (B), LEFT (L), RIGHT (R) (1):

COND'N(D,M) LOC'N(B,L,R) LENGTH(in.) DIST FROM TOP/LEFT(ft.)

(2):

(3):

$(4):$

(5):
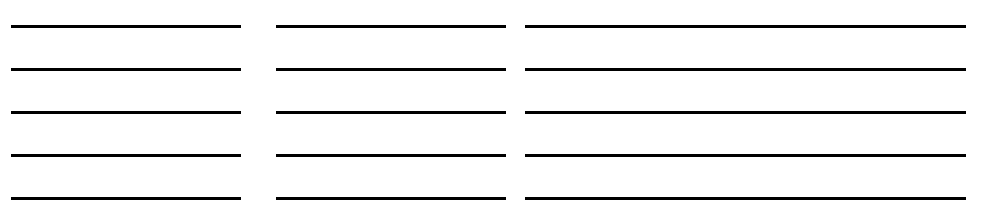
Completed at site inspection.

CRACKS: The presence of cracks on any component, especially the trunnion girder, trunnion yoke, trunnion hub and strut arms should be recorded. The location and length of upstream and downstream skin plate, rib, main girder, bracing, strut arm, trunnion hub, trunnion yoke, and trunnion girder cracks are made with a ruler or tape measure. The location of the crack on a component should be adequately described for evaluation purposes and future comparisons.

DENTS: For upstream and downstream skin plates, the height, width, depth, and location of dents are recorded using a ruler or tape measure. For rib, main girder, bracing, and strut arm dents, the length, out of plane distance, and location of each dent is recorded. Out of plane distance refers to the displacement of the member with respect to its longitudinal axis.

LEAKS: Record the location of leaks as, bottom (B), left (L), or right side (R). Record side leaks only if there is more than $2 \mathrm{ft}$. of head on the gate. Ignore leaks within 3 in. of the corners. The length and location of each entry is also recorded. The length is estimated and the location is in reference to the top or left side of the gate.

SEAL CONDITION: Record the number of seal bolts which are missing. Record any damaged (D) or missing (M) sections of seal and record the location as, bottom (B), left (L), or right side (R). A section of seal is considered damaged if it is cracked, ripped, or improperly attached. Missing sections refer to complete sections broken off because of debris, age, or other causes. Also, the length and location of each entry is recorded. The length is measured with a ruler and the location is in reference to the top or left side of the gate. 


\section{Condition Index}

The common definition of a $\mathrm{CI}$ as it relates to all the structures investigated thus far by the ISU and other project teams is shown in Table 1 of Chapter 1 .

Engineering judgment and experience are needed to develop the set of criteria from which the CI of a structure will be established. The process of identifying this set of criteria for tainter dam and lock gates was similar to the procedure used for other structures. Interviews and discussions held between the ISU project team and Corps experts continued until a general approach for tainter gate inspections began to develop. Preliminary field visits and meetings with engineers took place at Red Rock Dam on the Des Moines River and at the Rock Island District Office; Ice Harbor Lock and Dam on the Snake River; Old Hickory Dam on the Cumberland River; David D. Terry Lock and Dam 6 on the Arkansas River; Greers Ferry Dam and Powerhouse on the Little Red River; and Lower St. Anthony Falls Lock and Dam, Lock and Dam 2, 4, and 5A on the Mississippi River. Serviceability or performance and subjective evaluation of safety were the primary factors considered by the experts. Their opinions have been combined and classified by the authors into a set of problems or distresses and "expert opinion" rules that are embedded in the evaluation that constitutes the CI. The distresses are used to organize straightforward, visual observation data for interpretation by the rules in the same manner that a seasoned engineer would interpret field observations. The rules will continue to evolve.

During the development of the dam gate rules, the experts assumed that the integrity of the dam gates is critical. The experts assumed the gates must function at all times, and that no backup system (except for bulkheads) is available. The loss of pool has serious consequences for navigation, power generation, and flood control.

The distresses identified for tainter gates are quantified by a measurement $\mathrm{X}$. These measurements can consist of actual data-taking or are the result of a subjective evaluation. Experts were asked to interpret these measurements in light of the serviceability and safety of a tainter gate and to assign limiting values to the measurements.

Typically, each distress can be either a problem in itself or an indication of a problem. For example, anchorage movement is a problem in itself if it is sufficiently large to impede tainter gate operation; otherwise it can be an indication of a potential structural problem. The individual distress CI is quantified by

$$
\text { Condition Index }=100(0.4)^{x / x_{\max }}
$$


where $X_{\max }$ is some limiting value of $X$. The CI zones given in Table 2 define $X_{\max }$ as the point at which the $\mathrm{CI}$ is 40 , that is, the dividing point between Zones 2 and 3 .

In other words, the experts have chosen the limiting value $X_{\max }$ to be the point at which a tainter gate requires immediate repair or, at least, a more detailed inspection. Figure 13 illustrates the equation and zones from Table 2.

Table 2. Condition index zones.

\begin{tabular}{|c|c|l|}
\hline Zone & CI Range & \multicolumn{1}{c|}{ Action } \\
\hline 1 & $70-100$ & Immediate action not required \\
\hline 2 & $40-69$ & $\begin{array}{l}\text { Economic analysis of repair alternatives recommended to determine } \\
\text { appropriate maintenance action }\end{array}$ \\
\hline 3 & $0-39$ & $\begin{array}{l}\text { Detailed evaluation required to determine the need for repair, rehabilitation } \\
\text { or reconstruction, safety evaluation recommended }\end{array}$ \\
\hline
\end{tabular}

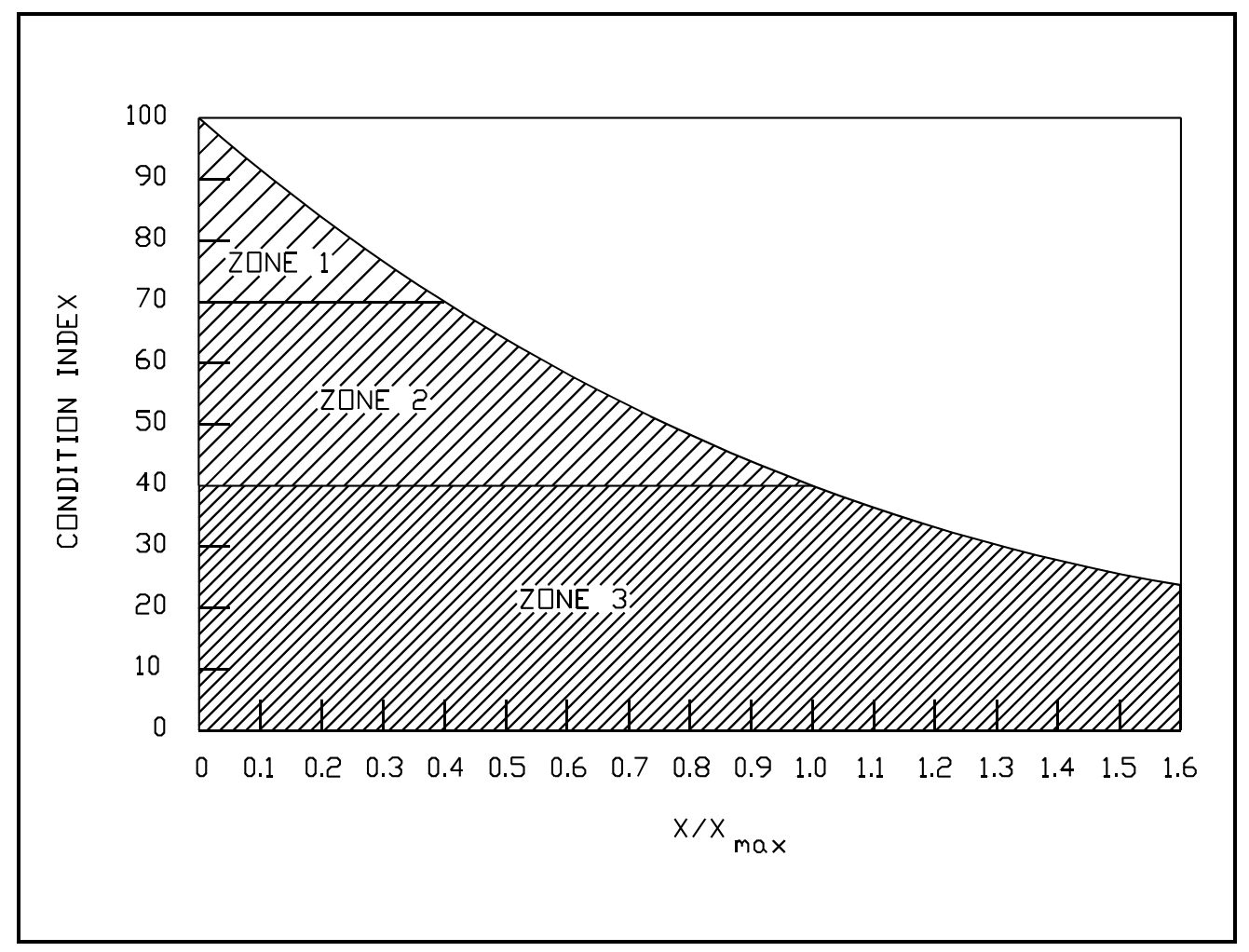

Figure 13. Condition index related to $X / X_{\max }$. 


\section{Distress Descriptions and $\mathbf{X}_{\max }$}

If a tainter gate structure is designed and constructed properly, it has an initial CI of 100. Over time the structure will be exposed to varying environmental and operational situations that will lead to the deterioration of its condition. As a result of this continuing process the $\mathrm{CI}$ will be reduced. Eleven distresses for tainter lock and dam gates, the first 10 of which affect the combined CI, have been identified for categorization in this project. Each is identified and described briefly in Table 3.

In the following sections, potential causes of each distress are listed and discussed. Diagnosing causes for each distress is a complex issue. Many times a distress may have several possible causes, and often a combination of distresses must be present before a certain cause can be identified. The sections describe the measurement of $X$ and limiting $X_{\max }$ values for each distress. Examples also have been provided to show how the measurements of $\mathrm{X}$ and limiting values are used to produce a CI for each distress.

\section{Noise, Jumping, and Vibration Distress}

\section{Definition and causes}

Noise, jumping, and vibration represent tainter gate sounds and motions during opening and closing of the gate. Abnormal noise, jumping, and vibration can be caused by several factors:

- improper lubrication

- misalignment of gate

Table 3. Tainter dam and lock gate distresses.

\begin{tabular}{|l|l|}
\hline \multicolumn{1}{|c|}{ Distress } & \multicolumn{1}{c|}{ Description } \\
\hline Noise/jump/vibration & Abnormal noise, jumping, or vibration during gate operation \\
\hline Vibration with flow & Vibration of gate as water flows underneath \\
\hline Misalignment & Twisting of gate between piers or lockwalls during lifting \\
\hline $\begin{array}{l}\text { Anchorage assembly } \\
\text { deterioration }\end{array}$ & $\begin{array}{l}\text { Movement of embedded anchorage system and damaged } \\
\text { components }\end{array}$ \\
\hline $\begin{array}{l}\text { Trunnion assembly } \\
\text { wear }\end{array}$ & Displacement between pin and bushing \\
\hline Cracking & Breaks in structural steel components \\
\hline Dents & Disfiguration of the steel components \\
\hline Corrosion/erosion & Loss of steel due to interaction with the environment \\
\hline Cable/chain plate wear & $\begin{array}{l}\text { Wear on the skin or bearing plate due to sliding action of cable or } \\
\text { chain }\end{array}$ \\
\hline Leaks & Water passing around the gate \\
\hline Seal condition & Condition of seals \\
\hline
\end{tabular}


- floating debris

- damaged gate.

Normal noises, jumping, and vibration are generally caused by seals or operating machinery.

\section{Measurement and limits}

The presence of any noise, jumping, and vibration are recorded as the gate is opened and closed through a 2-ft cycle. If any of the three occur, they are further classified as normal or abnormal. Subjective judgement is required, in consultation with the chief gate operator. Normal occurrences do not reduce the CI. The CI for the possible combinations of abnormal noise, jumping, and vibration is shown below:

$\begin{array}{cll}\text { Abnormal Noise, Jumping, or Vibration } & & \text { CI } \\ \text { None } & 100 \\ \text { Yes for one of the three } & 70 \\ \text { Yes for any two } & 40 \\ \text { Yes for all three } & 30\end{array}$

Obviously, this distress is more subjective than quantifiable; however, its importance should not be minimized. Abnormal jumping, for example, can indicate structural problems.

Example: As a gate was lifted, it made a popping noise. Also, a squealing noise due to the gate seals occurred throughout the gate operation. The $\mathrm{CI}$ is

$$
C I=70
$$

because the popping noise is abnormal. From Table 1, this CI is rated very good. If the popping noise had not occurred, the CI would have been 100 because the squealing noise due to the seals is considered normal. 


\section{Vibration With Flow Distress}

\section{Definition and Causes}

The vibration with flow distress represents the level of vibration present on a gate opened $2 \mathrm{ft}$ as water flows underneath it. The causes of this distress can be attributed to:

- loose connections

- poor inflow conditions

- poor lip design

- trash or debris.

A gate subjected to vibration over an extended period of time could reduce the structural integrity of the gate due to fatigue.

\section{Measurement and Limits}

The level of gate vibration is recorded on the inspection form. The severity of gate vibration and the corresponding CI are determined by comparing sensory observations with the following descriptive levels:

\begin{tabular}{|c|c|c|}
\hline $\mathrm{CI}$ & Level & $\underline{\text { Level Description }}$ \\
\hline 100 & 0 & No vibration \\
\hline 90 & 1 & $\begin{array}{l}\text { Feel with finger tips, hear humming noise, or standing } \\
\text { water in strut arm ripples }\end{array}$ \\
\hline 70 & 2 & Large ripples, approximately $1 / 2$ in. high, on upper pool \\
\hline 40 & 3 & Rattles grating, handrails, and bracing, etc. \\
\hline 30 & 4 & Vibrates or shakes pier \\
\hline
\end{tabular}

If vibration can be eliminated by lifting or lowering the gate, then the $\mathrm{CI}$ is raised to the CI of the next lower level.

Example: The grating and handrails were rattling as water rushed underneath the gate. The gate was raised another foot and the signs of vibration discontinued. The $\mathrm{CI}$ for vibration with flow is $\mathrm{CI}=70$ because the Level 3 vibration could be eliminated. Table 1 indicates the $\mathrm{CI}$ is rated very good. If the vibration had continued, the CI would have been 40 . 


\section{Misalignment Distress}

\section{Definition and Causes}

The misalignment distress refers to the misalignment of the gate between the piers or lockwalls as it is lifted. The skin plate may begin to twist or even hang up on the pier or lockwall. The three principle causes of this distress are:

- cable or chain tension

- trunnion problems

- pier shifting.

The operating machinery used to lift the gate is often designed to self-adjust the amount of tension in the cables or chains on either side of the gate as it is lifted.

\section{Measurement and Limits}

Measurements can be made using tape measures or an electronic level. Tape measures are used to measure a vertical distance from the skin plate to a fixed reference point for the closed, $\mathrm{X}_{\mathrm{C}}$, and 2 -ft open positions, $\mathrm{X}_{\mathrm{O}}$. The distance each edge of the skin plate rises is the difference between the closed and 2-ft open positions.

$$
x_{v}=x_{c}-x_{0}
$$

The height differential between the edges of the skin plate, $\mathrm{X}$, is the difference between the distance each edge rose.

$$
X=X_{\text {Uleft }}-x_{U_{\text {righ }}} \mid
$$

When a level is used, the inclination angle of the skin plate is recorded. The absolute value of the difference in the angles for the closed, $\mathrm{A}_{\mathrm{C}}$, and the 2-ft open, $\mathrm{A}_{\mathrm{O}}$, positions is used to determine the difference in height between each edge of the skin plate as

$$
X=W \tan \left(\left|A_{c}-A_{o}\right|\right)
$$

where $\mathrm{W}$ is the width of the gate. The limiting horizontal misalignment of the vertical edge for a gate of any height was judged to be $0.25 \mathrm{in}$. Larger values may 
inhibit gate movement along the pier. The limiting value of the $\mathrm{X}$ measurement (height differential between the two edges of the gate) is, therefore, a function of the width and height, $\mathrm{H}$, of the gate:

$$
X_{\max }=(0.25 \text { in. })(W / H)
$$

Example: A gate is $60 \mathrm{ft}$ wide and $30 \mathrm{ft}$ high. Measurements reveal that the right edge of the gate rises $0.30 \mathrm{in}$. higher than the left side during the nominal $2-\mathrm{ft}$ opening. From Eq. (3.5),

$$
X_{\max }=(0.25)(60 / 30)=0.50 \text { in }
$$

The CI for misalignment is

$$
C I=100(0.4)^{0.30 / 0.50}=58
$$

From Table 1, the CI for misalignment is described as being good.

\section{Anchorage Assembly Deterioration Distress}

\section{Definition and Causes}

Anchorage assembly deterioration represents the displacement of the embedded anchorage system and the current condition of the assembly components, especially the trunnion casting and anchorage bolts. Movement can occur during opening and closing of a gate or, over time, because of sustained loading. There are several causes of anchorage deterioration:

- corrosion

- concrete cracking and spalling

- anchor bolt elongation or movement

- loose or missing casting bolts

- additional load.

The anchorage system on either side of the pier or lockwall is the only mechanism that connects a gate to the concrete support. Hence, the presence of anchorage movement may indicate a significant structural problem, or it could eventually introduce structural problems into other gate components. In addition, corroded, loose, or missing casting and anchorage bolts and nuts can cause irregular movement of the gate, introducing functional and structural problems into various components. Corrosion of high strength steels, such as prestressing tendons, may be particularly important. 


\section{Measurement and Limits}

If anchorage movement becomes significant, it can be detected by visually inspecting the interface around the anchorage connections. This is usually the first indicator of a significant problem. Any structural cracking or spalling of the concrete in this area will reduce the CI by a factor of 0.85 . If any of the anchor or casting bolts and nuts are corroded, loose, or missing, the CI decreases by a 0.70 factor. When more than one reduction factor is applicable, the $\mathrm{CI}$ is reduced by the most severe reduction factor only.

Measurements of the anchorage movement are made between the concrete pier or lockwall and the trunnion yoke or girder using dial gauges and trammels (Figure 8). The measurements are made in the downstream direction to detect elongated or broken anchor bolts, loose anchor nuts, or deterioration of the anchorage system. Anchorage motion is divided into two categories: (1) short-term movement and (2) motion over long periods of time. Short-term movement is generally detected by changing the loading conditions on the gate at the time of inspection in order to measure the amount of motion in the anchorage system. Motion of the anchorage over time refers to the long-term displacements of the trunnion girder. Short- and long-term motion measurements are made under two distinct conditions: (1) normal operating conditions and (2) bulkheaded conditions.

Normal operating conditions: Dial gauge measurements are taken in the closed and 2-ft open positions and then again in the closed position. The short-term movement, $\mathrm{X}_{\mathrm{S}}$, is found by taking the difference between the 2-ft open and the closed measurements.

Some embedded anchorage systems are designed to permit movement. These types of anchorage configurations are called flexible anchorage systems. All other anchorage systems are termed rigid. A short-term displacement of 0.005 in. has been selected as the limiting motion at the steel and concrete interface for a rigid anchorage.

$$
X_{\operatorname{maxR(s)}}=0.005 \text { in }
$$

The limiting value for flexible anchorage motion is a function of the embedment length, $\mathrm{L}$, in inches.

$$
X_{\operatorname{maxF}(s)}=0.0001(L)
$$

The Corps experts judged that motion greater than this could indicate a significant structural problem. 
Trammel measurements are used to measure long-term displacements and are recorded in the closed position after the gate has been lifted and reset. This motion, $\mathrm{X}_{\mathrm{L}}$, is found by taking the difference between the maximum and minimum trammel measurements (normal operating and bulkhead conditions) since the last repair. At best, trammel measurements can probably be made with $1 / 32$ in. accuracy.

Improved accuracy in this measurement is needed. Rigid anchorages have a limiting long-term motion of

$$
X_{\operatorname{maxR(L)}}=1 / 8 \text { in }
$$

The limiting motion for flexible anchorages is a function of $\mathrm{L}$, the embedment length.

$$
X_{\max (L)}=0.0025(L)
$$

The CI for anchorage assembly deterioration will be the minimum of the CIs calculated for the short- and long-term motion.

$$
\text { CI }=\text { Minimum }\left(C I_{s}, C I_{L}\right)
$$

Example: Measurements of anchorage movement were made during an inspection performed under normal operating conditions. The anchorage system was flexible with an embedment length of $72 \mathrm{in.}$ The maximum displacement found using dial gauges was

$$
x_{s}=0.005 \text { in } .
$$

Trammel measurements indicate a displacement of

$$
X_{L}=1 / 16 \text { in }
$$

occurred between this inspection and a bulkheaded inspection 10 years ago. Cracked and spalled concrete was evident around the trunnion yoke. Also, the casting bolts and nuts had a significant amount of corrosion. The limiting value of short-term anchorage motion is found using Eq. (3.7).

$$
X_{\operatorname{maxF}(s)}=0.0001(72)=0.0072 \text { in. }
$$

The limiting value of long-term anchorage motion over time is found using Eq. (3.9).

$$
X_{\operatorname{maxF}(L)}=0.0025 \text { (72) }=0.180 \text { in. }
$$


The CI calculated for short-term anchorage movement is

$$
C I_{s}=\left[100(0.4)^{0.005 / 0.0072}\right] 0.70=37
$$

where the 0.70 factor was used because the casting bolts and nuts had significant corrosion. The CI for long-term anchorage assembly motion is

$$
C I_{L}=\left[100(0.4)^{0.0625 / 0.180}\right] 0.70=51
$$

Therefore, the CI for anchorage assembly deterioration is

$$
\text { CI }=\text { Minim um }(37,51)=37
$$

From Table 1 the $\mathrm{CI}$ is rated poor; that is, there is serious deterioration of the anchorage.

Bulkheaded conditions: Dial gauges are used to measure short-term movement under bulkheaded conditions. This displacement, $\mathrm{X}_{\mathrm{S}}$, is the difference between the full-head and no-head readings. The limiting value is dependent upon the percent of head present on the gate, $\% \mathrm{H}$, which is equal to the head applied to the gate when the bulkhead is removed, expressed as a percent of gate height, $\mathrm{H}$ (Figures 14 and 15). For a rigid anchorage, the limiting values are, if there is less than 20 percent head on the gate,

$$
X_{\operatorname{maxR}(s)}=0.005 \text { in }
$$

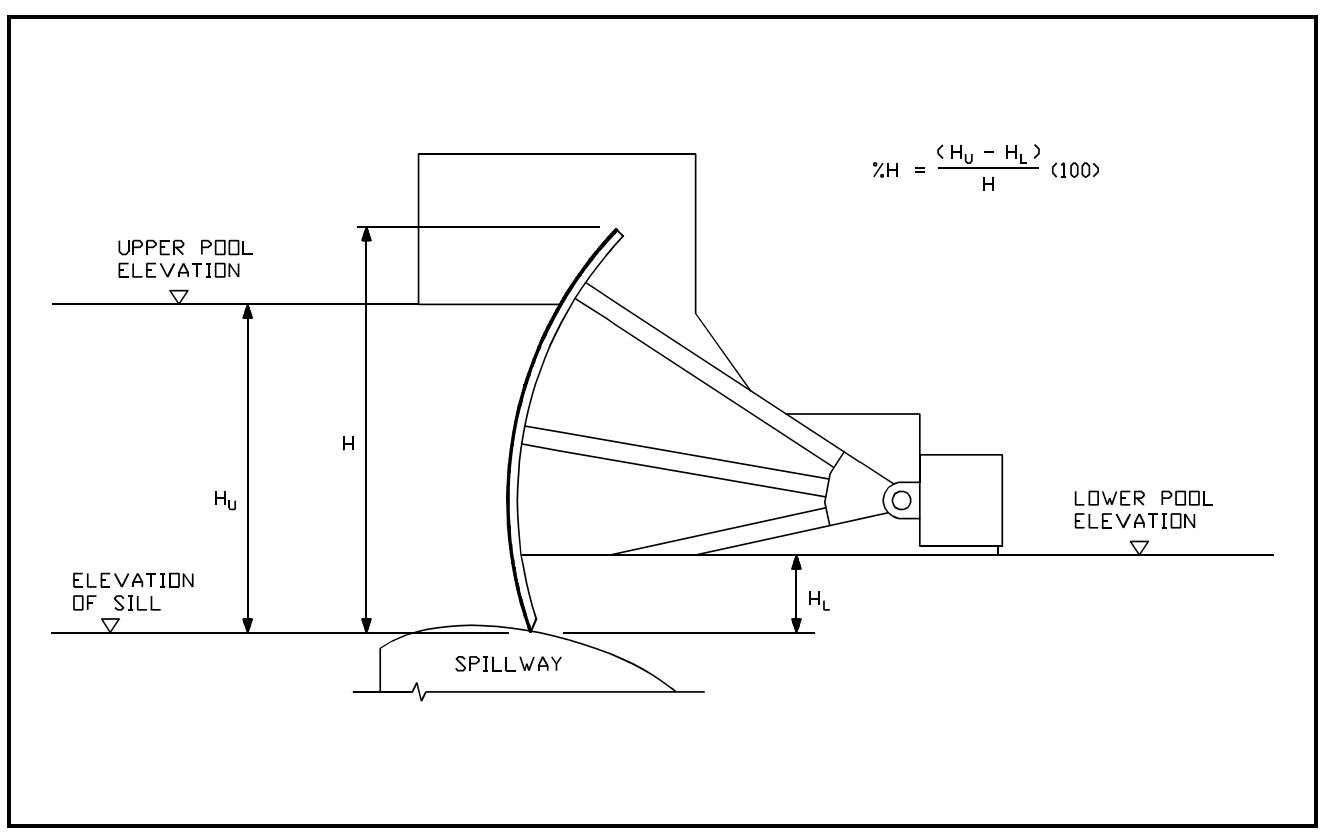

Figure 14. Percent head with tailwater. 


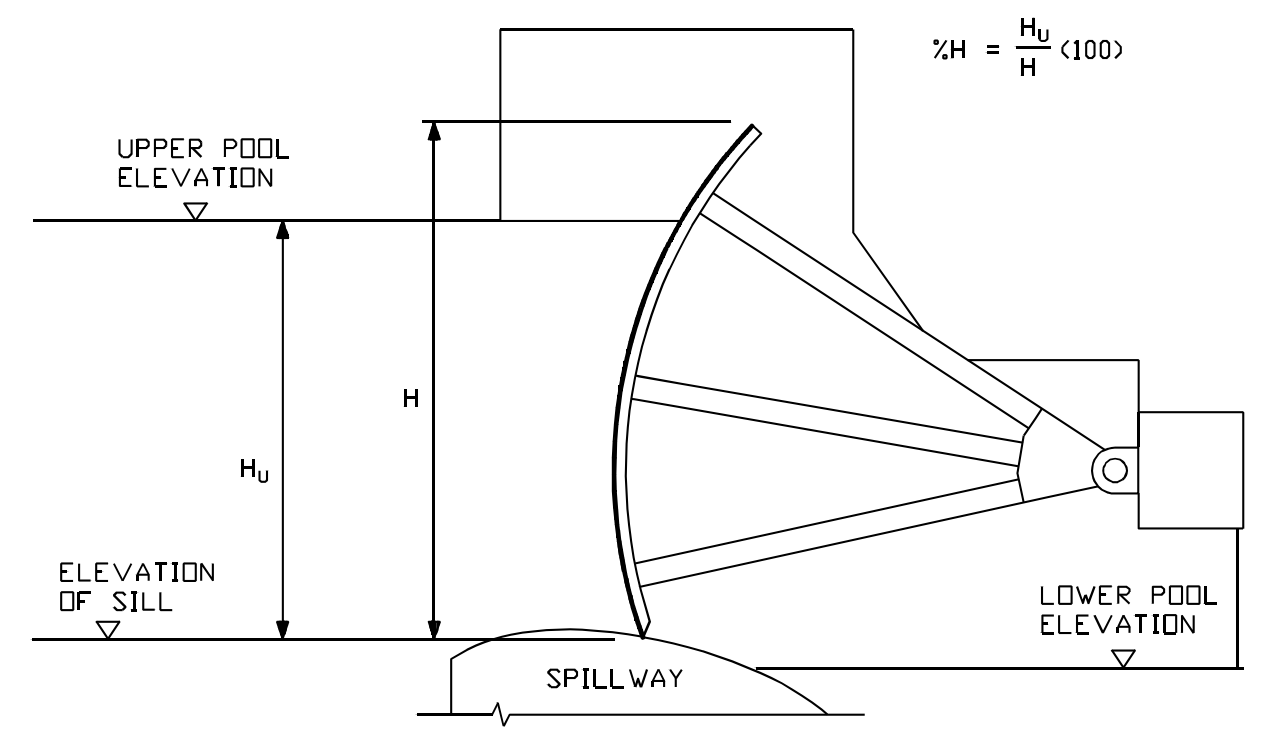

Figure 15. Percent head without tailwater.

For 20 to 50 percent head, $\mathrm{X}_{\max }$ is a linear function of head.

$$
X_{\operatorname{maxR(s)}}=(0.005)+\frac{(0.030-0.005)}{(50 \%-20 \%)}(\% \quad H-20 \%)
$$

If the head exceeds 50 percent, then

$$
X_{\operatorname{maxR}(s)}=0.030 \text { in }
$$

Limiting values for flexible anchorage systems are defined in the following three equations. If there is less than 20 percent head on the gate,

$$
X_{\operatorname{maxF}(S)}=0.0001 \quad(L)
$$

For 20 to 50 percent head,

$$
X_{\operatorname{maxF}(s)}=0.0001(L)+\frac{[0.0006(L)-0.0001(L)]}{(50 \%-20 \%)}(\% H-20 \%)
$$

If head is greater than 50 percent, then

$$
X_{\operatorname{maxF}(S)}=0.0006(L)
$$

As in normal operating conditions, trammel measurements are used to monitor anchorage motion over time. A minimum extension will probably be recorded during the first bulkhead inspection because the anchorage system will relax under the nohead condition. The displacement, $\mathrm{X}_{\mathrm{L}}$, is calculated by taking the difference between 
the maximum and minimum distances (bulkheaded and normal operating conditions). The limiting long-term anchorage movement is given by Eqs. (3.8) and (3.9).

Example: Measurements of anchorage movement were taken during an inspection performed under bulkheaded conditions. When the bulkhead was removed, the amount of head present on the gate was 45 percent. From dial gauge readings, the rigid anchorage assembly had a short-term movement of

$$
x_{s}=0.019 \mathrm{in} .
$$

The long-term maximum movement was

$$
x_{L}=1 / 32 \text { in }
$$

which is the difference between the current full-head trammel measurement and a critical trammel measurement from a previous inspection. The limiting short-term motion for a rigid anchorage from Eq. (3.12) is

$$
x_{\operatorname{maxR(s)}}=(0.005)+\frac{(0.030-0.005)}{(50 \%-20 \%)}(45 \%-20 \%)=0.026 \mathrm{in} .
$$

The limiting long-term anchorage motion is from Eq. (3.8).

$$
X_{\operatorname{maxR(L)}}=1 / 8 \text { in } .
$$

Cracked and spalled concrete was evident around the bearing plate. The CI for shortterm rigid anchorage motion is

$$
C I_{s}=\left[100(0.4)^{0.019 / 0.026}\right] 0.85=44
$$

where the 0.85 factor was used because the concrete was cracked and spalled. The long-term $\mathrm{CI}$ is

$$
C I_{L}=\left[100(0.4)^{0.0313 / 0.125}\right] 0.85=68
$$

The CI, from Eq. (3.10), for overall anchorage assembly deterioration is

$$
C I=M \text { inimum }(44,68)=44
$$

From Table 1, the CI is rated fair; that is, there is moderate deterioration of the anchorage. 


\section{Trunnion Assembly Wear Distress}

\section{Definition and Causes}

Trunnion assembly wear refers to the total relative movement of the trunnion pin or hub with respect to the bushing or trunnion yoke. This movement takes place while the gate rotates through its normal range of motion and, over time, because of sustained loading. Trunnion assembly wear can occur between the trunnion pin and the bushing or laterally between the hub and trunnion yoke. It can be caused by several factors:

- improper lubrication

- improper gate alignment

- opening and closing motion

- jumping and vibration.

\section{Measurement and Limits}

The condition of the lubricating system is recorded on the inspection form. If the lubrication system is not functioning properly, it may not be critical, but over a long period of time it can cause accelerated wear in the trunnion assembly. Therefore, a reduction factor of 0.85 is used if lubrication is inadequate. Measurements of relative movement are made in the horizontal, vertical, and lateral directions. As with anchorage assembly deterioration, trunnion assembly wear measurements can be made under normal operating conditions or bulkheaded conditions. The lateral measurement, $\mathrm{X}_{\mathrm{LAT}}$, is estimated using a ruler (Figure 12). The limiting value for lateral motion is the same regardless of the conditions under which the inspection is performed.

$$
X_{\operatorname{maxLAT}}=3 / 8 \text { in } .
$$

The measurements taken in the horizontal, $\mathrm{X}_{\mathrm{HOR}}$, and vertical, $\mathrm{X}_{\mathrm{VER}}$, directions can be made using feeler or dial gauges and trammels (Figures 9, 10, 11). The total motion, no matter what measuring device is used, is calculated by taking the square root of the sum of the squares of the horizontal and vertical movements in each direction:

$$
X_{\text {TOT }}=\sqrt{\left(X_{H O R}\right)^{2}+\left(X_{V E R}\right)^{2}}
$$


The limiting value of the total motion is also the same regardless of the conditions under which the inspection is performed and whether the movements are short- or long-term:

$$
X_{\max O T}=0.125 \text { in }
$$

The CI for trunnion assembly wear will be the minimum of the CIs calculated for the lateral and total movement.

$$
C I=M \text { inimum }\left(C I_{L A T}, C I_{T o T}\right)
$$

The following two sections will describe how to calculate the horizontal and vertical short-term and long-term movements for the different inspection conditions.

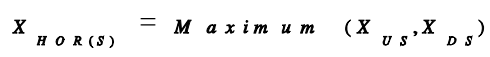

Normal operating conditions: Either dial or feeler gauge measurements must be made in order to monitor short-term horizontal, $\mathrm{X}_{\mathrm{HOR}(\mathrm{S})}$, and vertical, $\mathrm{X}_{\mathrm{VER}(\mathrm{S})}$, movements. If dial gauges are used, the short-term horizontal and vertical movements are the difference between the 2 -ft open and the closed position readings. If feeler gauges are used, the short-term horizontal motion is the maximum of the movements measured in either the upstream gap, $X_{U S}$, or the downstream gap, $X_{D S}$. The movements in the upstream and downstream gaps are the absolute difference between the 2-ft. open and the closed feeler gauge measurements, $X_{O}$ and $X_{C}$, respectfully.

$$
\begin{aligned}
& x_{U S}=I_{o(U S)}-x_{c(U S)} \mid \\
& X_{D S}=I_{O(D S)}-X_{C(D S)} \mid
\end{aligned}
$$

Similarly, the short-term vertical motion is the maximum of the movements measured in the top, $\mathrm{X}_{\mathrm{TOP}}$, and bottom, $\mathrm{X}_{\mathrm{BOT}}$, gaps.

The horizontal and vertical long-term displacements are determined using trammel measurements by taking the difference between the maximum and minimum inspection distances since the last repair.

Bulkheaded conditions: The short-term displacements are found in the same manner as under normal operating conditions, except that the feeler or dial gauge measurements would have been taken under the no-head and full-head conditions with the gate in the closed position. 
Trammel measurements also are recorded under the no-head and full-head conditions. These measurements are used with the normal operating trammel measurements to determine the maximum and minimum values. First-time measurements taken under the no-head condition probably will yield a critical reference distance.

Example: A first-time inspection was performed on a gate. It was found that the lubrication system was leaking grease. From dial gauge measurements taken under normal operating conditions, the following horizontal and vertical short-term movements were calculated by taking the difference between the 2 -ft open and the closed readings.

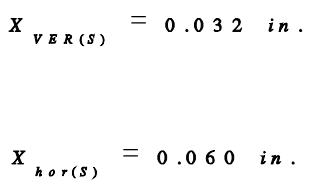

Trammel measurements were also taken for the first time and, therefore, no movements were calculated because no previous measurements between the benchmarks existed. The total movement is found by Eq. (3.18):

$$
x_{\text {TOT }}=\sqrt{(0.060)^{2}+(0.032)^{2}}=0.068 \mathrm{in} .
$$

The CI for total movement is

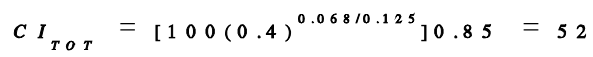

where the 0.85 factor was used because of problems with the lubrication system. The lateral movement was estimated as $1 / 8$ in.

$$
X_{L A T}=1 / 8 \text { in }
$$

The CI for lateral movement is

$$
C I_{L A T}=\left[\begin{array}{llll}
1 & 0 & 0 & \left.(0.4)^{(1 / 8) /(3 / 8)}\right] 0.85=63
\end{array}\right.
$$

Therefore, the final CI for trunnion assembly wear is the minimum of the individual CIs

$$
C I=M \text { inimum }(52,63)=52
$$

This CI is rated fair. 


\section{Crack Distress}

\section{Definition and Causes}

Cracks usually represent a narrow opening, break, or discontinuity in the structural steel members. Cracks are caused by:

- fatigue

- brittle fracture

- overstressed components.

Obviously, cracks have significant structural implications because they can continue to grow if the cause of the overstress still exists or if the remaining steel cross section cannot carry the normal loads.

\section{Measurements and Limits}

The number of cracks in the upstream skin (U), downstream skin (D), ribs (R), main girders $(\mathrm{M})$, bracing $(\mathrm{B})$, strut arms $(\mathrm{S})$, trunnion hub $(\mathrm{H})$, trunnion yoke $(\mathrm{Y})$, or trunnion girder $(\mathrm{G})$ are recorded on the inspection form. Length and location of cracks also are recorded but are not used in the calculation of the CI. For cracks on the main girders, ribs, bracing, upstream skin plate, and downstream skin plate, the limiting values are

$$
\begin{aligned}
& X_{\operatorname{maxM}_{a \times M}}=1 \\
& X_{\operatorname{maxR}_{a \times R}}=1 \\
& X_{\operatorname{maxB}_{a \times B}}=1 \\
& X_{\max _{a \times V}}=3 \\
& X_{\operatorname{maxD}_{a \times D}}=3
\end{aligned}
$$

The individual CIs for these components are calculated using Eq. 3.1.

The limiting values of cracks are handled differently for the remaining components. These components include the strut arms, trunnion girder, trunnion 
hub, and trunnion yoke. If a crack is present in these components, it could critically affect the overall structural integrity of the gate. The experts felt that, should a crack be present on any one of these components, the individual CI for the crack distress should be reduced to 30 .

$$
C I_{S}, C I_{H}, C I_{Y}, \text { or } C I_{G}=30
$$

But, more importantly, the combined CI for the entire gate should also be reduced to 30 .

$$
\text { C o m bined CI }=30
$$

The experts judged that a crack in these critical items could result in the loss of a gate and the upper pool. This could have serious consequences on navigation or power generation. Some cracks in concrete may be due to shrinkage and should not be recorded. The $\mathrm{CI}$ for all cracks is taken as the minimum of the CIs for all the components.

$$
C I=\operatorname{Minimum}\left(C I_{S} C I_{G}, C I_{H}, C I_{V} C I_{M}, C I_{R}, C I_{B}, C I_{U}, C I_{D}\right)
$$

Example: The following number of cracks were counted on a gate:

$$
\begin{aligned}
& x_{s}=1 \\
& x_{v}=2
\end{aligned}
$$

Since the strut arm is a critical member, the CI for strut arm cracks by Eq. (3.29) is

$$
C I_{s}=30
$$

By Eq. (3.27), the limiting value is three cracks and the CI for upstream skin plate cracks is

$$
C I_{U}=100(0.4)^{2 / 3}=54
$$


The CI for all other cracks is 100 . The individual distress CI for cracks using Eq. (3.31) is

$$
\text { Cracks CI = Minimum (30,100,100,100,100,100,100,54,100)=30 }
$$

Because a crack is present in the strut arms, the combined CI for the gate is automatically reduced to

$$
\text { Co } m \text { bined } C I=30
$$

From Table 1, the crack CI and the combined CI are rated as poor; function is seriously impaired.

\section{Dents Distress}

\section{Definition and Causes}

Dents represent a disfiguration of the major components of tainter gates. Dents are typically caused by:

- vessel or barge impact

- debris impact

- operation with ice.

Dents could pose a safety problem, particularly if a badly deformed component cannot safely carry its design load.

\section{Measurement and Limits}

The number of dents on the upstream skin plate $(\mathrm{U})$, downstream skin plate $(\mathrm{D})$, strut arms (S), main girders (M), bracing (B), and ribs (R) will be recorded. Size and location of dents also will be recorded, but are not used in the CI calculation. The limiting values for these components are

$$
\begin{aligned}
& x_{\operatorname{maxU}}=10 \\
& x_{m_{a \times D}}=10
\end{aligned}
$$




$$
X_{\text {maxs }}=1
$$

The CI for all dents is the minimum of the CIs for the individual components:

$$
\begin{gathered}
x_{\operatorname{maxM}_{a \times M}}=1 \\
x_{m a \times B}=3 \\
X_{m a \times R}=3 \\
C I=M \text { inimum }\left(C I_{U}, C I_{D}, C I_{S}, C I_{M}, C I_{B}, C I_{R}\right)
\end{gathered}
$$

Example: The only dent data observed were six dents on the upstream skin plate of a tainter gate.

$$
x_{v}=6
$$

The CI for upstream skin dents is

$$
C I_{U}=100(0.4)^{6 / 10}=58
$$

The CI for all dents is

$$
C I=M \text { inimum }(58,100,100,100,100,100)=58
$$

The CI is rated fair.

\section{Corrosion/Erosion Distress}

\section{Definition and Causes}

Corrosion involves the uniform loss of steel material on a gate structure because of interaction with the environment. Pitting is a result of corrosion, caused by the loss of steel section in localized areas. Erosion describes an accelerated rate of deterioration caused by movement between water and metal. Varying rates of degradation exist, depending upon the length of time the gate has been submersed, 
the site-specific water conditions (chemistry and abrasive material content), the environmental conditions of the air, and the normal amount of head on the structure.

Localized deterioration also takes place in the form of galvanic corrosion. When dissimilar metals are placed in a conductive solution, a potential difference exists. This situation arises when gates, constructed primarily of structural steel, have stainless steel components attached. Structural steel has a different electrical potential than stainless, and electron flow is toward the more resistant material. Therefore, structural steel acts as the anode and stainless as the cathode.

Most light corrosion has little structural significance. However, extensive deterioration can sufficiently reduce the steel cross-sectional area so that stresses are significantly increased.

\section{Measurement and Limits}

To measure the amount of material loss due to corrosion or erosion, the one square foot with the greatest material loss is selected. The material loss in this square foot should be designated as corrosion (C) or erosion (E). The average pitting depth, D, and the average pitting diameter, $\mathrm{d}$, are recorded. Within the square foot, either the percent of area, $\mathrm{P}$, that is affected or the number of pits, $\mathrm{N}$, is recorded. Information for this distress is recorded for a variety of tainter gate components: upstream skin (U), downstream skin (D), strut arms (S), trunnion girder $(\mathrm{G})$, main girders (M), ribs (R), and bracing (B). Corrosion on the upstream skin is measured at the top (UT), splash zone (UZ), and bottom $2 \mathrm{ft}(\mathrm{UB})$. The $X$ value for this distress is the percent volume of steel loss due to corrosion. If the percentage area of the selected square foot that is pitted is entered, the percent volume loss is

$$
X=\frac{P \quad D}{T}
$$

where $\mathrm{T}$ is the steel plate thickness. If the number of pits is recorded, the area of one pit is

$$
\text { A rea of } 1 \text { pit }=\frac{\pi \times d^{2}}{4}
$$

Since there are $\mathrm{N}$ pits with an average depth, $\mathrm{D}$, the volume loss is

$$
\text { Volume loss }=\frac{N \quad x \quad \pi \times d^{2} \times D}{4}
$$

If inch units are used to record the material loss, the percent volume loss is 


$$
X=100 \times \frac{\text { Volume loss }}{144 x T}
$$

The limiting value for section losses on the strut arms, main girders, and trunnion girders is

$$
X_{\max }=10 \%
$$

The ribs, upstream and downstream skin plates, and bracing have a limiting value equal to 20 percent of the original volume:

$$
X_{\max }=20 \%
$$

The CI for corrosion is the minimum of the CIs from all the components.

$$
C I=M \operatorname{inimum}\left(C I_{U T}, C I_{U Z}, C I_{U B}, C I_{D}, C I_{R}, C I_{M}, C I_{S}, C I_{B}, C I_{G}\right)
$$

Example: A gate has a skin plate thickness of $3 / 8$ in. From an inspection, the average pit depth due to corrosion is recorded to be $1 / 8$ in. on the upstream skin at the splash zone, and it is estimated that approximately 10 percent of the one-squarefoot area is affected by the pitting. The percentage volume loss is calculated from Eq. (3.39).

$$
x_{U z}=\frac{10 \times 0.125}{0.375}=3.3 \%
$$

The limiting value from Eq. (3.44) is

$$
X_{\operatorname{maxUz}}=20 \%
$$

The CI for the upstream skin at the splash zone is

$$
C I_{V Z}=100(0.4)^{3.3 / 20}=86
$$

From Table 1, this CI is rated excellent.

Example: A gate has skin plate thickness of $3 / 8$ in. From an inspection, the average pit depth is recorded to be $1 / 8$ in. on the downstream skin, the average diameter is $2.0 \mathrm{in}$., and five pits are recorded on the one square foot section. From Eq. (3.41) 


$$
\text { Volume loss }=\frac{5 \quad x \quad \pi \quad x \quad 2^{2} \times 0.125}{4}=1.96 \text { in }^{2}
$$

and the percent volume loss is calculated from Eq. (3.42).

$$
X_{D}=100 \times \frac{1.96}{144 x 0.375}=3.6 \%
$$

The limiting value from Eq. (3.44) is

$$
X_{\operatorname{maxD}}=20 \%
$$

The CI for the lower portion of the downstream skin is

$$
C I_{D}=100(0.4)^{3.6120}=85
$$

From Table 1, this CI is rated excellent.

\section{Cable/Chain Plate Wear Distress}

\section{Definition and Causes}

Cable or chain plate wear is a loss of steel material on the bearing plate or skin plate of a gate. The wear is caused by the sliding contact between the cable or chain and the surface it bears on while the gate is being raised or lowered.

\section{Measurement and Limits}

Measurement of this distress is based on the reduced thickness of the bearing surface. The $X$ value is the maximum percent of wear depth on the bearing surface. If a bearing plate is attached to the skin plate, only the thickness of the bearing plate is used to determine the percent of wear depth. The limiting amount of depth loss for a bearing plate is

$$
X_{\operatorname{maxBP}}=50 \%
$$

When a bearing plate is not present, the skin plate acts as the bearing surface and the limiting percent of wear depth is 


$$
X_{\operatorname{maxSP}}=25 \%
$$

If the depth of wear can not be measured or is not visible, the CI for this distress can not be calculated and is, therefore, not included in the combined gate CI.

Example: A 3/4-in. bearing plate has been worn 1/4 in. deep by the lifting cable. The percent wear is

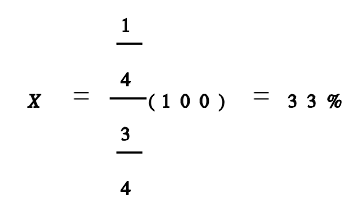

The CI for cable/chain plate wear is

$$
C I=100(0.4)^{33 / 50}=55
$$

The CI is rated good.

\section{Leaks Distress}

\section{Definition and Causes}

Leaks occur around the wetted perimeter of the gate. The two main causes of leaks are:

- improper gate alignment

- seal damage.

Leaks are recorded because they are an indication of how well a gate performs its primary function of holding back water.

\section{Measurement and Limits}

The length, height, and location of leaks are recorded on the inspection form. Only the length of leaks is used in the calculation of the CI. The $\mathrm{X}$ value is the percent of total length with seal distress (that is, the total length of all leaks) divided by the length of the wetted perimeter multiplied by 100 . If the gate is submersible, the $X$ value is the total length of all side leaks divided by the length of the wetted side perimeter multiplied by 100 . The limiting $X_{\max }$ is dependent upon the type of 
gate and project. Tainter dam and lock gates used in a power plant application have a limiting value of

$$
X_{\text {maxP }}=2 \%
$$

For non-power plant applications, submersible tainter dam and lock gates have a limiting value of

$$
x_{m a x s}=30 \%
$$

and non-submersible have a limiting value of

$$
X_{\operatorname{maxN}}=10 \%
$$

Example: From an inspection of a submersible lock gate, the leak length along the sides was $2 \mathrm{ft}$ with a wetted side perimeter of $32 \mathrm{ft}$. The percentage length of leaks around the wetted perimeter was

$$
x=\frac{2}{32}\left(\begin{array}{lll}
1 & 0 & 0
\end{array}\right)=6.3 \%
$$

The CI is calculated to be

$$
C I=100(0.4)^{6.3 / 30}=83
$$

From Table 1, this CI is very good.

\section{Seal Condition Distress}

\section{Definition and Causes}

When seals are damaged or sections are missing, it allows water to leak around the wetted perimeter of the gate. Seal damage is caused by several factors:

- floating debris

- improper lifting

- normal use over time.

\section{Measurement and Limits}

Seals are visually inspected for damaged and missing sections. The length and location of these sections are recorded. The experts judged that the seal condition 
distress is not sufficiently important to be included in the CI although damage should be recorded.

\section{Multiple Distresses}

The CI for each distress contributes to the combined CI for a gate. However, some distresses reflect the condition of the gate more than others. To account for this, weighting factors, $\mathrm{w}_{\mathrm{i}}$, are assigned to each distress. Relative initial weights are listed in Table 4. They reflect to some degree the opinions of the Corps experts and the opinions of the authors. The normalized weighting factors, $\mathrm{W}_{\mathrm{i}}$, are defined by

$$
w_{i}=\frac{w_{i}}{\sum_{w_{i}}}\left(\begin{array}{lll}
1 & 0 & 0
\end{array}\right)
$$

where

$$
\sum_{W_{i}}=100
$$

These normalized values are also listed in Table 4. The combined CI for all distresses is given by

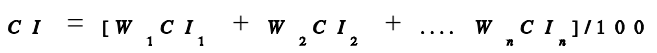

where $\mathrm{n}$ represents the total number of distresses. (Note: If the cable/chain plate is

Table 4. Unadjusted weighting factors for tainter gate distresses.

\begin{tabular}{|l|c|c|}
\multicolumn{1}{|c|}{ Distress } & $\mathbf{w}_{\mathbf{i}}$ & $\mathbf{W}_{\mathbf{i}}$ \\
\hline Noise, jump, and vibration & 5.5 & 10.6 \\
\hline Vibration with flow & 5.8 & 11.2 \\
\hline Misalignment & 4.1 & 8.0 \\
\hline Anchorage assembly deterioration & 10.0 & 19.3 \\
\hline Trunnion assembly wear & 8.5 & 16.4 \\
\hline Cracks & 5.9 & 11.3 \\
\hline Dents & 0.8 & 1.6 \\
\hline Corrosion/Erosion & 6.8 & 13.2 \\
\hline Cable/Chain plate wear & 3.0 & 5.8 \\
\hline Leaks & 1.3 & 2.6 \\
\hline If cable/chain plate wear is not measurable, the $\mathrm{w}_{\mathrm{i}}$ must be recalculated based on the $\mathrm{w}_{\mathrm{i}}$ of the \\
other nine distresses.
\end{tabular}


not visible and no CI was calculated, it is omitted from Eq. 3.51 and 3.52.)

Equation (3.52) is always valid unless a crack is detected in the strut arms, trunnion girder, trunnion hub, or trunnion yoke (see section entitled Crack Distress). The experts have judged that a crack in any one of these components could seriously affect the structural integrity of the gate. In that case, the combined CI for the gate is automatically reduced to 30 .

$$
C I=30
$$

Previous work done by the ISU project team has established that the relative importance of a distress should be greater as the distress becomes more severe. This concept is established by introducing a variable adjustment factor, which will increase the distress weighting factor $\mathrm{w}_{\mathrm{i}}$ as its CI approaches Zone 3. The adjustment factor plotted in Figure 16 has a maximum value of eight; that is, if a distress has a CI that is less than 40, its importance increases eight times. 


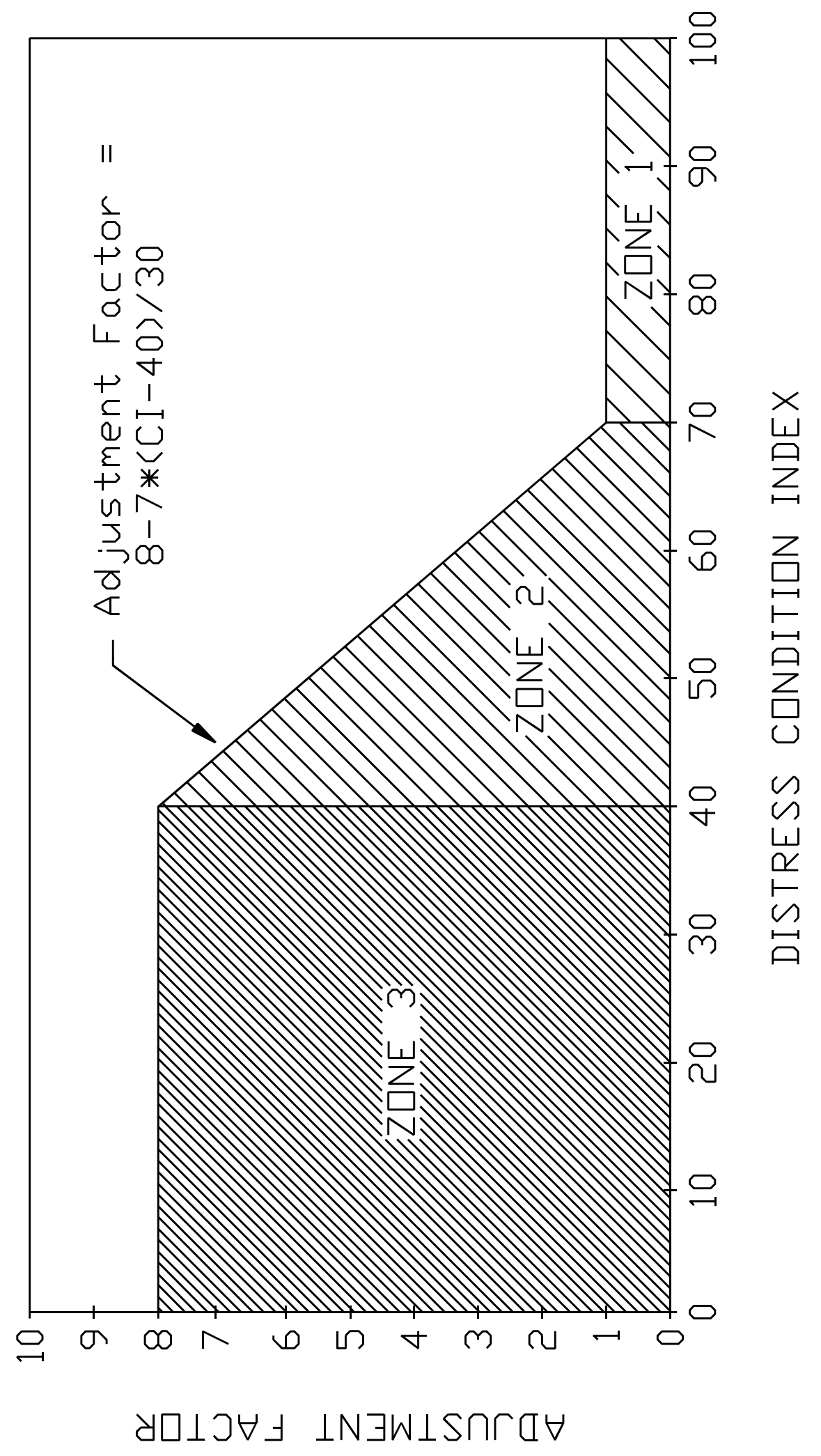

Figure 16. Weight adjustment factor for condition index 


\section{Field Testing}

As summarized in Chapter 3, several site visits were conducted to establish the condition index rules. To test the performance of the rating rules, a field test was conducted to compare the calculated CI values based on those rules to the CI values subjectively determined by several Corps engineers who are tainter dam and lock gate experts. The experts involved in the initial rule development that took place at Ice Harbor Lock and Dam in the Walla Walla District were Scott Sutliff (Walla Walla District), Brian Schmidtke (Portland District), Ed Reynolds (Seattle District), Al Hokanson (Walla Walla District), Marty Mendiola (Walla Walla District), Jim Bluhm (Walla Walla District), and Tom Schmitz (Seattle District).

In July 1993, inspections were performed in the Little Rock District on gates at David D. Terry Lock and Dam 6 and at Greers Ferry Dam and Powerhouse. The experts who participated in the inspections and furthered the development of the rating rules were Scot Sutliff, Brian Schmidtke, Bob Harris (Little Rock District), and Jon Gartner (Omaha District). No calibration with expert judgments was performed.

In November 1993, a field test was conducted in the St. Paul District. The experts involved were Bob Harris, Brian Schmidtke, Gerald Cohen (St. Paul District), Jim Bigham (Rock Island District), and Fred Joers (Rock Island District). The field test was conducted at four different sites along the Mississippi River: Lock and Dam 2, 4, and 5A, and Lower St. Anthony Falls. Two gates were inspected at each site. The gates at Lock and Dam 2, 4, and 5A were all nonsubmersible tainter dam gates with rigid anchorages. Gate 1 at Lower St. Anthony Falls was a submersible dam gate with a flexible anchorage. The inspections on these gates were performed under normal operating conditions. The other gate inspected at Lower St. Anthony Falls was a submersible auxiliary lock gate with a unique flexible anchorage configuration (Figure 17). The inspection of this gate was performed under bulkheaded conditions. The results of these field tests were used to make minor modifications and one major modification (Eq. 3.53), and to calibrate the rating system for tainter dam and lock gates. Each expert was asked to assign a $\mathrm{CI}$ to the individual distresses for each gate investigated, based on their expert judgment. The experts also were asked to rate the overall condition of each gate. Their subjective ratings were compared to the CIs calculated from the rating rules. This led to some adjustment of the $X_{\max }$ values and weighting values to better fit the experts' ratings. The previous portions of Chapter 3 include these changes. 


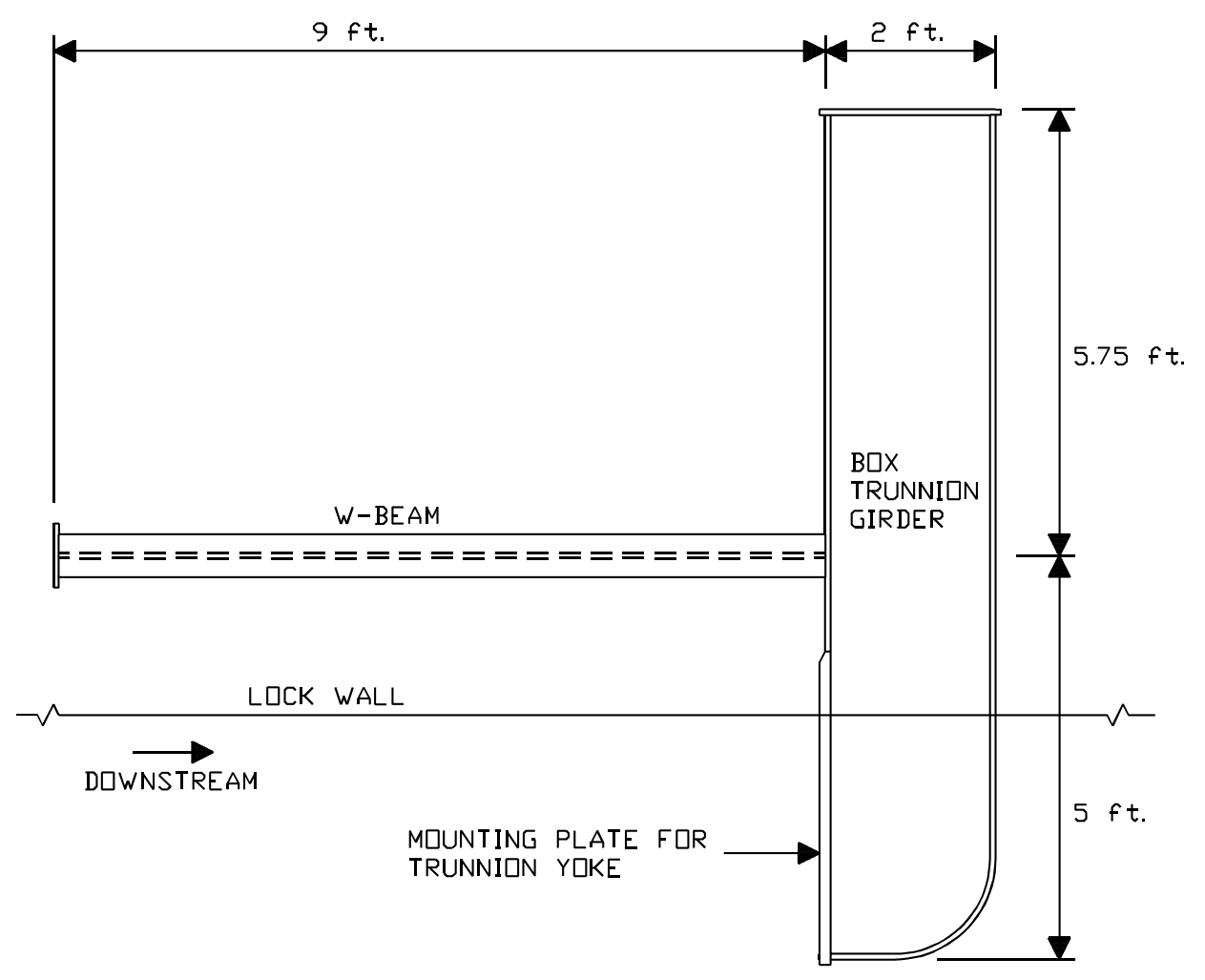

Figure 17. Flexible anchorage at lower St. Anthony Falls.

The following bar charts (Figures 18 to 25) present the experts' subjective CI versus the $\mathrm{CI}$ calculated by Chapter 3 rules for the distresses associated with tainter dam and lock gates. Each graph is for an individual distress. Within each group of data are four columns of data that represent

- expert average

- calculated CI (Chapter 3 rules)

- highest index assigned by an expert

- lowest index assigned by an expert.

The results of a comparison between the expert rating and the calculated values for each distress are summarized below. In addition, there is a comparison for the overall CI of each gate (Figure 26). 


\section{Noise, Jumping, and Vibration (Figure 18)}

Because no abnormal noise, jumping, or vibration was recorded, the calculated CI values were 100. Although no abnormal distress information was recorded, the experts did not give this distress a perfect rating. Normal vibration was observed on Gate 2 at Lock and Dam (L\&D) 2 and on Gate 10 at L\&D 4; also, normal noise and vibration were observed on Gate 9 at L\&D 5A. The experts may have rated this distress lower than 100, particularly on the gates where normal occurrences were observed, because they did not feel that a distress CI should be 100 if the structure was not new. This phenomena is consistent with what experts have felt about previous structures. Gate 8 at L\&D 4 has an expert average rating of 89 , which is unexplainably low because no normal or abnormal occurrences of this distress were recorded.

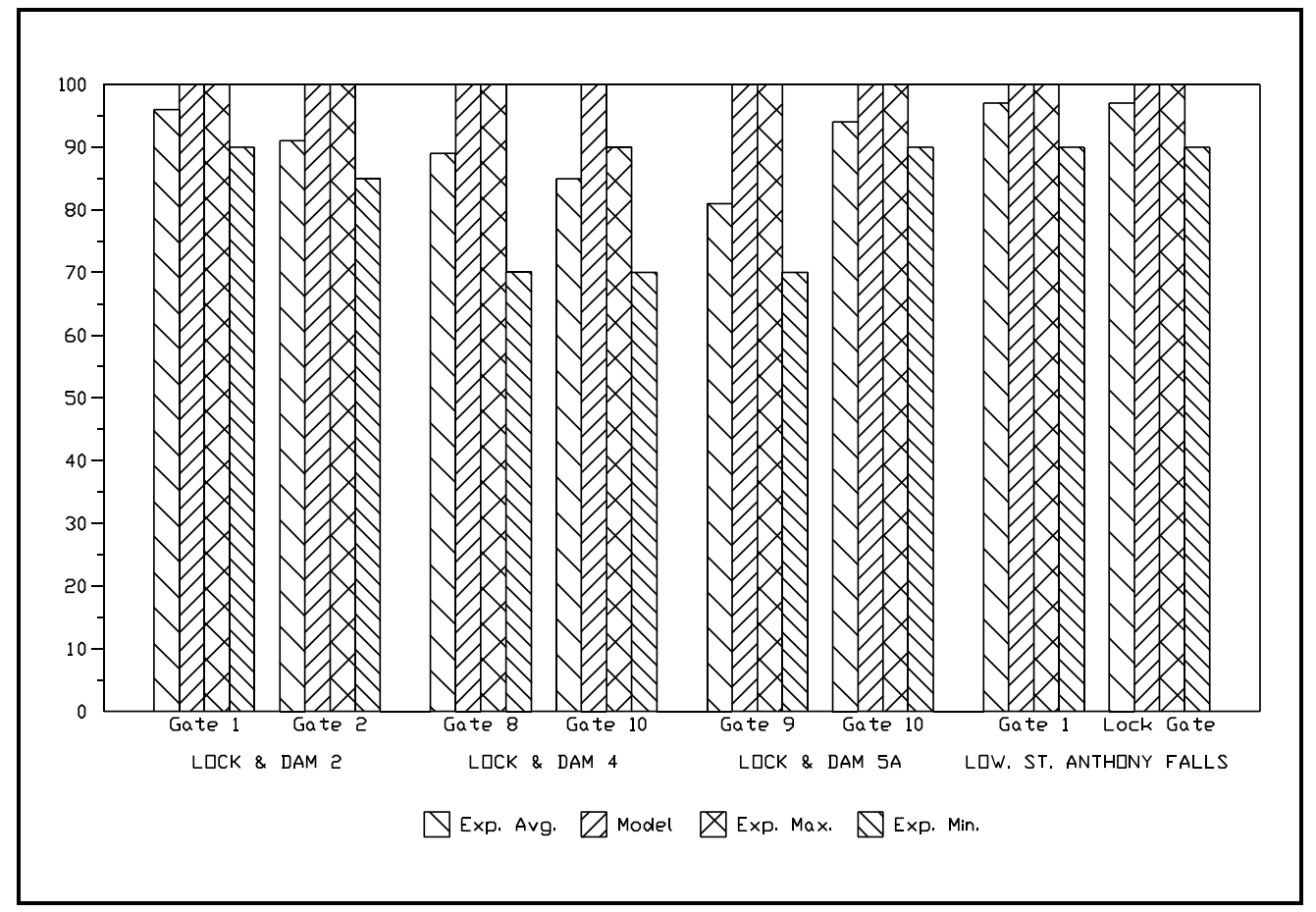

Figure 18. Noise, jumping, and vibration.

\section{Vibration With Flow (Figure 19)}

Again the calculated CIs for each gate were 100 and the experts rated the gate lower. Level 1 gate vibration was experienced on Gate 2 at L\&D 2 and on Gate 9 at L\&D 5A, which explains the lower-than- normal expert average rating for these two gates. However, the vibration disappeared when the position of the gates was adjusted and, therefore, the calculated CI was 100. 


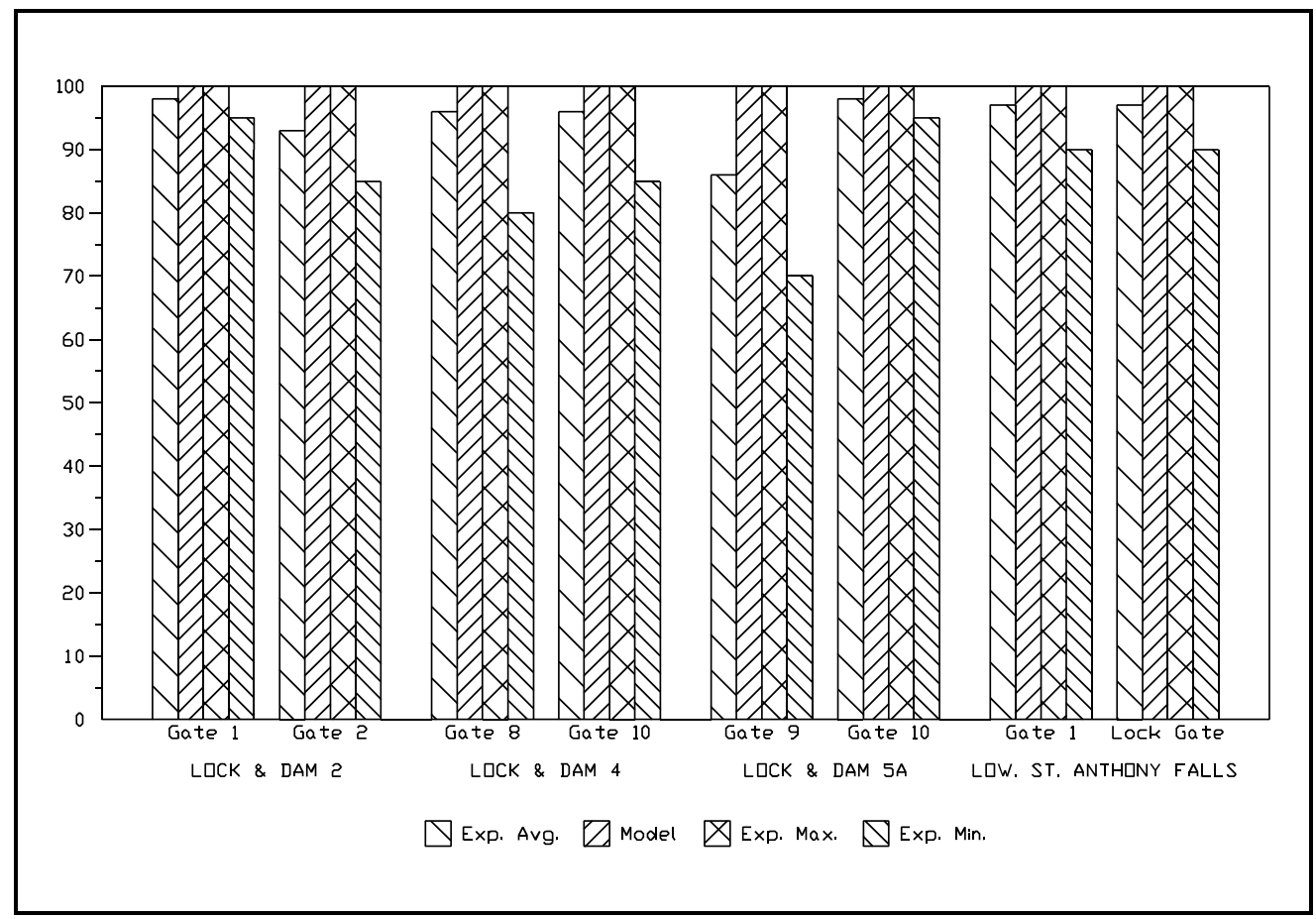

Figure 19. Vibration with flow summary.

\section{Misalignment}

The misalignment distress was measured on each gate using tape measures.

However, the accuracy of the data collected was in question and, therefore, the results were not plotted.

\section{Anchorage Assembly Deterioration (Figure 20)}

The calculated anchorage assembly CIs closely approximated the expert averages, except for Gate 1 at L\&D 2, Gate 8 at L\&D 4, and the lock gate at Lower St. Anthony Falls. Movements of 0.001 in. were recorded for Gates 1 and 8, which result in a calculated $\mathrm{CI}$ of 83 . The experts assigned a limiting $\mathrm{X}_{\max }$ value of 0.005 in. for rigid anchorage motion under normal operating conditions. However, the higher CIs assigned by the experts do not support the appropriateness of this limiting value, and suggest that $X_{\max }$ should be increased. Nevertheless, the authors feel that the movement is significant, especially because the load variation on the gate is small under a normal operating condition, and that the calculated CI is appropriate. The calculated CI for the lock gate at Lower St. Anthony Falls was 11 points lower than the expert average. The limiting value for flexible anchorage movement is 


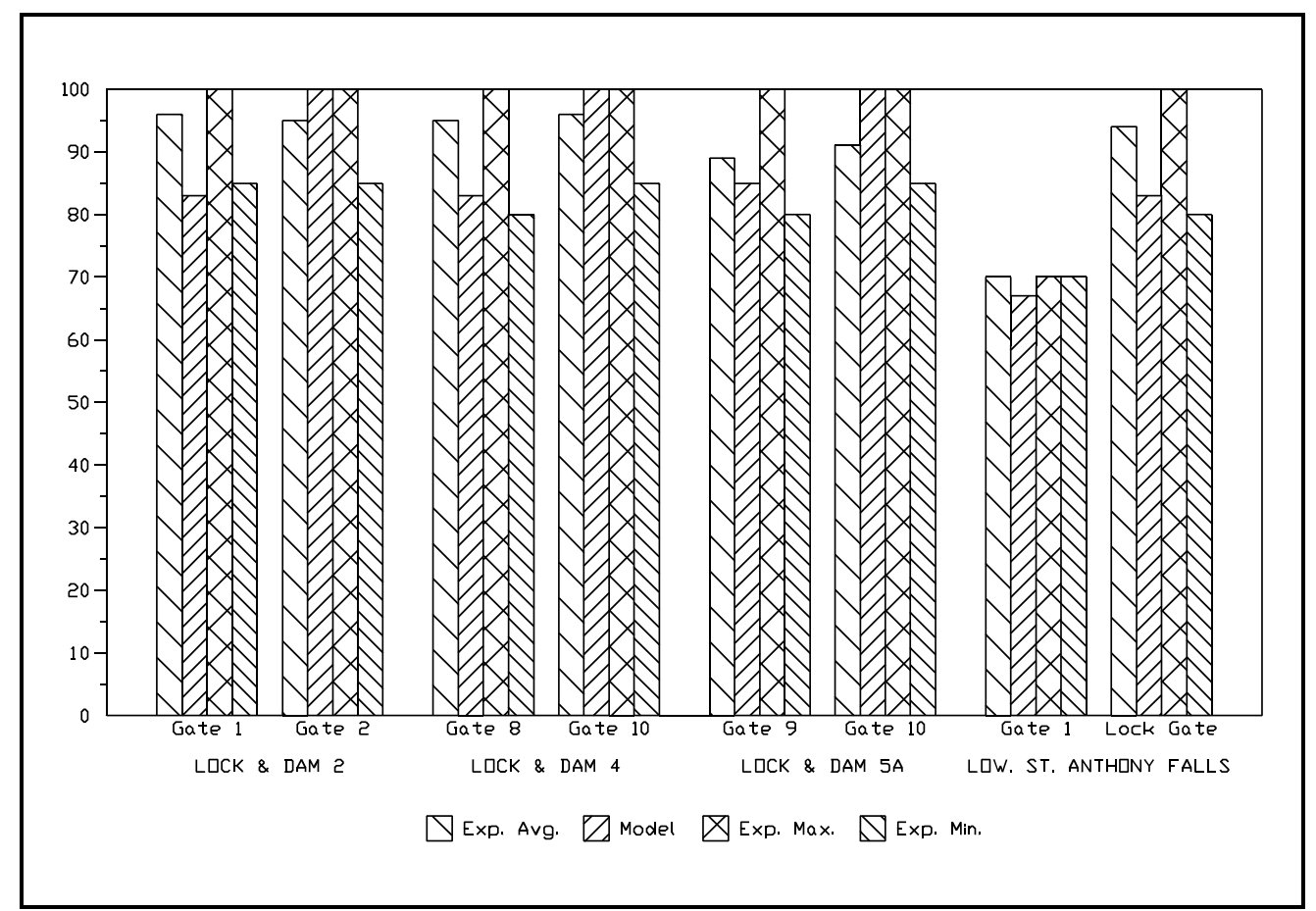

Figure 20. Anchorage assembly deterioration.

0.065 in. using Eq. 3.16 with an embedment length, $\mathrm{L}$, of $9 \mathrm{ft}$, which is the length of the W-beam (Figure 17). The movement measured during the inspec-tion was 0.013 in. The calculated CI would more closely approximate the expert average if the rule, which is based on an allowable axial deformation, included the deformation of the 5$\mathrm{ft}$ box trunnion girder. However, the authors feel that the anchorage configuration is unique, and therefore an analysis is not warranted. Long term movements could not be determined because only current readings were available. The accuracy of trammel measurements may not be sufficient.

\section{Trunnion Assembly Wear (Figure 21)}

The calculated CIs for trunnion wear closely approximated the expert average with the exception of Gate 1 at Lower St. Anthony Falls. The authors have no explanation for the difference. Horizontal and vertical measurements were made using feeler gauges at every site except at Lower St. Anthony Falls, where dial gauges were used.

\section{Cracks (Figure 22)}

No cracks were recorded on any gate, resulting in a calculated CI of 100 for the crack distress on each gate. Similar to the noise, jumping, and vibration distress, though, the experts rated the gates slightly lower than 100 . 


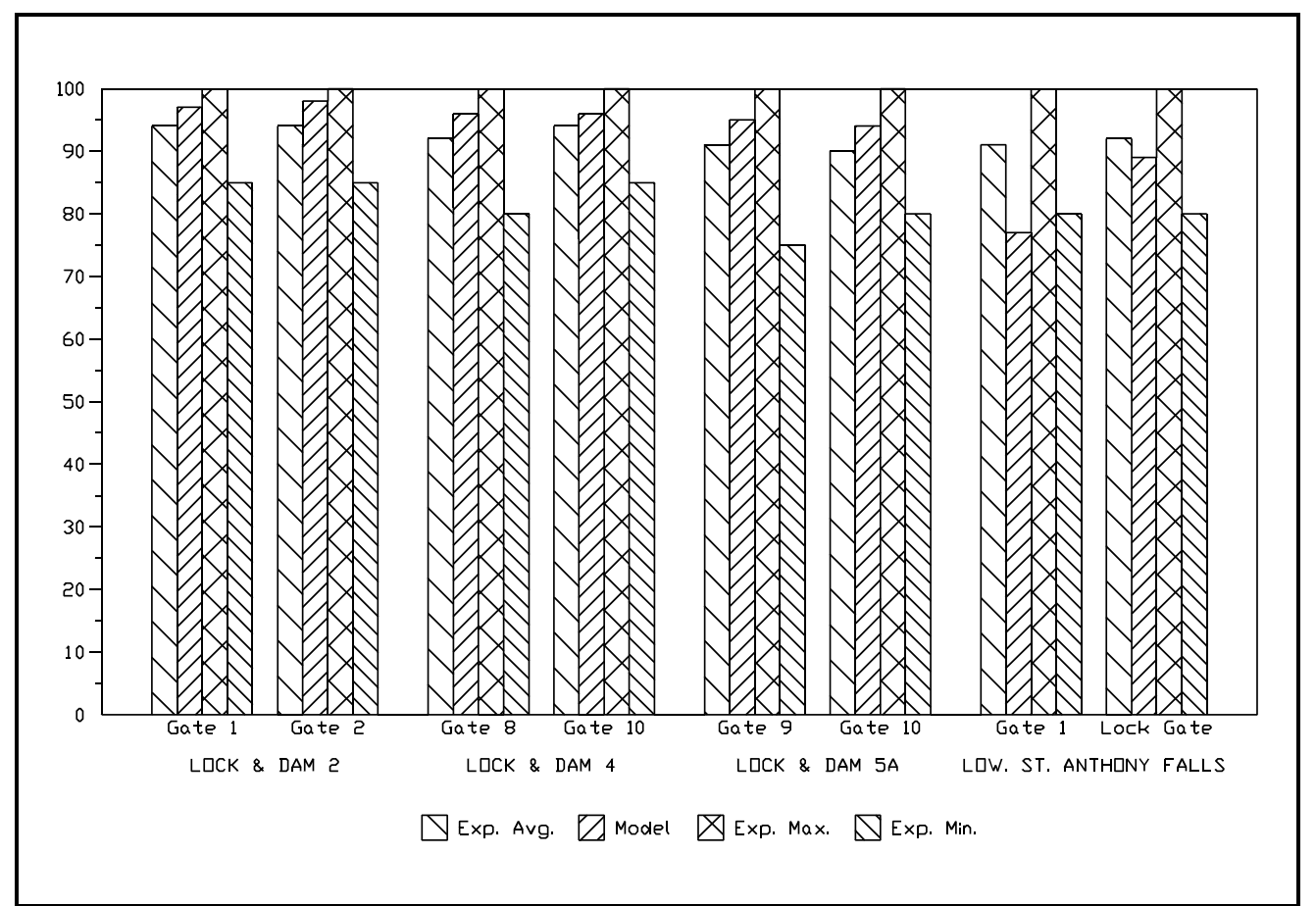

Figure 21. Trunnion assembly wear.

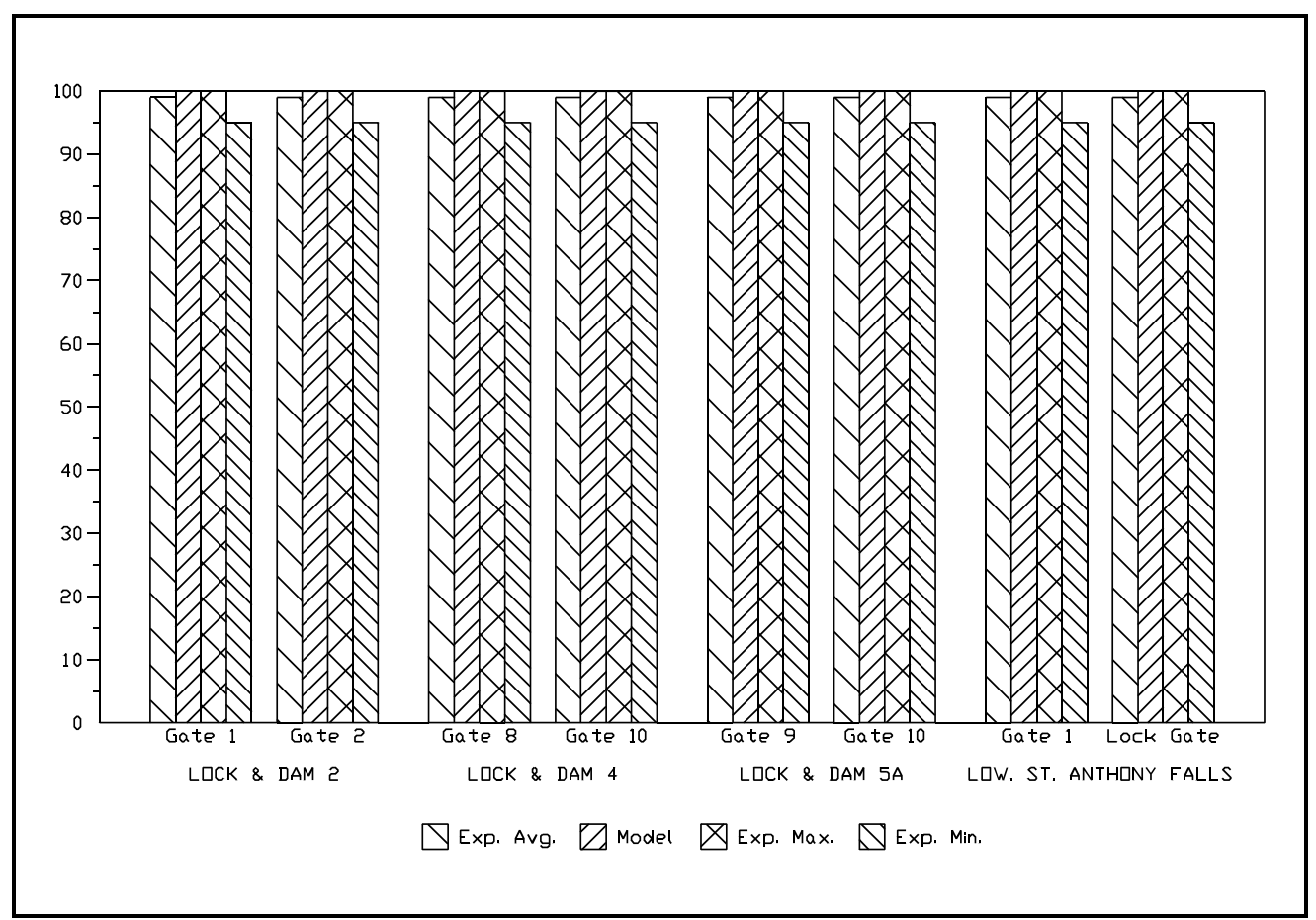

Figure 22. Cracks. 


\section{Dents (Figure 23)}

The only dents recorded in the field test (three on the skin plate and one on the ribs) were on Gate 10 at Lock and Dam 5A. The calculated CI describing the dent condition was 14 points lower than the expert average for this gate. This calculated CI was controlled by the rib dent; however, the CI calculated for the skin dents was only two points higher at 76. As future inspections are performed, it may be necessary to increase the value of $X_{\max }$ to better reflect the condition of a gate. The more conservative $\mathrm{X}_{\max }$ is appropriate at this time.

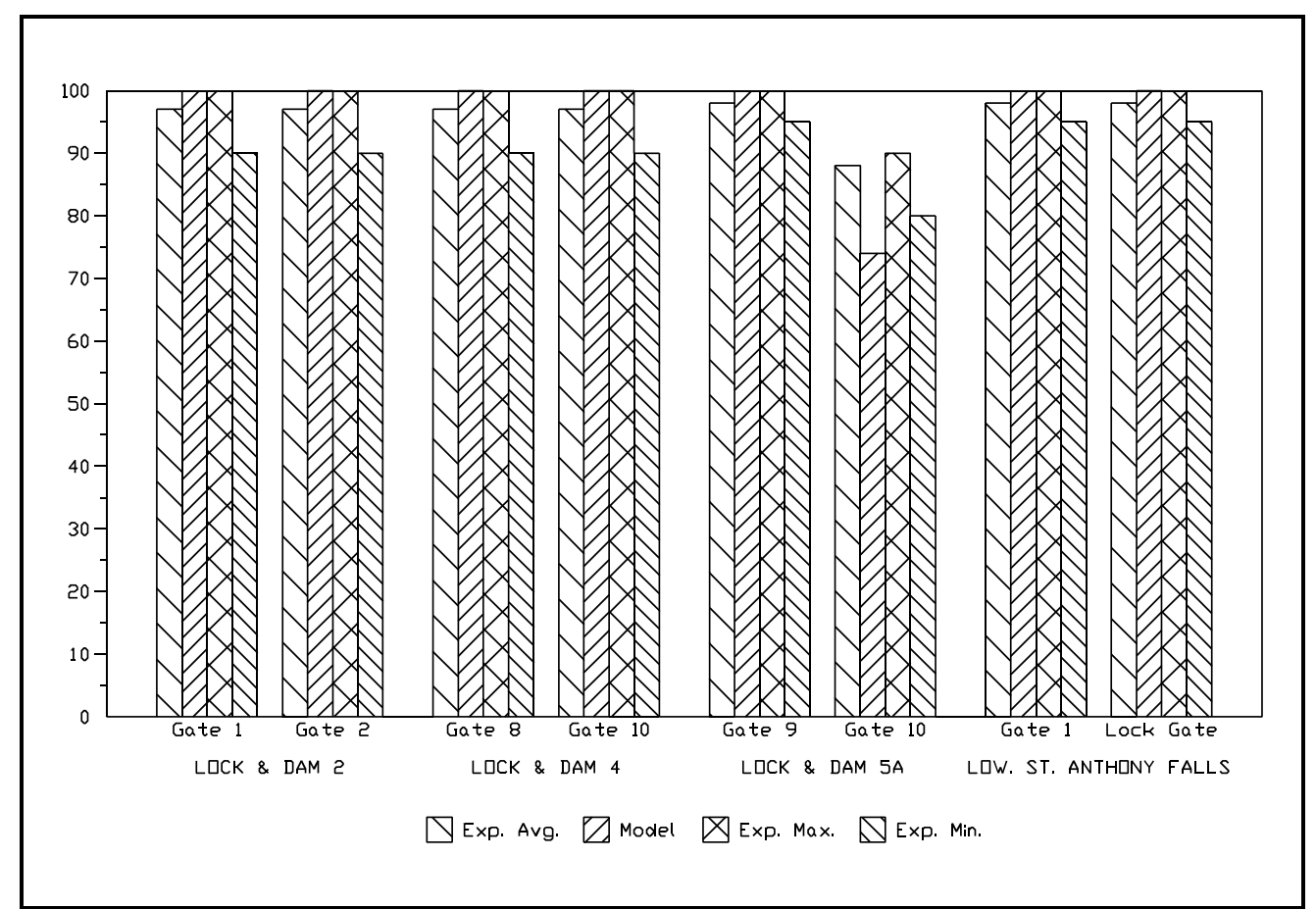

Figure 23. Dents.

\section{Corrosion/Erosion (Figure 24)}

No corrosion or erosion was recorded on Gate 1 at L\&D 2 and the gates at Lower St. Anthony Falls. The expert average for Gate 1 at L\&D 2 cannot be accounted for by the authors. Strut arm corrosion was the controlling CI for Gate 10 at L\&D 4 and the gates at L\&D 5A. The calculated CI for Gate 10 at L\&D 4 compared well with the expert average. The gates at L\&D 5A, however, had calculated CIs that were substantially lower than the expert average. The calculated CI values for Gate 2 at L\&D 2 and Gate 8 at L\&D 4 correspond relatively well with the expert averages. The corrosion was recorded on the inspection form using primarily the percentage area method. 


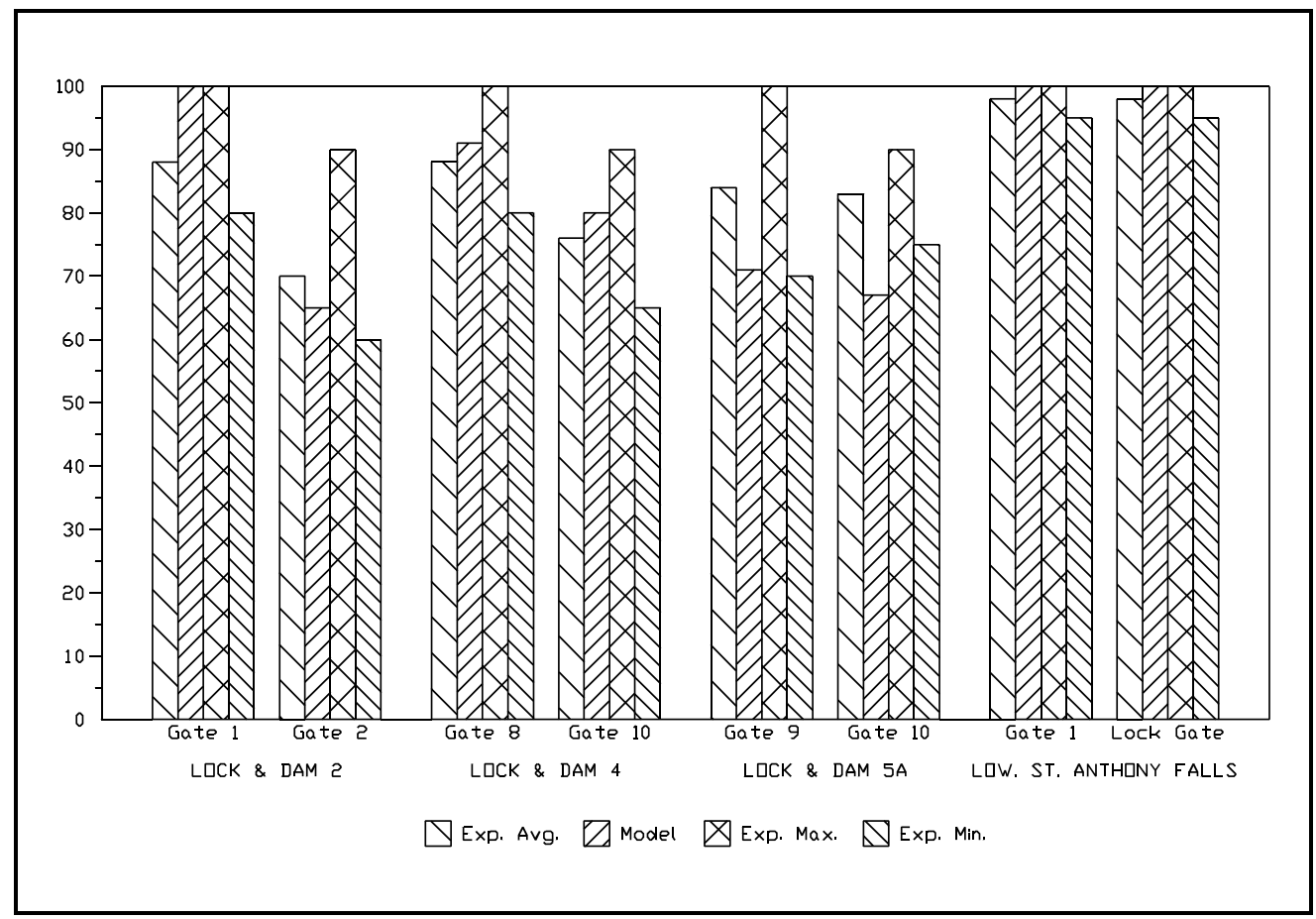

Figure 24. Corrosion/erosion.

\section{Cable/Chain Plate Wear}

Because cable/chain plate wear could not be observed, no CI calculations were performed.

\section{Leaks (Figure 25)}

The gates at Lower St. Anthony Falls were submersible, and the expert average closely approximated the calculated CI for these gates. The gates at the other sites were nonsubmersible. No leaks were recorded at L\&D 2 or at Gate 10 at L\&D 4; however, the expert average CI was less than 100, which cannot be explained by the authors. Gate 8 at L\&D 4 had a 1-in.-long leak and a wetted perimeter of $58 \mathrm{ft}$. At L\&D 5A, Gate 9 had a leak length totaling 12 in. and Gate 10 had a 2.5-in. leak. The wetted perimeters on these gates were both $58 \mathrm{ft}$. In all three cases, the expert average is lower than the calculated CI. The authors do not feel that the $\mathrm{X}_{\max }$ for these types of gates should be reduced at this time because the expert averages for these gates, though consistently lower than the calculated CI, are highly variable among the gates.

\section{Overall Gate Ratings (Figure 26)}

The overall gate ratings from the calculated model tended to track higher than the expert average, except for Gate 1 at Lower St. Anthony Falls, which was 


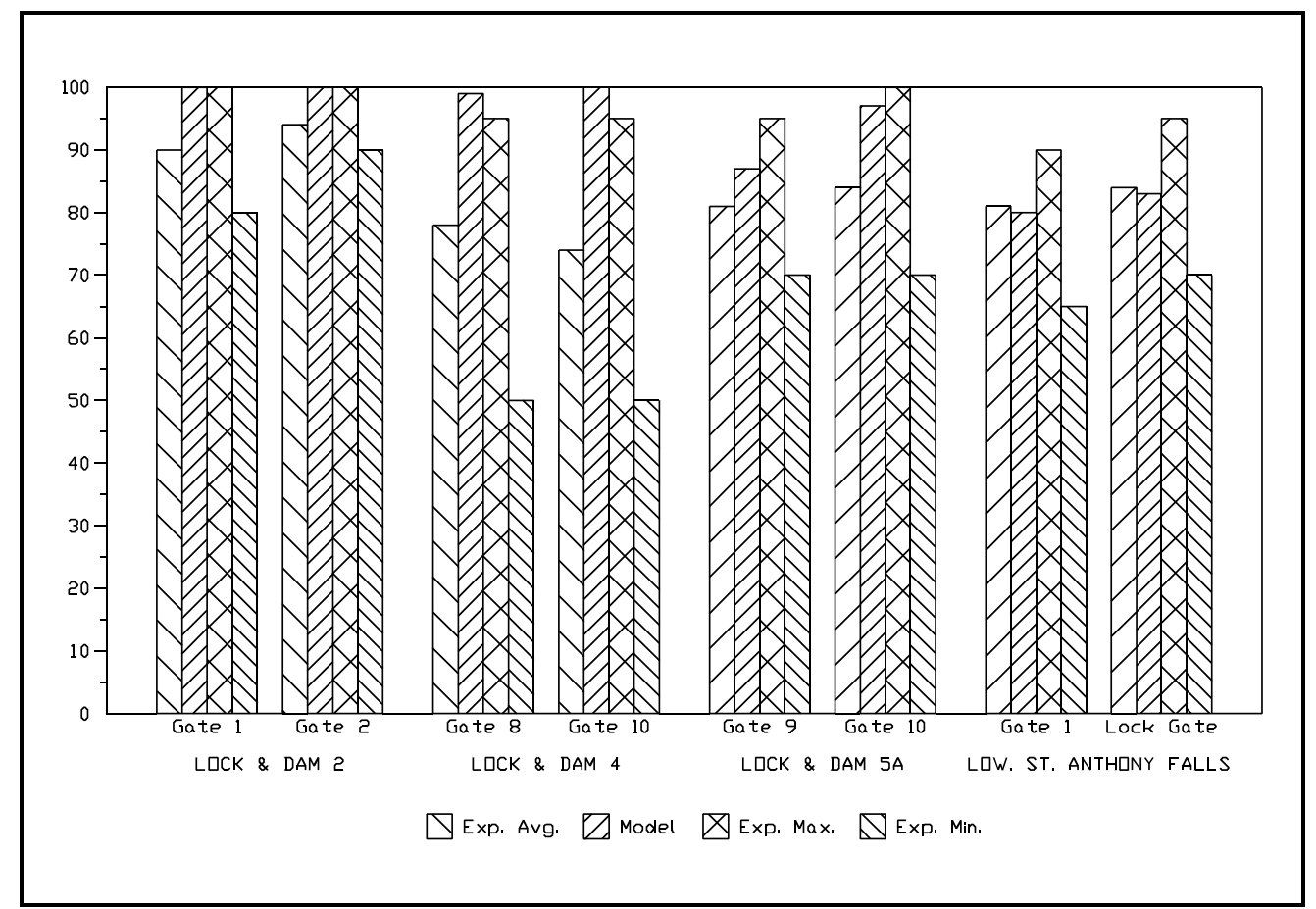

Figure 25. Leaks.

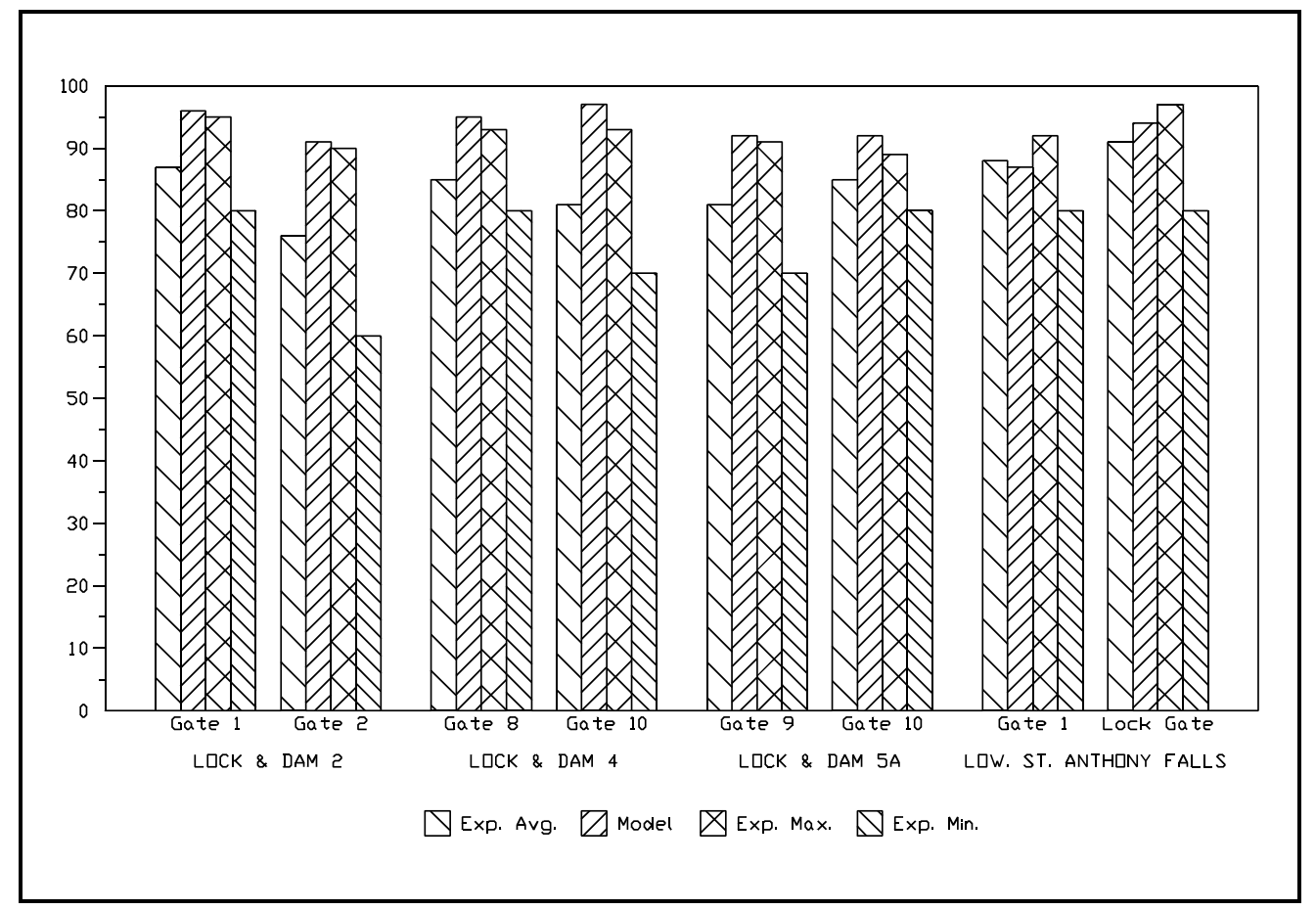

Figure 26. Overall ratings for the gates. 
slightly lower. The primary reason that most calculated CIs were higher is that the experts based their overall gate rating on the lowest individual distress CIs, generally leak and corrosion CIs, without considering the other distresses.

\section{Summary}

Overall, the calculated CIs tracked fairly well with the expert ratings. Two very good discussion sessions were held with experienced Corps of Engineers experts to develop the framework for the rules and to establish $X_{\max }$ values. The initial set of rules will require continual monitoring as the inspection procedure is put into use.

There are a few shortcomings regarding the development of the rules and the field test. First, the field calibration involved only five experts. If one of the five

gives a much different rating, the average is affected significantly by that individual.

Also, the gates that were inspected were generally in very good condition. The expert ratings and the calculated CIs were both quite high relative to Zone 3 in Table 1. The result is that the rating system was calibrated only for the upper range of the CI scale. A more complete calibration of the CI scale could have been achieved if one or more of the gates would have been in worse condition.

Finally, more testing and calibration should be performed. Although several field tests were performed, improvements in the rules may be required to better portray the experts' evaluation of a gate condition. However, at this point it is justifiable to implement the procedure in its current state and allow the rules to evolve as Corps personnel apply them.

Software has been written to automatically calculate the CIs, using data from the inspection form (Chapter 2) and the rules in this chapter. The software is also capable of maintenance and repair analysis with evaluation of repair alternatives by economic analysis and consequence modeling. User implementation is similar to steel sheet pile, miter lock gates, sector gates, and emptying and filling valves. 


\section{Structural Considerations}

One of the primary factors taken into account by the experts during the development of the CI rules was subjective safety. Subjective safety assumes that an engineer is capable of using his or her judgment to detect a safety problem. Their observations during an inspection may indicate that the potential for a problem exists or that a safety problem is developing and may soon become critical. For example, a crack in the strut arm almost certainly indicates a safety problem. A more detailed inspection will reveal the seriousness of the situation. Deterioration such as this usually is not accounted for in a classical structural analysis technique and cannot be easily quantified.

The experts took many of these structural considerations into account when assigning limiting values, tolerances, and weight factors for all the CI rules in Chapter 3. However, certain distress measurements characterize the structural adequacy of a gate more than others. This important subset of structural distresses is listed in Table 5.

To alert an engineer that a potential safety problem could be developing or already exists, these distresses are flagged with a structural note along with the corresponding measurement, $\mathrm{X}$. Three CI levels are used to characterize the severity of the note. The levels and a typical note for anchorage assembly deterioration are as follows:

Level 1 Flag: $\quad 55<\mathrm{CI}<70$

Note: The anchorage movement was measured to be $\mathrm{X}$ inches and should be monitored.

Table 5. Tainter gate structural distresses.

\begin{tabular}{|l|l|}
\hline \multicolumn{1}{|c|}{ Structural Distress } & \multicolumn{1}{c|}{ Brief Description } \\
\hline $\begin{array}{l}\text { Anchorage assembly } \\
\text { deterioration }\end{array}$ & Embedded steel movement and concrete and steel deterioration \\
\hline Crack-strut arms & Break in strut arms \\
\hline Crack-trunnion girders & Break in trunnion girder \\
\hline Crack-main girders & Break in main girders \\
\hline Crack-trunnion hubs & Break in trunnion hubs \\
\hline Crack-trunnion yokes & Break in trunnion yokes \\
\hline Corrosion-strut arms & Loss of strut arm steel \\
\hline Corrosion-main girders & Loss of main girder steel \\
\hline
\end{tabular}


Level 2 Flag: $40<\mathrm{CI}<55$

Note: The anchorage movement was measured to be $\mathrm{X}$ inches and could be a problem. Further investigation may be needed.

Level 3 Flag: $\quad 0<$ CI $<40$

Note: The anchorage movement was measured to be $\mathrm{X}$ inches. This is potentially a structural hazard. Further investigation is needed.

For all the component crack distresses (except main girder cracks) listed in the structural distress subset, only a Level 3 Flag would apply because the CI is automatically 30 if such a crack exists. 


\section{Summary and}

The inspection and rating procedures described in this report have intentionally been kept as simple as possible. The inspections require only simple tools such as a tape measure, dial gauge, and ruler. An inspection form has been developed for tainter gates to record historical information (location, previous inspections, repair history, and so forth) and to document distress information (anchorage assembly deterioration, cracking, corrosion, and so on).

The tools and the inspection procedures are relatively simple, but preparation for an inspection is not always as simple. An inspection performed under bulkheaded conditions requires setting the bulkhead(s) in place. There are distresses, such as corrosion and trunnion assembly wear, that require several measurements.

Once the data is obtained, software has been developed to compute the CI directly from the inspection records. The $\mathrm{CI}$ is a numbered scale from 0 to 100 that indicates the current state of the structure. It is primarily a planning tool that indicates the relative need to perform REMR work. CIs below 40 indicate that immediate repair may be necessary or possibly that a more detailed inspection and analysis is required.

Several distresses reduce the CI according to rules based on the opinion of Corps experts. They involve at least two considerations: (1) serviceability, or how the structure performs its function on a day-to-day basis, and (2) subjective safety, or how, in the judgment of expert engineers, the safety of the structure has been degraded by various distresses. A combined CI for each gate is calculated by weighting each distress. Structural considerations are flagged on the CI list on the basis of subjective safety. A structural note is generated on the summary report for the structural subset of distresses as the CI decreases.

The inspection and rating procedure has been applied in one field test on eight different gates (November 1993). The results of these tests have been incorporated into the current version of the procedure. The current inspection and rating procedure for tainter gate structures will undergo some modifications. 


\section{References}

Greimann, L., and J. Stecker, User's Manual: Inspection and Rating of Steel Sheet Pile_Structures, Technical Report REMR-OM-3 (U.S. Army Corps of Engineers, Washington, D.C., 1989).

Greimann, L., and J. Stecker, Maintenance and Repair of Steel Sheet Pile Structures, Technical Report REMR-OM-9 (U.S. Army Corps of Engineers, Washington, D.C., 1990).

Greimann, L. Stecker, J., and K. Rens, Management System for Miter Lock Gates, Technical Report REMR-OM-08 (U.S. Army Corps of Engineers, Washington, D.C., 1990).

Greimann, L., Stecker, J., Rens, K., and J. Veenstra, Inspection and Rating of Sector Gates (Submitted to the U.S. Army Corps of Engineers, 1991).

Greimann, L., Stecker, J., and J. Veenstra, Condition and Rating Procedures for Tainter and_Butterfly Valves, Technical Report REMR-OM-14 (U.S. Army Corps of Engineers, Washington, D.C., 1993).

Greimann, L., Stecker, J., Rens, K., and M. Nop, REMR Management Systems Navigation_Structures, User's Manual for Inspection and Rating Software, Version 2.0, Technical Report REMR-OM-114 (U.S. Army Corps of Engineers, Washington, D.C., 1994). 